\title{
FLORA Y VEGETACIÓN DE LA SIERRA DE ALCAPARAÍN (MÁLAGA, ESPAÑA)
}

\author{
Andrés V. PÉREZ LATORRE*, Federico CASIMIRO SORIGUER-SOLANAS \\ y Baltasar CABEZUDO \\ Dpto. de Biología Vegetal. Facultad de Ciencias. Universidad de Málaga. 29071 Málaga. \\ *Autor para correspondencia: avperez@uma.es
}

Recibido el 5 de septiembre de 2015, aceptado para su publicación el 10 de octubre de 2015

\begin{abstract}
RESUMEN. Flora y vegetación de la Sierra de Alcaparaín (Málaga, España). El objetivo de este trabajo es realizar un catálogo de la flora, de las comunidades vegetales y el estudio del dinamismo sucesional y del paisaje vegetal de la Sierra de Alcaparaín, que forma parte de una Zona de Especial Conservación (ZEC) situada en la provincia de Málaga (Andalucía, España). El macrobioclima es de tipo mediterráneo con termotipos termo y mesomediterráneo y ombrotipos seco y subhúmedo. El área de estudio está compuesta geológicamente por materiales calizo-dolomíticos, silíceos y peridotíticos, con elevadas pendientes y altitudes entre 400 y 1295 m. y se encuentra en la provincia fitogeográfica Bética (región Mediterránea), con los sectores Rondeño (zonas calizo-dolomíticas), Malacitano-Axarquiense (zonas silíceas) y Bermejense (zonas peridotíticas). El catálogo florístico se compone de 467 taxones, destacando el endemismo local Armeria grajoana y Centaurea carratracensis (VU), endémica del subsector Carratracense (sector Bermejense). Otros taxones interesantes son Linaria clementei (VU), Platycapnos tenuiloba subsp. parallela (VU), Polygala webbiana (única localidad europea), Salvia candelabrum (VU) y Sarcocapnos baetica subsp. baetica(VU). Son remarcables también un total de 7 serpentinófitos destacando Crepis bermejana, Galium boissieranum (VU) y G. viridiflorum (VU). Se han catalogado 28 comunidades y asociaciones vegetales, entre las que destacan como novedades sintaxonómicas la vegetación glerícola vivaz sobre peridotitas (Crambe filiformisCentaureetum carratracensis comb. nova et stat. nov.), los jarales silicícolas rondeños (Lavandulo stoechadisGenistetum equisetiformis ulicetosum baetici subass. nova), los pinares-sabinares mesomediterráneos (Pino halepensis-Juniperetum phoeniceae rhamnetosum myrtifoliae subass. nova) y los encinares edafoxerófilodolomitícolas (Rhamno myrtifoliae-Quercetum rotundifoliae ass. nova). El dinamismo sucesional se expresa en seis series de vegetación. Dos series climatófilas termo y mesomediterráneas de Quercus rotundifolia y de Quercus suber. Tres series edafoxerófilas: termo-mesomediterránea calcícola-dolomitícola de Pinus halepensis y Juniperus phoenicea, mesomediterránea dolomitícola de Quercus rotundifolia y serpentinícola con Juniperus oxycedrus. Existe también una serie edafohigrófila de saucedas (Salix pedicellata). En los frecuentes hábitats rupícolas se describen 3 complejos topogénicos (entre ellos uno con Saxifraga globulifera) y 2 glerícolas (uno sobre kakiritas con Linaria clementei y otro sobre serpentinas con Centaurea carratracensis). En la Sierra existen 8 grandes unidades de paisaje zonopotencial, caracterizados en gran medida por la presencia de Quercus rotundifolia y $Q$. suber, así como por gimnospermas como Pinus halepensis, Juniperus phoenicea y J. oxycedrus.
\end{abstract}

Palabras clave. Flora, Comunidades vegetales, Sierra de Alcaparaín, Andalucía, Península Ibérica. 
SUMMARY. Flora and vegetation of the Sierra de Alcaparain (Malaga, Spain). The main objective of this work is to catalogue the flora and plant communities and to study the successional dynamics of the vegetation and landscape in the Alcaparain mountain range, which is part of a Special Area of Conservation (SAC) located in the province of Malaga (Andalusia, Spain). The macrobioclimate is Mediterranean with thermomediterranean and mesomediterranean thermotypes (vegetation belts) and dry and sub-humid ombrotypes. The study area is geologically composed of limestone-dolomitic materials, siliceous and ultramafic, with steep slopes and altitudes between 400 and $1295 \mathrm{~m}$. and it is placed in the Betica phytogeographical province (Mediterranean region), with Rondeño sector (limestone-dolomite areas) Malacitano-Axarquiense sector (siliceous areas) and Bermejense sector (peridotite-ultramafic areas). The floristic list consists of 467 taxa, highlighting local endemism Armeria grajoana and Centaurea carratracensis (VU), this latter endemic to the Carratracense subsector (Bermejense sector). Other interesting taxa are Linaria clementei (VU), Platycapnos tenuiloba subsp. parallela (VU), Polygala webbiana (unique European population), Salvia candelabrum (VU) and Sarcocapnos baetica subsp. baetica (VU). Also noteworthy are a total of 7 serpentinophytes highlighting Crepis bermejana, Galium boissieranum (VU) and G. viridiflorum (VU). 28 communities and plant associations have been catalogued, among which are new syntaxa as the perennial scree vegetation on peridotites (Crambe filiformisCentaureetum carratracensis comb. nova et stat. nov.), the silicicolous shrublands of Rondense subsector (Lavandulo stoechadis-Genistetum equisetiformis ulicetosum baetici subass. nova), the mesomediterranean pine-juniper open forest (Pino halepensis-Juniperetum phoeniceae rhamnetosum myrtifoliae subass. nova) and dolomitic edaphoxerophyllous oak shrublands (Rhamno myrtifoliae-Quercetum rotundifoliae ass. nova). The successional dynamism is expressed in six vegetation series. Two are thermo- and mesomediterranean climatophilous series of Quercus rotundifolia and Quercus suber respectively. Three are edaphoxerophyllous series: thermo-mesomediterranean calcicolous-dolomiticolous with Aleppo pine and Juniperus phoenicea, dolomiticolous mesomediterranean of Quercus rotundifolia and serpentinicolous with Juniperus oxycedrus. There is also one edaphohygrophyllous series of willow (Salix pedicellata). Vegetation of the frequent rocky and cliff habitats are described in three topogenous complexes (including one with Saxifraga globulifera) and two in screes (one on kakirite sands with Linaria clementei and another on serpentine small slopes with Centaurea carratracensis). In the Sierra there are eight large zonopotential units of landscape, mainly characterized by the presence of Quercus rotundifolia (and in a lesser extent, $Q$. suber) as well as gymnosperms as Aleppo pine, Juniperus phoenicea and J. oxycedrus.

Key words. Flora, Plant communities, Alcaparain, Andalusia, Iberian Peninsula.

\section{INTRODUCCIÓN Y OBJETIVOS}

Las sierras de Alcaparaín y Aguas (ES6170009), han sido declaradas Zonas de Especial Conservación (ZEC) (Decreto 2/2015, de 13 de enero de la Junta de Andalucía) e incluidas en el Inventario de Espacios Naturales Protegidos de Andalucía e integradas en la Red Ecológica Europea NATURA 2000. Ambas sierras forman parte de la Reserva de la Biosfera Intercontinental del Mediterráneo AndalucíaMarruecos aprobada por unanimidad en el Consejo Consultivo de la UNESCO en octubre de 2006. La información botánica de la Sierra de Alcaparaín que aparece en las propuestas de LIC y ZEC es prácticamente nula y por lo general hace referencia a especies de la cercana Sierra de Aguas. La información oficial destaca, sin ninguna justificación, como hábitats prioritarios y no prioritarios los siguientes: «Zonas subestépicas de gramíneas y anuales de Thero-Brachypodietea $\left(6220^{*}\right) »$ además de otros hábitats no prioritarios como «Desprendimientos mediterráneos occidentales y termófilos (8130)», «Pendientes rocosas silíceas con vegetación casmofítica (8220)», «Cuevas no explotadas por el turismo (8310)» y «Pinares mediterráneos de pinos mesogeanos endémicos (9540)».

Los trabajos anteriores que mencionan algunos datos concretos sobre la Sierra de Alcaparaín son los que realizaron Ceballos y Vicioso (1932 y 1933: 83), entre los que destacan los datos que aportan sobre cerca 


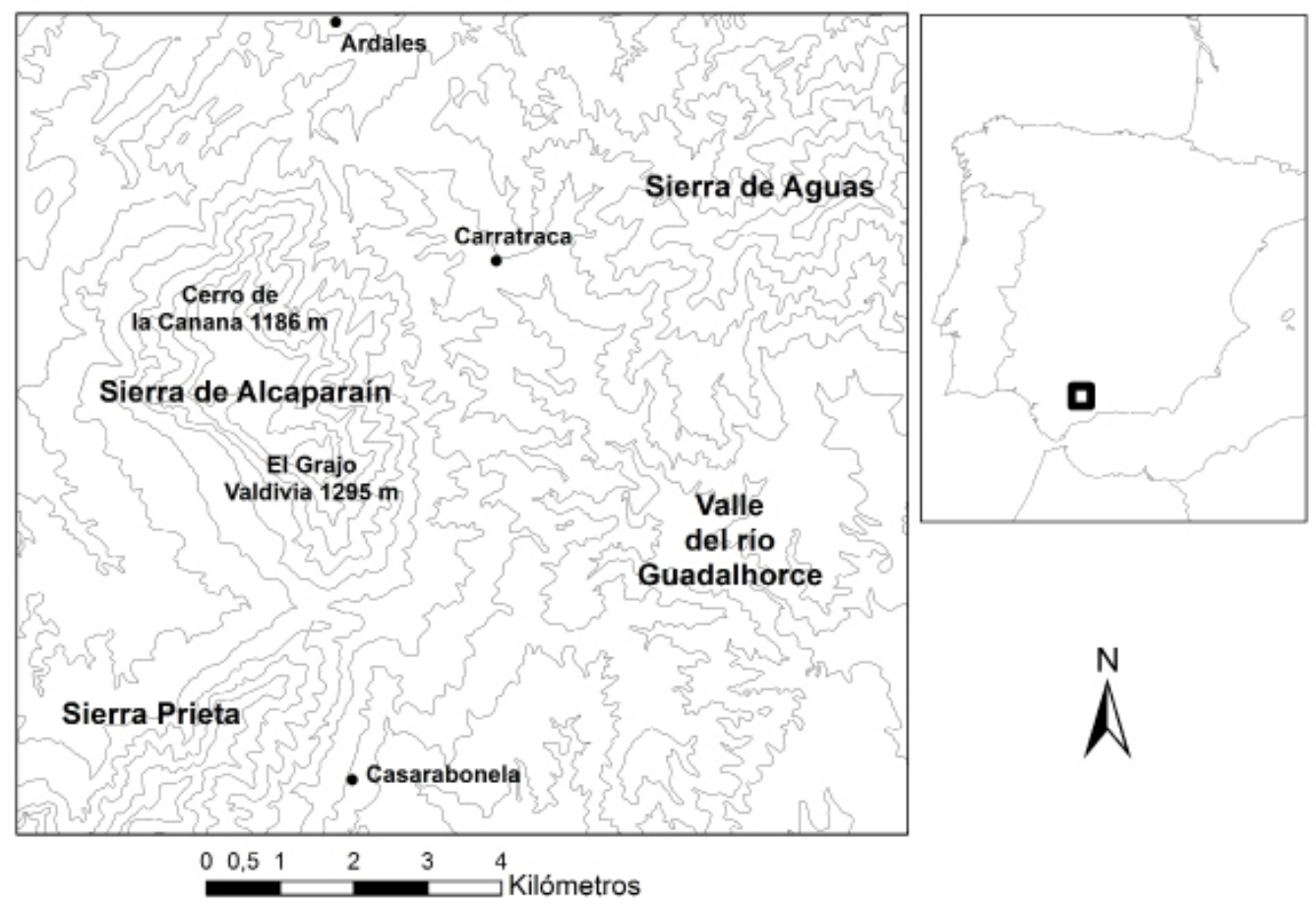

Figura 1. Localización del área de estudio (Sierra de Alcaparaín) en el sur de la Península Ibérica (Andalucía, provincia de Málaga). Location of the study area (Sierra de Alcaparain) in the south of the Iberian Peninsula (Andalusia, Malaga province).

de medio centenar de especies, comentarios muy interesantes sobre su vegetación (pinares, jarales, herbazales y espartales) y la constatación de sus dos principales factores de impacto: fuego y presión ganadera.

Los objetivos de este trabajo se centran en destacar los valores botánicos de la Sierra de Alcaparaín, mediante un estudio de su flora vascular, caracterización de sus comunidades vegetales más significativas, las series de vegetación y el esquema sintaxonómico.

\section{MATERIAL Y MÉTODOS}

\section{Geografía}

La Sierra de Alcaparaín se encuentra situada en la parte central de la provincia de Málaga (Andalucía, España) (fig. 1). Con una extensión de 6.500 Has., ocupa parte de los términos municipales de Ardales, Carratraca y Casarabonela. Limita al sur con la Sierra Prieta y al noreste con la Sierra de Aguas. Sus máximas alturas corresponden al Pico Valdivia con $1.295 \mathrm{~m}$, El Grajo (1.163 m) y al del Cerro de la Canana con $1.186 \mathrm{~m}$, y presenta una amplia meseta por encima de los $1000 \mathrm{~m}$, las partes más bajas de la sierra están sobre los $400 \mathrm{~m}$.

\section{Litología y Edafología}

La Sierra de Alcaparaín muestra una gran complejidad litológica (IGME, 1990), con materiales básicos, silíceos y ultramáficos, a veces mezclados los dos primeros. En base a la distribución litológica hemos definido 5 teselas que utilizaremos para la descripción de la vegetación: 
1. Rocas peridotíticas: compuestas por hazburguita y dunita piroxénica, localizadas al SE de la Sierra.

2. Rocas silíceas: compuestas fundamentalmente por rocas metamórficas ricas en silicatos, con algunas calizas y areniscas, que ocupan la base de la ladera este de la Sierra. (Filitas y micaesquistos, gneises bandeados, esquistos, grauvacas, calizas alabeadas)

3. Rocas calizas: compuestas por distintos tipos de calizas, a veces con calizo-dolomías, que ocupan fundamentalmente las laderas sur de la Sierra casi hasta la cumbre principal. (Calizas con sílex, calizas blancas, calizas oscuras, calizas tableadas negras, calizas y margas, calizas cristalinas azules, calizas dolomíticas, calizas oolíticas)

4. Rocas dolomíticas: generalmente dolomías e incluso mármoles dolomíticos cristalinos que se sitúan en las zonas superiores de las laderas este, oeste y norte. (Dolomías masivas, dolomías negras y grises, dolomías y calcoesquistos, mármoles sacaroideos -kakiritas-)

5. Brechas: ocupan la cumbre y la zona superior plana de la Sierra, constituidas mayoritariamente por carniolas (dolomías).

Este conjunto de materiales se encuentran rodeados por litologías arcillosas, que ya no entran a formar parte del territorio estudiado: margocalizas y margas blancas y arcillas neonumídicas, arcillas, coluviones, margas, areniscas, y piedemontes con costra calcárea.

Los suelos presentes en cada una de estas teselas son (Balsera, 1989):

Sobre la unidad peridotítica 1 , se desarrollan luvisoles y cambisoles crómicos, regosoles eútricos y litosoles (zonas erosionadas).

Sobre la unidad silícea 2, se desarrollan cambisoles y regosoles eútricos (laderas), litosoles (zonas altas y red de drenaje) y a veces rankers.

Sobre las unidades de materiales básicos 3, 4, y 5 se desarrollan litosoles (cimas y roquedos), luvisoles crómicos (bajas laderas y fondos de valle) y rendsinas (cambisoles cálcicos) (medias laderas).

\section{Clima y bioclimatología}

Para la caracterización bioclimática de la zona estudiada nos hemos basado en los conceptos de termotipo (piso bioclimático) y ombrotipo (Rivas Martínez, 1987). Los datos climatológicos se han obtenido de De León (1989) y Rivas Martínez (2007). La clasificación macrobioclimática está basada en los conceptos de Rivas Martínez (op . cit.).

En función de las estaciones meteorológicas de la zona de estudio (tab. 1), el macrobioclima del territorio se define como mediterráneo pluviestacional-oceánico. La variación de las principales variables bioclimatológicas indica lo siguiente:

a/ la zona basal, situada en el valle del río Guadalhorce (al E) desde los $400 \mathrm{~m}$ y hasta unos $700-800 \mathrm{~m}$ presenta un piso bioclimático termomediterráneo superior con ombrotipo seco superior hacia el NE y subhúmedo inferior hacia el SE; es la zona más oceánica.

\begin{tabular}{lccccccc}
\hline Estación & altitud & P & T & Itc & Io & Ic & Termotipo/ombrotipo \\
\hline Casarabonela & 480 & 797 & 16,2 & 389 & 4,1 & 13 & Termo Sup/Subhúmedo Inf \\
Ardales Caparaín & 700 & 671 & 16,4 & 355 & 3,4 & 15,5 & Termo Sup/Seco Sup \\
El Burgo ICONA & 580 & 602 & 15,0 & 303 & 3,3 & 16,8 & Meso inf/Seco sup \\
\hline
\end{tabular}

Tabla 1. Datos climatológicos de la zona estudiada. P: precipitación media anual. T: temperatura media anual. Itc: índice de termicidad compensado. Io: índice ombrotérmico. Ic: índice de continentalidad simple. Datos: www.globalbioclimatics.org. Climatic data. P: average annual rainfall. T: average annual temperature. Itc: Balanced thermicity index. Io: ombrothermic index.,Ic: single continentality index. Data: www.globalbioclimatics.org. 
Algunos bioindicadores en el territorio: Teucrium lusitanicum, Thymus capitatus; algunos sinfitoindicadores: Lavandulo caesiaeGenistetum equisetiformis thymetosum capitati.

b/ La zona basal, expuesta hacia el Valle del río Turón (al W) presenta un piso bioclimático mesomediterráneo inferior y es la más continental.

c/ Dada la ausencia de estaciones por encima de los $700 \mathrm{~m}$, hemos utilizado la prrsencia/ausencia de bioindicadores para su delimitación bioclimática:

-Piso bioclimático mesomediterráneo inferior en cualquier exposición por encima de 700-800 $\mathrm{m}$ aproximadamente y hasta unos $1000 \mathrm{~m}$.

-Piso bioclimático mesomediterráneo medio en la zona de planicie superior de la Sierra situada a unos $1000 \mathrm{~m}$. de altitud media. Algunos bioindicadores en el territorio son: Lavandula lanata, Thymus granatensis; algunos sinfitoindicadores: Lavandulo lanataeUlicetum baetici.

Finalmente en la cumbre situada casi a 1300 m. y por efecto topográfico que acentúa las condiciones de altitud, aparecen bioindicadores supramediterráneos como Bupleurum spinosum y algunos sinfitoindicadores como Lavandulo lanatae-Ulicetum baetici erinaceetosum anthyllidis.

En cuanto al ombrotipo, las zonas SE presentan mayor precipitación que las NE y W (ésta con ombrotipo seco). En función de la altitud y de cómo se comportan las sierras cercanas de Prieta, Cabrilla y Huma (Pérez Latorre et al., 2012, 2014) respecto a la distribución de la precipitación, las zonas superiores de la Sierra de Alcaparaín podrían llegar al ombrotipo subhúmedo superior ( $\mathrm{P}>800 \mathrm{~mm}$ aprox.), lo que concuerda con la presencia pretérita de Abies pinsapo (Ceballos y Vicioso, 1933). Sin embargo la ausencia de ciertos bioindicadores de este ombrotipo como Heleborus foetidus o Daphne laureola podría ser atribuida a los incendios recurrentes que ha sufrido la zona de estudio.

\section{Fitogeografía}

La sectorización fitogeográfica se basa fundamentalmente en la propuesta de Nieto Caldera et al. (1991) y Pérez Latorre y Cabezudo (2002) para la provincia de Málaga y de Pérez Latorre et al. (2008) e Hidalgo y Pérez Latorre (2013) para el sector MalacitanoAxarquiense y el Valle del Guadalhorce. Para las unidades superiores se ha seguido la sectorización propuesta por Galán de Mera et al. (2003). Los límites de las distintas unidades fitogeográficas se determinan en base a bioindicadores florísticos, comunidades, series de vegetación, paisaje vegetal, bioclimatología, geología y uso del territorio. La zona de estudio queda encuadrada en el siguiente esquema fitogeográfico:

Reino Holártico

Región Mediterránea. Subregión Mediterránea Occidental.

Superprovincia Iberomarroquí Atlántica. Provincia Bética.

A. Sector Rondeño [p.p. Sector Rondeño sensu Rivas Martínez et al. (2007)]

- Subsector Rondense [p.p. Subsector Rondeño sensu Rivas Martínez et al. (2007)]

Unidad de Alcaparaín: núcleo de la Sierra, El Grajo y El Gollino. Algunos bioindicadores en el territorio: Galium baeticum, Linaria clementei; algunos sinfitoindicadores: Galio baetici-Thymetum granatensis, Rhamno saxatile-Saxifragetum granatensis, LavanduloGenistetum equisetiformis ulicetosum baetici.

B. Sector Malacitano-Axarquiense [p.p. Sector Granadino-Almijarense sensu Rivas Martínez et al. (2007)]

- Subsector Malacitano [p.p. Distrito Axarquiense sensu Rivas Martínez et al. (2007)]

Distrito Pizarreño: base silícea termófila 
de la Sierra. Algunos bioindicadores en el territorio: Biscutella baetica, Ulex parviflorus; algunos sinfitoindicadores: comunidad de Biscutella baetica, Lavandulo caesiaeGenistetum equisetiformis thymetosum capitati.

C. Sector Bermejense [p.p. Subsector Aloreño-Bermejense sensu Rivas Martínez et al. (2007)]

- Subsector Carratracense [p.p. Distrito Aloreño sensu Rivas Martínez et al. (2007)]

Unidad de Las Minas: afloramiento ultramáfico. Algunos bioindicadores en el territorio: Centaurea carratracensis, Teucrium reverchonii; algunos sinfitoindicadores: Galio boissierani-Staehelinetum baeticae, Galio viridiflori-Schoenetum nigricantis.

\section{METODOLOGÍA}

El trabajo de campo se ha realizado durante los años 2014 y 2015 en todo el ámbito del ZEC que incluye la Sierra de Alcaparaín. Se ha recolectado material de todas las especies incluidas en los inventarios fitosociológicos y de otras especies de interés para la caracterización florística del territorio (endemismos, especies amenazadas, raras, singulares, etc.). Para la identificación del material recolectado, se han seguido las obras "Flora Vascular de Andalucía Oriental" (Blanca et al., 2011) y "Flora Iberica" (Castroviejo et al., 1986-2014). Todos los pliegos se han depositado e informatizado en el Herbario MGC de la Universidad de Málaga. Los datos de todo el material estudiado (identificación, recolectores, fechas de recolección, georreferenciación, ecología, etc.) han sido incorporados a la base de datos GBIF (Global Biodiversity Information Facility). Todos los pliegos incorporados al Herbario de la Universidad de Málaga (MGC) están georreferenciados. No obstante, para facilitar la incorporación cartográfica de todas la especies del Anexo I, hemos incluido toda la sierra en la siguiente georreferenciación: 30SUF3541578125 con un Rp (radio punto) de $3000 \mathrm{~m}$.

Con el fin de lograr un listado más detallado de la flora y vegetación de la Sierra de Alcaparaín, se realizaron consultas a algunas de las bases de datos internacionales y nacionales más importantes. Las bases consultadas han sido las siguientes: GBIF, ANTHOS y SIVIM. Para la flora legalmente protegida y amenazada presente en la Sierra de Alcaparaín se ha consultado el Decreto 23/2012 de 14 de febrero de la Junta de Andalucía y la información que aparece en los atlas y libros rojos de ámbito nacional (Bañares et al., 2004 y 2010) y autonómico (Blanca et al., 1999 y 2000) y en flora vascular de Andalucía Oriental (Blanca et al., 2011).

De todas las especies del catálogo florístico (Anexo I) hemos considerado en un apartado independiente aquellas de interés especial en función de su grado de amenaza, por tener distribución muy restringida en el territorio estudiado o por ser endemismos locales. La secuencia de datos sobre cada taxón de este apartado es: nombre y autores, distribución general, abundancia en el área de estudio, categorías de amenaza si hubiere, comportamiento ecológico, sintaxones principales en que aparece y pliegos MGC.

La información que aparece en el catálogo para cada especie es la siguiente (Anexo I): nombre científico del taxón, hábitat óptimo del mismo y abundancia en la zona estudiada. Para el nombre científico hemos seguido fundamentalmente el trabajo de Blanca et al. (2011). Para el hábitat se ha optado por dividirlos en 6 grandes grupos: vegetación arbórea y arbustiva, matorrales, pastizales, vegetación rupícola, ruderales y humedales. Para cada una de ellas, en su caso, se indica el carácter hacia el sustrato sobre el que se desarrollan: basófilo, silicícola, serpentinícola e indiferente.

Vegetación arbórea y arbustiva en suelos 
zonales (arb.). Matorrales basófilos (mat. basof.), que agrupa a la comunidades vegetales dominadas por leñosas sobre dolomías y calizas. Matorrales silicícolas (mat. sil.), que agrupa a la comunidades vegetales dominadas por leñosas sobre esquistos. Matorrales serpentinícolas (mat. serptc.), que agrupa a la comunidades vegetales dominadas por leñosas sobre peridotitas. Cuando el taxón aparece indistintamente en los diferentes tipos de matorrales (mat. ind.). Pastizales basófilos (past. basof.), que agrupa a la comunidades vegetales dominadas por herbáceas sobre dolomías y calizas. Pastizales silicícolas (past. sil.), que agrupa a la comunidades vegetales dominadas por herbáceas sobre esquistos. Pastizales serpentinícolas (past. serptc.), que agrupa a la comunidades vegetales dominadas por herbáceas sobre peridotitas. Cuando el taxón aparece indistintamente en los diferentes tipos de matorrales (past. ind.). Rupícolas (rup.), biotopos donde la roca es dominante, desde paredes verticales a gleras. Ruderales (rud.), en general todos los ambientes donde la acción antropógena es manifiesta, desde cultivos abandonados a bordes de camino. Por último zonas húmedas (higrf.).

En cuanto a la abundancia seguimos la nomenclatura y abreviaturas que aparecen en Blanca et. al. (2011): rr: muy rara; ra: rara; oc: ocasional; fr: frecuente, co: común

Las unidades de vegetación se han descrito en base a la metodología fitosociológica de Braun-Blanquet (1979), Gehú \& Rivas Martínez (1981) y Schuhwerk (1990). Los inventarios se encuentran georreferenciados en teselas ecológicamente homogéneas de tamaño estimado mediante el cálculo del área mínima. Las comunidades fragmentarias debidas a la antropización son descritas como comunidades basales (BC), (Foucault, 1981; Dierschke, 1993). Para las nuevas propuestas nomenclaturales sintaxonómicas se ha consultado el Código Internacional de Nomenclatura Fitosociológica (Weber et al., 2000). Los diferentes estadios dinámicos de la vegetación han sido analizados según la metodología sinfitosociológica bidireccional (Rivas Martínez, 2011), aunque existe también dinamismo horizontal "en red" (Pérez Latorre et al., 2012), sobre todo en los complejos de vegetación. Asumimos las propuestas tipológicas de Vigo (1998) para los complejos topogénicos y de Pérez Latorre et al. $(2004,2008)$ respecto a la zonopotencialidad de los territorios y teselas y la vegetación criptoclimácica. El esquema sintaxonómico sigue el orden de las grandes unidades ecológicas y sintaxonómicas propuestas por Rivas Martínez et al. (2011).

\section{RESULTADOS Y DISCUSIÓN}

\section{Flora}

Se han identificado un total de 467 taxones (especies y subespecies). Todas vienen reseñadas en el catálogo florístico (Anexo I) y con una georreferenciación básica 30SUF3541578125 y un Rp. de 3000 metros. Las especies que consideramos más interesantes de las localizadas en la sierra son las siguientes:

Armeria grajoana Casimiro-Soriguer Solanas \& Cabezudo

Especie endémica de la sierra de Alcaparaín. Muy rara. En Peligro Crítico (CR) (B1ab(ii,iv);C2a(i), (UICN). Se propone su inclusión en el Listado Andaluz de Especies Silvestres en Régimen de Protección Especial incluido el Catálogo Andaluz de Especies Amenazadas como especie amenazada con la categoría de En Peligro de Extinción (EN). Matorrales y tomillares dolomitícolas. LavanduloUlicetum baetici; Galio-Thymetum granatensis.

MÁLAGA. Carratraca. Sierra de Alcaparaín. El Grajo. Cara Norte. Collado Grajo-Espolón Norte. 30SUF3577. 1125 msnm. 05/06/2014. Blanquizar dolomítico en laderas de fuerte pendiente. Dolomías disgregadas. Leg.: F. Soriguer. MGC 79131; ibídem, E1 Grajo. Espolón Norte. 30SUF3577. $1210 \mathrm{msnm}$. 05/06/2014. Vegetación rupícola. Paredes verticales y repisas. Dolomías. Leg.: F. Soriguer. MGC 79121; Casarabonela. Sierra de 
Alcaparaín. Cerro de la Canana. 30SUF3379. 1180 msnm. 23/05/2014. Roquedos. Dolomías. Leg.: B. Cabezudo, A. V. Pérez Latorre \& F. Soriguer. MGC 78856; ibídem, Cerro de la Canana. 30SUF3379. 1141 msnm. 08/05/2014. Roquedos. Dolomías. Leg.: B. Cabezudo \& F. Soriguer. MGC 78573; ibídem, Sierra de Alcaparaín. Pico del Grajo (Valdivia) y alrededores. 30SUF3577. 1272 msnm. 23/05/2014. Cresterío rocoso. Dolomías. Leg.: B. Cabezudo, A. V. Pérez Latorre \& F. Soriguer. MGC 78846 y MGC 78842; Sierra de Alcaparaín. Entre los términos de Carratraca y Casarabonela. Cresterío entre el Pico Valdivia y El Grajo. 30SUF3577. $1227 \mathrm{msnm}$. 02/05/2014. Zona muy rocosa. Dolomías. Leg.: B. Cabezudo, F. Soriguer \& J. García-Sánchez. MGC 78499.

Atropa baetica Willk.

Ceballos \& Vicioso (1932:328) citan esta especie en "parajes sombríos de la Sierra de Caparain". Seguramente se refieren a la umbría de la cara norte del Grajo, donde hemos recolectado otras especies de óptimo supramediterráneo como Berberis hispanica Boiss. \& Reut. Nosotros no la hemos localizado.

\section{Centaurea carratracensis Lange}

Endémica de las sierras malagueñas de Alcaparaín, Aguas y de la Robla. Frecuente. EN (B1 ab(ii,iii)+2abb(ii,iii)). No incluida en el Listado Andaluz de Especies Silvestres en Régimen de Protección Especial. Pedregales y matorrales sobre peridotitas. Crambe-Centaureetum carratracensis; Galio-Staehelinetum baetici

MÁLAGA. Carratraca. Sierra de Alcaparaín. Pista del Puerto Martínez a Carratraca. Casa del Moro. 30SUF3678. 620 msnm. 25/04/2014. Matorral. Peridotitas. Leg.: B. Cabezudo \& F. Soriguer. MGC 78402; Casarabonela. Sierra de Alcaparaín. Cerro Minas. 30SUF3677. 600 msnm. 23/05/2014. Matorrales. Peridotitas. Leg.: B. Cabezudo, A. V. Pérez Latorre \& F. Soriguer. MGC 78830; ibídem. El Alcornocal-Cerro Minas. 30SUF3677. $600 \mathrm{msnm}$. 08/05/2014. Matorrales. Peridotitas. Leg.: B. Cabezudo \& F. Soriguer. MGC 78606.

Crepis bermejana M. Talavera, C. Sánchez Casimiro-Soriguer \& S. Talavera

Endémica de las sierras malagueñas de
Alcaparaín, Bermeja y de la Robla. Muy rara. Especie no evaluada pero que consideramos que se encuentra amenazada como VU según criterios UICN. Matorrales y pastizales sobre peridotitas. StaehelinoUlicion baetici; Cerastio-Brachypodietum retusi.

MÁLAGA. Casarabonela. Sierra de Alcaparaín. Cerro Minas. 30SUF3677. 600 msnm. 23/05/2014. Matorrales. Peridotitas. Leg.: B. Cabezudo, A. V. Pérez Latorre \& F. Soriguer. MGC 78822; ibídem, El Alcornocal-Cerro Minas. 30SUF3677. 600 msnm. 08/05/2014. Matorrales. Peridotitas. Leg.: B. Cabezudo \& F. Soriguer. MGC 78603; Carratraca. Sierra de Alcaparaín. Pista del Puerto Martínez a Carratraca. Casa del Moro. 30SUF3678. 620 msnm. 25/04/2014. Matorral. Peridotitas. Leg.: B. Cabezudo \& F. Soriguer. MGC 78403.

Hormathophylla longicaulis (Boiss.) Cullen \& T. R. Dudley

Especie endémica de Andalucía. Muy Rara. Tomillares y comunidades rupícolas magnesícolas. Galio baetici-Thymetum granatensis.

MÁLAGA. Carratraca. Sierra de Alcaparaín. El Grajo. Cara Norte. Collado Grajo-Espolón Norte. 30SUF3577. 1125 msnm. 05/06/2014. Blanquizar dolomítico en laderas de fuerte pendiente. Dolomías disgregadas. Leg.: F. Soriguer. MGC 79130; ibídem, Vertiente Este. Pista del Puerto Martínez a Carratraca. Entre El Alcornocal y Hoya Pata. 30SUF3678. 650 msnm. 23/05/2014. Taludes y laderas desbrozadas. Dolomías disgregadas. Leg.: B. Cabezudo, A. V. Pérez Latorre \& F. Soriguer. MGC 78865; Sierra de Alcaparaín. Entre los términos de Carratraca y Casarabonela. Cresterío entre el Pico Valdivia y El Grajo. 30SUF3577. 1227 msnm. 02/05/2014. Zona muy rocosa. Dolomías. Leg.: B. Cabezudo, F. Soriguer \& J. García-Sánchez. MGC 78501.

\section{Linaria clementei Haens. ex Boiss.}

Especie endémica de las sierras rondeñas de la provincia de Málaga. Muy rara. VU (B1ab(i,ii,iii,iv)+ 2ab(i,ii,iii,iv)). Herbazales sobre arenas dolomíticas. Linario clementei-Andryaletum ramosissimae.

MÁLAGA. Carratraca. Sierra Alcaparaín. 04/04/1990. Dolomías. Leg.: B. Cabezudo. MGC 25939; ibídem, 30SUF3679. 630 msnm. 27/10/1994. Dolomías. Leg.: Y. Gil, J. M. Nieto \& A. V. Pérez Latorre. MGC 39450; ibídem, Pista del Puerto Martínez a Carratraca. Cantera abandonada. 30SUF3679. 630 msnm. 25/04/2014. Dolomías 
disgregadas. Leg.: B. Cabezudo \& F. Soriguer. MGC 78378; Casarabonela. Sierra Alcaparaín. 800 msnm. 28/04/1988. Dolomías arenosas. Leg.: B. Cabezudo, J. M. Nieto \& A. V. Pérez Latorre. MGC 26556.

Petrorhagia saxifraga (L.) Link.

Ocasional en las sierras béticas occidentales (Málaga). Muy rara en la zona. Comunidades rupícolas dolomitícolas. Rhamno-Saxifragetum granatensis.

MÁLAGA. Carratraca. Sierra de Alcaparaín. El Grajo. Espolón Norte. 30SUF3577. 1210 msnm. 05/06/2014. Vegetación rupícola. Paredes verticales y repisas. Dolomías. Leg.: F. Soriguer. MGC 79127; Casarabonela. Sierra de Alcaparaín. Cerro de la Canana. 30SUF3379. 1180 msnm. 23/05/2014. Roquedos. Dolomías. Leg.: B. Cabezudo, A. V. Pérez Latorre \& F. Soriguer. MGC 78857; ibídem, Cerro de la Canana. 30SUF3379. 1150 msnm. 29/05/2015. Zona muy rocosa. Dolomías. Leg.: B. Cabezudo, A. V. Pérez Latorre, N. Hidalgo \& F. Soriguer. MGC 81143.

\section{Platycapnos tenuiloba subsp. parallela Lidén}

Endemismo de Andalucía. Incluida en el Listado Andaluz de Especies Silvestres en Régimen de Protección Especial. VU (B2ab((i,ii,iii,iv);C2b) (UICN). Muy rara. Pastizales terofíticos sobre arenas calizo-dolomíticas. Comunidad de Chaenorrhinum rubrifolium.

MÁLAGA. Carratraca. Sierra de Alcaparaín. 900 msnm. 28/04/1988. Leg.: B. Cabezudo, J. M. Nieto \& A. V. Pérez Latorre. MGC 23048; ibídem, 10/04/1990. Calizas. Cultivo de olivos. Leg.: B. Cabezudo \& R. Suau. MGC 25942; ibídem, 22/03/1996. Leg.: B. Cabezudo, A. V. Pérez Latorre, P. Navas \& Y. Gil. MGC 43868; ibídem, Cerro Gollino. 02/05/1996. Calizas. Leg.: D. Navas, P. Navas \& Y. Gil. MGC 43867; ibídem, Cerro Gollino, parte baja lindando con cultivos. 15/04/1996. Calizas. Leg.: D. Navas, P. Navas \& Y. Gil. MGC 43864; ibídem, Subida al Cerro Gollino. 15/04/1996. Calizas. Leg.: D. Navas, P. Navas \& Y. Gil. MGC 43871.

\section{Pleurosorus hispanicus (Cosson) C. V. Morton}

Especie mediterránea occidental muy rara en la zona. Grietas de rocas dolomíticas. RhamnoSaxifragetum granatensis.

MÁLAGA. Carratraca. Sierra de Alcaparaín.
Cabecera del arroyo del Conejo. Ramal Sureste (vereda con marcado zigzag). 30SUF3452578970. Rp: 415. 925 msnm. 29/05/2015. Zona rocosa. Rupícolas y subrupícolas. Dolomías. Leg.: B. Cabezudo, A. V. Pérez Latorre, N. Hidalgo \& F. Soriguer. MGC 81152.

\section{Polygala webbiana Coss.}

Endemismo bético-rifeño. En Europa se localiza exclusivamente en la Sierra de Alcaparaín. Muy raro. CR (B2a,C2a(i), D). Comunidades rupícolas dolomitícolas. Sarcocapnetum baeticae.

MÁLAGA. Carratraca. Sierra de Alcaparaín. Vereda desde la casa del Cerro del Gollino al Cerro de la Canana. 30SUF3479. 875 msnm. 25/04/2014. Grandes espolones rocosos. Rupícolas. Dolomías. Leg.: B. Cabezudo \& F. Soriguer. MGC 78340; Casarabonela. Sierra de Alcaparaín. Orientación Noreste. 30SUF3477. $900 \mathrm{msnm}$. 11/10/2013. Rupícola en paredones dolomitícolas. Leg.: B. Cabezudo \& F. Soriguer. MGC 77944.; ibídem, Vertiente Noroeste. Entre Cueva Bermeja y el Cerro de la Canana. 30SUF3345778241. 1000 msnm. $11 / 04 / 2014$. Zona muy rocosa. Tajos verticales y matorrales en laderas de fuerte pendiente. Leg.: B. Cabezudo \& F. Soriguer. MGC 78200.

\section{Potentilla caulescens L.}

Especie mediterránea occidental. Muy rara en la zona. Comunidades rupícolas orófilas en roquedos dolomíticos. Rhamno-Saxifragetum granatensis.

MÁLAGA. Casarabonela. Sierra de Alcaparaín. Cerro de la Canana. 30SUF3379. $1141 \mathrm{msnm}$. 08/05/2014. Extraplomos umbríos. Dolomías. B. Cabezudo \& F. Soriguer. MGC 78575.

\section{Salvia candelabrum Boiss.}

Endemismo andaluz. Sierras béticas. Frecuente. VU(A2a;2ab(ii,ii,iii,iv)) ( UICN). Matorrales sobre substratos dolomíticos. Lavandulo-Ulicetum baetici.

MÁLAGA. Ardales. Sierra de Alcaparaín. Fuente del arroyo del Tranco. 30SUF3380. 650 msnm. 08/05/2014. Matorrales, esquistos y dolomías. Leg.: B. Cabezudo \& F. Soriguer. MGC 78586; Carratraca. Sierra de Alcaparaín. 30SUF3680. 620 msnm. 27/10/1994. Calizas. Leg.: J. M. Nieto, A. V. Pérez Latorre \& Y. Gil. MGC 39310; ibídem, 10/04/1990. Leg.: B. Cabezudo \& R. Suau. MGC 27972; ibídem, vereda de subida al pico Valdivia desde la cara Este. 30SUF3597678147. Rp: 250. 
$750 \mathrm{msnm}$. 02/05/2014. Matorrales y pastizales. Dolomías disgregadas. Leg.: B. Cabezudo, F. Soriguer \& J. García-Sánchez. MGC 78537; ibídem, vertiente Este. Vereda de subida al Grajo desde Hoya Pata. 30SUF3597678147. Rp: 250. 750 msnm. 23/05/2014. Matorrales. Dolomías disgregadas. Leg.: B. Cabezudo, A. V. Pérez Latorre \& F. Soriguer. MGC 78810; ibídem, cabecera del arroyo del Conejo. Ramal Sureste (vereda con marcado zigzag). 30SUF3452578970. Rp: 415.925 msnm. 29/05/2015. Matorrales. Dolomías. Leg.: B. Cabezudo, A. V. Pérez Latorre, N. Hidalgo \& F. Soriguer. MGC 81192; Casarabonela. Sierra de Alcaparaín. Vertiente Oeste. Alrededores de Cueva Bermeja. 30SUF3377. 850 msnm. 15/05/2015. Pinar-sabinar sobre grandes espolones rocosos. Dolomías. Leg.: J. García-Sánchez \& F. Soriguer. MGC 80864; ibídem, 3650’38'N 0452'35"W. 700 msnm. 11/06/2009. Leg.: A. M. Pérez Ortigosa. MGC 70771.

Sarcocapnos baetica subsp. baetica (Boiss. \& Reut.) Nyman

Endemismo bético-magrebí. Incluida (VU) en el Catálogo Andaluz de Especies Amenazadas. Ocasional. Comunidades de extraplomos en rocas dolomíticas. Sarcocapnetum baeticae.

MÁLAGA. Carratraca. Sierra Alcaparaín. 1000 msnm. 22/03/1996. Leg.: B. Cabezudo, A. V. Pérez Latorre, P. Navas \& Y. Gil. MGC 41644; ibídem, 30SUF3478. $900 \mathrm{msnm}$. 04/04/2014. Tajos verticales y rellanos terrosos. Dolomías. Leg.: J. GarcíaSánchez, C. Bouvier \& F. Soriguer. MGC 78145; ibídem, vereda de subida al pico Valdivia desde la cara Este. 30SUF3278. 700 msnm. 11/04/2014. Tajos verticales. Dolomías. Leg.: B. Cabezudo \& F. Soriguer. MGC 78167; ibídem, vereda desde la casa del Cerro del Gollino al Cerro de la Canana. 10/04/1990. Leg.: B. Cabezudo \& R. Suau. MGC 25938; ibídem, vertiente Noreste. Cabecera del arroyo del Conejo. 1000 msnm. 28/04/1988. Leg.: B. Cabezudo, J. M. Nieto \& A. V. Pérez Latorre. MGC 23047; ibídem, cabecera del arroyo del Conejo. Ramal Sureste (vereda con marcado zigzag). 30SUF3377. 850 msnm. 15/05/2015. Pinar-sabinar sobre grandes espolones rocosos. Dolomías. Leg.: J. García-Sánchez \& F. Soriguer. MGC 80862; Casarabonela. Sierra de Alcaparaín. 3650'38'N 04'52'35"W. 700 msnm. 11/06/2009. Leg.: A. M. Pérez Ortigosa. MGC 70772; ibídem, Cerro de la Canana. 30SUF3597678147. Rp: 250. 750 msnm. 02/05/2014. Rupícolas. Dolomías. Leg.: B. Cabezudo, F. Soriguer \& J. García-Sánchez. MGC 78552; ibídem, vertiente Oeste. Alrededores de Cueva Bermeja. 30SUF3479. $875 \mathrm{msnm}$. 25/04/2014. Grandes espolones rocosos. Rupícolas. Dolomías. Leg.: B. Cabezudo \& F. Soriguer. MGC 78342; ibídem, Cerro de la Canana. 30SUF3278. $700 \mathrm{msnm}$. 04/04/2014. Espolones rocosos. Dolomías. Leg.: J. García-Sánchez, C. Bouvier \& F. Soriguer. MGC 78153; ibídem, vertiente Noroeste. Cabecera del arroyo de las Cuevas. 30SUF3379. 1180 msnm. 23/05/2014. Roquedos. Dolomías. Leg.: B. Cabezudo, A. V. Pérez Latorre \& F. Soriguer. MGC 78859; ibídem, vertiente Noroeste. Cabecera del arroyo de las Cuevas. Junto a las casas cueva. 30SUF3452578970. Rp: 415. $925 \mathrm{msnm}$. 29/05/2015. Zona rocosa. Rupícolas y subrupícolas. Dolomías. Leg.: B. Cabezudo, A. V. Pérez Latorre, N. Hidalgo \& F. Soriguer. MGC 81155.

Entre la flora recolectada e inventariada en la Sierra de Alcaparaín destaca la propia del afloramiento ultramáfico de la tesela 1. En ella habitan hasta 7 serpentinófitos (Pérez Latorre et al., 2013b): a/ obligados y endémicos: Alyssum serpyllifolium subsp. malacitanum, Centaurea carratracensis, Crepis bermejana, Teucrium reverchonii, Linum suffruticosum var. carratracensis; b/ preferentes: Galium boissieranum (VU (LRA, LRE)), G. viridiflorum (VU (LRE, LRA); LESRPE).

LRE $=$ Lista Roja de la Flora Vascular Española (Moreno, 2008); LRA=Lista Roja de la Flora Vascular de Andalucía (Cabezudo et al., 2005); LESRPE=Listado de Especies Silvestres en Régimen de Protección Especial (Real Decreto 139/2011).

\section{Novedades y comentarios sintaxonómicos}

A continuación se comentan y/o describen las asociaciones y comunidades de interés presentes en el territorio estudiado. El número corresponde al que se les asigna en el esquema 
Tabla 2

1. Comunidad de Saxifraga globulifera sensu Pérez Latorre et al. (2012)

(Campanulion velutinae, Asplenietalia petrarchae, Asplenietea trichomanis)

\begin{tabular}{|c|c|c|c|c|}
\hline INVENTARIO N & 1 & 2 & 3 & 4 \\
\hline Orientación & E & $\mathrm{N}$ & $\mathrm{NE}$ & $\mathrm{E}$ \\
\hline Inclinación $\left(^{\circ}\right)$ & 90 & 70 & 90 & 90 \\
\hline Área $\left(\mathrm{m}^{2}\right)$ & 1 & 4 & 16 & 16 \\
\hline Litología & Dol & $\mathrm{Cal}$ & Mar & Mar \\
\hline Altitud (m) & 750 & 710 & 450 & 450 \\
\hline Altura vegetación (cm) & 15 & 10 & - & - \\
\hline Cobertura vegetación (\%) & 10 & - & 10 & 15 \\
\hline \multicolumn{5}{|c|}{ Característica de comunidad } \\
\hline Saxifraga globulifera & 1 & 3 & 1 & 1 \\
\hline Erodium cicutarium & - & - & 1 & 1 \\
\hline \multicolumn{5}{|c|}{ Características de unidades superiores } \\
\hline Ceterach officinarum & + & + & + & - \\
\hline Campanula mollis & + & - & 1 & 2 \\
\hline Linaria tristis & - & + & 1 & 1 \\
\hline Silene andryalifolia & - & - & 1 & 1 \\
\hline Sedum dasyphyllum & - & - & 1 & + \\
\hline \multicolumn{5}{|c|}{$\begin{array}{l}\text { Otras características. En 3: Cosentinia vellea }+ \text {. En 4: Anthyllis polycephala 1, Melica } \\
\text { minuta } 1 .\end{array}$} \\
\hline \multicolumn{5}{|l|}{ Compañeras } \\
\hline Chaenorrhinum villosum & + & - & 2 & 1 \\
\hline Sedum album & + & 2 & - & - \\
\hline Polypodium cambricum & - & - & 1 & + \\
\hline
\end{tabular}

Otras compañeras. En 1: Parietaria judaica +, Scabiosa turolensis grosii +. En 2: Geranium lucidum +, Hedypnois rhagadioloides,+ Lactuca tenerrima + , Musgos acrocárpicos 2, Rumex induratus + , Theligonum cynocrambe +, Valantia hispida +. En 3: Galium boissieranum 1. En 4: Lapiedra martinezii +, Umbilicus rupestris 1

Localidades. 1. Málaga. Carratraca. Sierra de Alcaparaín. Barranco del Arroyo de los Pinos. 30SUF3578. 2. Málaga. Alozaina. Sierra Prieta. Matemil. Cortafuegos. 30SUF3369 (tomado de Pérez Latorre et al., 2012). 3 y 4. Málaga. Torremolinos. Sierra de Torremolinos (tomados de Pérez Sanz, 1986: 169, tabla 9, invs. 1 y 3). Dol: dolomías. Cal: calizas. Mar: mármoles dolomíticos.

sintaxonómico. El conjunto de todas las comunidades y asociaciones localizadas en la zona estudiada se reúnen en un esquema sintaxonómico y ecofisionómico al final del trabajo.

1. Comunidad de Saxifraga globulifera sensu Pérez Latorre et al. (2012) [Tabla 2]
La vegetación rupícola basófila de areal rondeño caracterizada por Saxifraga globulifera fue descrita a nivel de asociación supraoromediterránea como Rhamno pumilaeSaxifragetum granatensis (Saxifragion camposii). Presenta una variante con Hieracium baeticum empobrecida, termófila-heliófila, mesomediterránea y una subasociación 
Tabla 3

2. Rhamno pumilae-Saxifragetum granatensis Pérez Latorre \& Cabezudo in Pérez Latorre, P.

Navas, D. Navas, Gil \& Cabezudo 1998

saxifragetosum granatensis, var. con Hieracium baeticum

(Saxifragion camposii, Potentilletalia caulescentis, Asplenietea trichomanis)

$\begin{array}{lcc}\text { INVENTARIO N } & & \\ \text { Orientación } & \mathrm{N} & 2 \\ \text { Inclinación }\left({ }^{\circ}\right) & 90 & \mathrm{~N} \\ \text { Área }\left(\mathrm{m}^{2}\right) & 10 & 50 \\ \text { Litología } & \text { Dol } & \text { Dol } \\ \text { Altitud }(\mathrm{m}) & 1110 & 900 \\ \text { Altura vegetación }(\mathrm{cm} .) & 10 & 15 \\ \text { Cobertura vegetación }(\%) & 15 & 30\end{array}$

Características y diferenciales de asociación

Saxifraga globulifera

Silene andryalifolia

2

$+$

Diferencial de variante

Galium baeticum

1

Características de unidades superiores

Campanula mollis

$+2$

Crepis albida

Melica minuta

Compañeras

Chaenorrhinum villosum

Scabiosa turolensis grosii

1

2

$1+$

Otras compañeras. En 1: Lavandula lanata +, Rhamnus myrtifolia +, Sedum dasyphyllum +, Teucrium similatum +. En 2: Cerastium gibraltaricum 1, Sarcocapnos baetica + , Stachys circinata + , Pleurosorus hispanicus + .

Localidades. 1. Málaga. Carratraca. Sierra de Alcaparaín. Cerro de la Canana. 30SUF3479. 2. Málaga. Carratraca. Sierra de Alcaparaín. Cabecera del Ayo. del Conejo. 30SUF3478. Dol: dolomías. dolomitícola mesomediterránea con el endemismo rondeño Galium pulvinatum (Pérez Latorre et al., 1998) que alcanza la Sierra Blanca de Marbella (Merino López, 1984). La asociación se localizó en las Sierras Prieta y Blanquilla (Pérez Latorre et al., 2012) continuación hacia el sur de la Sierra de Alcaparaín. En la propia Sierra de Alcaparaín hemos detectado, de modo finícola, esta asociación en su variante más termófila. Sin embargo tanto en Sierra Prieta, como en Alcaparaín e incluso Sierra de Mijas (Pérez Sanz, 1986), se han detectado formaciones rupícolas de Saxifraga globulifera en el piso termomediterráneo, aunque en zonas subhúmedas y con orientaciones favorecedoras ( $\mathrm{N}$ y E) que incluimos en la comunidad ya indicada por Pérez Latorre et al. (2012) dentro de la alianza termófila Campanulion velutinae.

\section{Rhamno pumilae-Saxifragetum granatensis} Pérez Latorre \& Cabezudo in Pérez Latorre, P. Navas, D. Navas, Gil \& Cabezudo 1998 [Tabla 3]

subass. saxifragetosum granatensis

var. con Hieracium baeticum sensu Pérez Latorre et al. (1998)

Esta asociación rupícola supraoromediterránea umbrófila, que tiene su centro de origen en Sierra de las Nieves, alcanza de modo finícola la Sierra de Alcaparaín, de mucha menor altitud. Por ello se empobrece en todos los taxones orófilos y se encuentra como la variante xero-heliófila propia del piso mesomediterráneo (Pérez Latorre et al., 1998, 2012). Se trata de las localizaciones más al norte en el sector Rondeño para este tipo de vegetación.

4. Sarcocapnetum baeticae Pérez Latorre \& Cabezudo in Pérez Latorre, P. Navas, D. Navas, Gil \& Cabezudo 1998 [Tabla 4] subass. sarcocapnetosum baeticae var. con Polygala webbiana subass. moehringietosum giennensis 
Tabla 4

4. Sarcocapnetum baeticae Pérez Latorre \& Cabezudo in Pérez Latorre, P. Navas, D. Navas, Gil \& Cabezudo 1998

sarcocapnetosum baeticae, var. con Polygala webbiana

(Sarcocapnion crassifoliae, Sarcocapnetalia enneaphyllae, Petrocoptido-Sarcocapnetea enneaphyllae)

$\begin{array}{lccccccccccccccc}\text { INVENTARIO N } & 1 & 2 & 3 & 4 & 5 & 6 & 7 & 8 & 9 & 10 & 11 & 12 & 13 & 14 & 15 \\ \text { Orientación } & \mathrm{N} & \mathrm{O} & \mathrm{O} & \mathrm{N} & \mathrm{N} & \mathrm{SO} & \mathrm{O} & \mathrm{N} & \mathrm{N} & \mathrm{N} & \mathrm{N} & \mathrm{SO} & \mathrm{N} & \mathrm{N} & \mathrm{O} \\ \text { Inclinación }\left({ }^{\circ}\right) & 90 & 90 & 90 & 90 & 120 & 100 & 135 & 120 & 120 & 120 & 110 & 180 & 135 & 120 & 100 \\ \text { Área }\left(\mathrm{m}^{2}\right) & 4 & 20 & 6 & 1 & 10 & 4 & 5 & 5 & 6 & 4 & 4 & 10 & 1 & 10 & 10 \\ \text { Litología } & \mathrm{Dol} & \mathrm{Dol} & \mathrm{Dol} & \mathrm{Dol} & \mathrm{Dol} & \mathrm{Dol} & \mathrm{Dol} & \mathrm{Dol} & \mathrm{Dol} & \mathrm{Dol} & \mathrm{Dol} & \text { Dol } & \text { Dol } & \text { Dol } & \text { Dol } \\ \text { Altitud }(\mathrm{m}) & 900 & 1000 & 800 & 1100 & 750 & 700 & 700 & 1000 & 900 & 900 & 1110 & 950 & 900 & 1140 & 700 \\ \text { Altura vegetación }(\mathrm{cm}) & 10 & 20 & 40 & 4 & 15 & 10 & 5 & 20 & 5 & 10 & 4 & 15 & 15 & 10 & 8 \\ \text { Cobertura vegetación }(\%) & 10 & 5 & 20 & 3 & 10 & 3 & 5 & 5 & 10 & 2 & 10 & 5 & 5 & 5 & 5\end{array}$

\section{Característica de asociación}

Sarcocapnos baetica

\section{Diferencial de variante}

Polygala webbiana

\section{Compañeras}

Chaenorrhinum villosum +

Parietaria judaica

Galium baeticum

Campanula mollis

Crepis albida

Melica minuta

Putoria calabrica

Rhamnus myrtifolia

Scabiosa turolensis grosii -

Otras compañeras. En 2: Teucrium similatum +. En 3: Bupleurum gibraltaricum +, Lapiedra martinezii + , Silene andryalifolia 1. En 6: Lactuca tenerrima +, Phagnalon sordidum +. En 8: Saxifraga globulifera + . En 14: Juniperus phoenicea +, Potentilla caulescens + .

Localidad. 1. Málaga. Carratraca. Sierra de Alcaparaín. Cabecera del Ayo. Del Conejo. 30S UF3478. 2. Málaga. Carratraca. Sierra de Alcaparaín. Entre Cueva Bermeja y Cerro de la Canana. 30SUF3378. 3. Málaga. Carratraca. Sierra de Alcaparaín. Entre la Casa forestal y el Cerro de la Canana. 4. Málaga. Carratraca. Sierra de Alcaparaín. Cabecera del Ayo. de los Pinos 30SUF3477. 5. Málaga. Carratraca. Sierra de Alcaparaín. Cabecera del Ayo. del Conejo. 30S UF3478. 6. Málaga. Carratraca. Sierra de Alcaparaín. Cabecera del Ayo. de la Cueva. 30SUF3278. 7. Málaga. Carratraca. Sierra de Alcaparaín. Cabecera del Ayo. de la Cueva. 30SUF3278. 8. Málaga. Carratraca. Sierra de Alcaparaín. Entre la Casa forestal y el Cerro de la Canana. 9. Málaga. Carratraca. Sierra de Alcaparaín. Subida al pico Valdivia por el este. 30SUF3578. 10. Málaga. Carratraca. Sierra de Alcaparaín. Subida al pico Valdivia por el este. 30SUF3578. 11. Málaga. Carratraca. Sierra de Alcaparaín. Cerro de la Canana. 30SUF3479 12. Málaga. Casarabonela. Sierra de Alcaparaín. Cueva Bermeja. 30SUF4291. 13. Málaga. Carratraca. Sierra de Alcaparaín. Cabecera del Ayo. del Conejo. 30S UF3478. 14. Málaga. Casarabonela. Sierra de Alcaparaín. Cerro de la Canana. 30SUF3378. 15. Málaga. Carratraca. Sierra de Alcaparaín. Cabecera del Ayo. De la Cueva. 30SUF3278. Dol: dolomías. 
Fernández Casas 1972 corr. Mota, Gómez Mercado y F. Valle 1991 comb. nova et stat. nov.

[Moehringietum giennensis Fernández Casas 1972 corr. Mota, Gómez Mercado y F. Valle 1991 in Trab. Dpto. Bot. Univ. Granada 1: 39, Tab. 2, 1972]

Asociación espeluncícola, umbrófila, mesomediterránea, dominada por Sarcocapnos baetica subsp. baetica. Tiene interés por el cenotopo colonizado (extraplomos dolomíticos) prácticamente inhóspito para los cormófitos, por tratarse su especie característica de una especie amenazada y por presentar en esta Sierra de Alcaparaín el mayor número de poblaciones de todo su areal bético occidental (rondeño) (Pérez Latorre et al., 1998, 2012). Además, es en esta asociación donde encuentra cobijo el taxón relictual Polygala webbiana, sobre todo en paredes con inclinaciones más cercanas a la verticalidad $\left(90^{\circ}\right)$. A la vista de los inventarios de Gómez Mercado (2011: 70, tabla 15) en la Sierra de Cazorla, con S. baetica como especie dominante, esta asociación alcanzaría el sector Subbético, donde se enriquece en la especie territorial endémica Moehringia intricata subsp. giennensis Díaz de la Guardia, Mota \& Valle. Al existir una asociación para este tipo de vegetación subbética (Moehringietum giennensis), se hace necesaria su combinación y cambio de estatus a subasociación moehringietosum giennensis subordinada al más amplio (bético) Sarcocapnetum baeticae.

\section{Linario clementei-Andryaletum} ramosissimae Rivas Goday \& Esteve 1972 [Tabla 5]

Vegetación herbácea perenne de taludes y derrubios dolomíticos y mármoles kakiritizados, que en la zona de estudio se desarrolla en el tránsito entre los pisos termo y mesomediterráneo. Asociación de gran interés por la presencia de edafoendemismos dolomitófitos (Mota et al., 2008) como Linaria
Tabla 5

5. Linario clementei-Andryaletum ramosissimae Rivas Goday \& Esteve 1972

(Andryalo-Crambion filiformis, PhagnaloRumicetalia indurati, Phagnalo-Rumicetea indurati)

$\begin{array}{lccc}\text { INVENTARIO N } & 1 & 2 & 3 \\ \text { Orientación } & \mathrm{NE} & - & \mathrm{E} \\ \text { Inclinación }\left({ }^{\circ}\right) & 10 & - & 30 \\ \text { Área }\left(\mathrm{m}^{2}\right) & 30 & 30 & 4 \\ \text { Litología } & \mathrm{Kak} & \mathrm{Kak} & \mathrm{Kak} \\ \text { Altitud (m) } & 680 & 670 & 680 \\ \text { Altura vegetación }(\mathrm{cm}) & 25 & 25 & 30 \\ \text { Cobertura vegetación }(\%) & 30 & 25 & 20\end{array}$

Características y diferenciales de asociación

Linaria clementei $\quad+\quad+\quad 2$

Andryala ragusina

ramosissima

$2 \quad 2 \quad-$

Características de unidades superiores

$\begin{array}{llll}\text { Echium albicans } & 1 & +\end{array}$

Biscutella laxa $\quad+\quad+\quad+$

Scrophularia crithmifolia $\quad-\quad+\quad+\quad-$

\section{Compañeras}

Dianthus hispanicus $\quad+\quad \begin{array}{ll}1 & 2\end{array}$

Erucastrum virgatum baeticum $1+1$

Paronychia sufruticosa hirsuta $+\quad 1 \quad 1$

$\begin{array}{llll}\text { Sedum sediforme } & - & 1 & 1\end{array}$

Coris monspeliensis syrtica $\quad+\quad+\quad-$

Erysimun mediohispanicum rondae

Koeleria crassipes filifolia

Stipa offneri

Teucrium lusitanicum

Otras compañeras. En 1: Aetheorrhiza bulbosa + , Anthyllis polycephala + , Anthyllis vulneraria +, Cistus albidus 1, Helianthemun cinereum rotundifolium + , Iberis carnosa granatensis + , Linum suffruticosum + , Neotinea maculata + , Reseda gayana 1. En 2: Asperula aristata,+ Fumana ericifolia 1, Helianthemun appeninum suffruticosum 1, Helichrysum stoechas + , Leuzea conifera + , Linaria saturejoides + , Polygala rupestris + , Ptilostemon hispanicus + .

Localidades. 1, 2 y 3. Málaga. Carratraca. Sierra de Alcaparaín. Los Arenales. 30SUF3678. Kak: kakiritas. 
clementei (endemismo del sector Rondeño).

\section{Centaureenion lainzii-carratracensis suball. nova hoc loco}

[Holotypus hoc loco: Crambe filiformisCentaureetum carratracensis ass. nova en este trabajo]

\section{Crambe filiformis-Centaureetum carratracensis stat. nov. et ass. nova}

[Echio albicantis-Crambeetum filiformis Rivas Goday \& Esteve 1972 centaureetosum carratracensis (Rivas Goday \& Esteve 1972) Nieto y Cabezudo 1988 in Monografías del Instituto Pirenaico de Ecología, 4: 672, 1988, lectotypus inv. 7, tabla 4. de Rivas Goday \& Esteve (1972)]

subass. centaureetosum carratracensis

subass. centaureetosum lainzii (Asensi \& Díez 1977) comb. nova

[Echio albicantis-Crambeetum filiformis centaureetosum lainzii Asensi \& Díez Garretas 1977 in Anal. Inst. Bot. Cavanilles 34 (1): 183-185, tabla única, 1977]

La vegetación herbácea perenne de taludes y canturriales peridotíticos (hazburguitas y dunitas piroxénicas) propia del subsector Carratracense fue descrita por Rivas Goday \& Esteve (1972: 424, tabla 4) y tipificada como subasociación por Nieto \& Cabezudo (1988). La amplia tabla de Rivas Goday \& Esteve (op . cit.) ha sido desmembrada para tipificar asociaciones de terófitos por Rivas Martínez et al. (1973:26) y para designar diversas subasociaciones de gleras y arenales dolomíticos y serpentínicos. Desde la fecha de la tipificación del amplio Echio-Crambetum filiformis, los diversos autores se han inclinado por designar como asociaciones a cada una de sus subasociaciones: 1/ Linario clementei-Andryaletum ramosissimae (antes subass. linarietosum clementei, sector Rondeño), 2/ Anthyllido plumosae-Andryaletum ramosissimae (antes subass. resedetosum almijarensis, sector Almijaro-Granatense). De las dos subasociaciones restantes, la centaureetosum carratracensis (sector Bermejense, subsector Carratracense) se separa claramente de las otras tres por ser serpentinícola: 3/ Crambe filiformis-Centaureetum carratracensis, sector Bermejense) y la subass. típica 4/ crambeetosum filiformis, queda reducida a un solo inventario (inv. 9, tabla 4 de Rivas Goday $\&$ Esteve, 1972) que creemos que se trata de un representante en el mismo área de distribución (sector Rondeño) y ligeramente empobrecido de Linario clementei-Andryaletum ramosissimae. Al desaparecer la asociación, combinamos la subasociación Bermejense centaureetosum lainzii (Asensi \& Díez, 1977) con la nueva asociación.

Nuestros inventarios en la Sierra de Alcaparaín incluyen la presencia de varios edafoendemismos serpentinícolas y/o serpentinófitos tales como Centaurea carratracensis, Alyssum serpyllifolium malacitanum, Teucrium reverchonii o Galium boissieranum. Esta nueva asociación fue citada por López (1975) en la Sierra de Aguas (sub. Echio-Crambeetum centaureetosum carratracensis), continuación hacia el NE de las propias peridotitas de Alcaparaín.

Localidad. Málaga. Carratraca. Sierra de Alcaparaín. Cerro Minas. 30SUF3677. Orientación: E. Inclinación: $80^{\circ}$. Área: 30 $\mathrm{m}^{2}$. Litología: peridotitas (hazburguitasdunitas piroxénicas). Altitud: $560 \mathrm{~m}$. Altura vegetación: $30 \mathrm{~cm}$. Cobertura vegetación: 20\%. Características y diferenciales de asociación: Crambe filiformis + , Centaurea carratracensis 1, Alyssum serpyllifolium malacitanum (terr.) + , Linum suffruticosum carratracensis +, Teucrium reverchonii (terr.) +. Característica de unidades superiores: Rumex induratus + . Compañeras: Arrhenatherum album + , Bunium macuca + , Dactylis glomerata hispanica +, Galium boissieranum +, Linum tenue +, Macrochloa tenacissima + , Scorzonera baetica 1, Sesamoides purpurascens +. terr.: taxon territorial. 
La existencia de un fondo florístico propio de las gleras, taludes y canturriarles peridotíticos del sur de la Península Ibérica (sector Bermejense, provincia Bética) hace necesaria la existencia de al menos una subalianza (Centaureenion lainziicarratracensis suball. nova) que englobe y diferencie a este tipo de vegetación del resto de comunidades béticas, generalmente asociadas a substratos dolomíticos. Especies características y diferenciales* de esta subalianza son: Silene fernandezii Jeanmonod, Centaurea carratracensis*, Armeria colorata Pau*, Centaurea lainzii Fern. Casas, Centaurea haenseleri (Boiss.) Boiss. \& Reut.

\section{Comunidad de Biscutella baetica}

Los pastizales anuales oligótrofos silicícolas están muy reducidos y empobrecidos en el territorio de estudio, situados en pequeños claros del matorral-jaral del Lavandulo-Genistetum equisetiformis typicum y thymetosum capitati en la tesela 2, donde además existe un mosaico litológico entre rocas ácidas y básicas (calizas alabeadas y pizarras). La comunidad podría estar relacionada con las representaciones existentes en la Sierra de Cártama del Biscutello baeticae-Anthoxanthetum ovati (Galán de Mera) Hidalgo \& Pérez Latorre 2013, como una representación finícola de éste, ya que se localiza en la zona más norteña del sector Malacitano-Axarquiense en la misma Cuenca (río Guadalhorce) y en biotopos similares (Hidalgo \& Pérez Latorre, 2013).

Localidad. Málaga. Carratraca. Sierra de Alcaparaín. Cerro del Mojón. 30SUF3680. Orientación: W. Inclinación: 5º́rea: 3 $\mathrm{m}^{2}$. Litología: calizas alabeadas-pizarras. Altitud: $640 \mathrm{~m}$. Altura vegetación: $15 \mathrm{~cm}$. Cobertura vegetación: $70 \%$. Características de comunidad: Biscutella baetica 2, Asterolinon linum-stellatum 2, Briza maxima + , Euphorbia exigua + , Leontodon longirrostris

1, Trachynia distachya 3, Trifolium cherleri 1. Características de unidades superiores:
Crupina crupinastrum +, Logfia gallica + , Vulpia muralis 1. Compañeras: Anagallis arvensis 1, Bromus hordeaceus 1, Centranthus calcitrapae 1, Filago pyramidata + , Lotus longisiliquosus 1, Medicago polymorpha + , Tyrimnus leucographus +, Valantia muralis + , Valerianella coronata + .

\section{Jasiono penicillatae-Linarietum saturejoides}

Rivas-Martínez, Izco \& Costa 1973

subass. linarietosum saturejoides

Nanopastizales fugaces terofíticos y dolomitícolas, que se desarrollan en primavera sobre arenales kakiríticos y cuentan con algunos dolomitófitos (Mota et al., 2008) como Linaria saturejoides o Silene germana. Son muy escasos y aparecen en los blanquizares con suelo arenoso entre los pisos termo y mesomediterráneo de la tesela 4; constituyen la expresión más septentrional de esta asociación en la Serranía de Ronda y en el sector Rondeño (Pérez Latorre et al., 2012).

Localidad. Málaga. Carratraca. Sierra de Alcaparaín. Los Arenales. 30SUF3678. Orientación: -. Inclinación: $0^{\circ}$. Área: $1 \mathrm{~m}^{2}$. Litología: Kakiritas. Altitud: $680 \mathrm{~m}$. Altura vegetación: $5 \mathrm{~cm}$. Cobertura vegetación: 15\%. Característica de asociación: Linaria saturejoides 1. Características de unidades superiores: Arenaria modesta 1, Asterolinon linum-stellatum 1, Jasione blepharodon +, Logfia gallica +, Minuartia mediterranea 1, Narduroides salzmannii 1, Silene germana +, Vulpia muralis +. Compañeras: Linaria clementei + , Sedum sediforme + .

\section{Comunidad de Chaenorrhinum rubrifolium}

Pastizales fugaces nanoterofíticos de desarrollo primaveral y que aparecen sobre arenas dolomíticas en el piso mesomediterráneo medio y superior. Su presencia es de interés ya que en su seno es donde tradicionalmente se han localizado poblaciones del taxón Platycapnos tenuiloba subsp. parallela. Sin embargo, estos pastizales no se han desarrollado óptimamente 
Tabla 6

10. Comunidad de Narduroides salzmanii y Arenaria retusa

(Omphalodion commutatae, Trachynietalia distachyae, Helianthemetea guttati)

\begin{tabular}{lccccc}
\hline INVENTARIO N $^{\text {o }}$ & 1 & 2 & 3 & 4 & 5 \\
Orientación & $\mathrm{NO}$ & $\mathrm{N}$ & $\mathrm{NE}$ & $\mathrm{E}$ & $\mathrm{E}$ \\
${\text { Inclinación }\left({ }^{\circ}\right)}^{\text {Área }\left(\mathrm{m}^{2}\right)}$ & 65 & 30 & 30 & 30 & 50 \\
Litología & 2 & 2 & 1 & 1 & 1 \\
Altitud $(\mathrm{m})$ & $\mathrm{Per}$ & $\mathrm{Per}$ & $\mathrm{Per}$ & Per & Per \\
Altura vegetación $(\mathrm{cm})$ & 385 & 550 & 500 & 400 & 400 \\
Cobertura vegetación $(\%)$ & 10 & 15 & 10 & 10 & 10 \\
Características de comunidad & 70 & 40 & 40 & 50 & 50 \\
Arenaria retusa & & & & & \\
Leontodon longirrostris & 4 & - & 3 & 3 & 2 \\
Narduroides salzmannii & 1 & - & 2 & 2 & 1 \\
Características de unidades superiores & - & 1 & 3 & 1 & 2 \\
Omphalodes linifolia & 2 & - & - & & \\
Trachynia distachya & - & 2 & - & 2 & 1 \\
Crucianella angustifolia & + & + & - & - & - \\
Euphorbia exigua & - & 1 & - & - & + \\
Iberis fontqueri & - & 2 & - & - & - \\
\hline
\end{tabular}

Otras características. En 1: Rumex bucephalophorus +. En 2: Asterolinon linum-stellatum 1, Atractylis cancellata 1, Logfia gallica 1. En 5 Hypochaeris achyrophorus + .

Compañeras. En 1: Silene gallica +, Bromus madritensis + , Centranthus calcitrapae 3, Sesamoides purpurascens 1. En 2: Aegilops geniculata 1, Aegilops triuncialis 1. En 3: Centranthus macrosiphon 3. Iberis nazarita 1 en $4,+$ en 5.

Localidades. 1. Málaga. Carratraca. Sierra de Alcaparaín. Los jarales. 30SUF3877. 2. Málaga. Casarabonela. Sierra de La Robla, zona superior. 30SUF3973. 3. Málaga. Casarabonela. Sierra de Alcaparaín. Alrededores del Ayo. de Las Cuevas. 30SUF3777. 4 y 5. Málaga. Casarabonela. Sierra de La Robla. 30SUF4073. Per: peridotitas.

durante el año climatológico de estudio de este trabajo, por lo que se encuentran muy empobrecidos, incluyendo la ausencia de dicha especie de interés. Una comunidad similar habita en la cercana Sierra de Huma, también sobre dolomías (comunidad de Arenaria modesta y Chaenorrhinum rubrifolium; Pérez Latorre et al., 2014).

Localidad. Málaga. Casarabonela. Camino del Cerro del Gollino. 20SUF3477. Orientación: -. Inclinación: $0^{\circ}$. Área: $1 \mathrm{~m}^{2}$. Litología: Arenas dolomíticas. Altitud: $1130 \mathrm{~m}$. Altura vegetación: $7 \mathrm{~cm}$. Cobertura vegetación: 10\%. Características de comunidad: Arenaria retusa 1, Chaenorrhinum rubrifolium + . Características de unidades superiores: Narduroides salzmannii +. Compañeras: Bromus hordeaceus + , Catapodium rigidum +, Filago pyramidata +

Arenario capillipedis-Iberidenion fontqueri suball. nova hoc loco

[Holotypus hoc loco: Arenario-Iberidetum fontqueri Rivas Martínez, Izco y Costa 1973 in 
Trab. Dep. Botánica F. Veg. 6: 23-30, nota al final de página 26, 1973]

\section{Comunidad de Narduroides salzmanii y Arenaria retusa [Tabla 6]}

Nanopastizales terofíticos, fugaces, primaverales, que se desarrollan sobre litosuelos serpentínicos oligótrofos (hazburguitas y dunitas piroxénicas) en el piso termomediterráneo subhúmedo. Se caracteriza básicamente por la presencia de Arenaria retusa (subserpentinófito; Pérez Latorre et al., 2013a). Hasta el momento, de nuestros inventarios se deduce una distribución para el suroeste del subsector Carratracense (peridotitas de Alcaparaín y Sierra de la Robla). En la Sierra de Aguas, pastizales similares fueron detectados por López (1975: 104-105), encabezados también por Arenaria retusa, aunque no llegó a individualizarlos. También existen pastizales de este tipo pero de modo finícola (pastizales anuales de Arenaria retusa y Rumex bucephalophorus) en el afloramiento ultramáfico de Sierra Prieta (Alozaina) (Pérez Latorre et al., 2012). Durante el estudio de esta comunidad se ha recolectado Iberis fontqueri Pau (inv. 2, tabla 6) en Sierra de la Robla, lo que constituye la primera cita en el subsector Carratracense de este serpentinófito estricto (López, 1975; Pérez Latorre et al., 2012, 2013a, 2013b).

La existencia de un fondo florístico propio de los pastizales nanoterofíticos oligotróficos de sustratos peridotíticos del sur de la Península Ibérica (sector Bermejense, provincia Bética) hace necesaria la existencia de al menos una subalianza (Arenario capillipedis-Iberidenion fontqueri suball. nova) que englobe y diferencie a este tipo de vegetación del resto de comunidades béticas que están generalmente asociadas a substratos dolomíticos. Especies características: Arenaria capillipes (Boiss.) Boiss., Iberis fontqueri, Silene inaperta subsp. serpentinicola Talavera.
11. Cerastio gibraltarici-Brachypodietum retusi Díez Garretas \& Asensi in Rivas Martínez \& al. 2011

subass. elaeoselinetosum millefolii Pérez Latorre, Hidalgo, Casimiro-Soriguer y Cabezudo 2013

var. con Centaurea carratracensis

Los yesquerales o pastizales graminoides xerófilos y perennes, sobre peridotitas y dominados por Brachypodium retusum, fueron descritos por Pérez Latorre et al. (2013a) en el afloramiento ultramáfico de Sierra Alpujata (subsector Bermejense). Con el inventario que aportamos, extendemos su presencia al subsector Carratracense. Aparecen en laderas inclinadas con suelo poco profundo $\mathrm{y}$ contactando con la comunidad de Scorzonera baetica y Celtica gigantea.

Localidad. Málaga. Carratraca. Sierra de Alcaparaín. Los jarales. 30SUF3877. Orientación: N. Inclinación: $45^{\circ}$. Área: $25 \mathrm{~m}^{2}$. Litología: hazburguita y dunita piroxénica. Altitud: $370 \mathrm{~m}$. Altura vegetación: $25 \mathrm{~cm}$. Cobertura vegetación: 100\%. Características y diferenciales de asociación: Brachypodium retusum 4, Crepis bermejana + . Diferencial de subasociación Elaeoselinum asclepium millefolium 3. Diferencial de variante: Centaurea carratracensis 2. Características de unidades superiores: Dactylis glomerata hispanica +. Compañeras: Adenocarpus telonensis 1, Anthyllis vulneraria + , Asparagus acutifolius + , Biscutella laxa + , Cistus albidus 1, Crambe filiformis +, Lavandula stoechas + , Phlomis purpurea 1, Rubia agostinhoi + , Ulex baeticus + .

\section{Comunidad de Scorzonera baetica y Macrochloa tenacissima}

Espartales serpentinícolas, caracterizados por la dominancia de Macrochloa tenacissima, caméfito herbáceo, amacollado, perenne y xerófilo de gran talla (más de 1,5 m.), que se acompaña de varios serpentinófitos como Teucrium reverchonii, Alyssum serpyllifolium 
subsp. malacitanum o hemicriptófitos frecuentes en estos medios como Scorzonera baetica. El taxón Centaurea carratracensis aporta un componente territorial propio del subsector Carratracense. Los espartales de la alianza Stipion tenacissimae constituyen vegetación basófila (Rivas Martínez et al., 2011) y los afloramientos ultramáficos (peridotitas) están constituidos por silicatos de hierro y magnesio y poseen un $\mathrm{pH}$ cercano a la neutralidad que incluso puede ser más alto en zonas poco lluviosas (Pérez Latorre, 1989) como la base del área de estudio (ombrotipo seco-subhúmedo). En esas condiciones, y en presencia de antiguos incendios (delatados por los restos carbonizados de especies leñosas), el espartal toma preponderancia. Creemos posible su existencia en afloramientos seco-subhúmedos que hayan sufrido incendios del subsector Bermejense (Sierra Bermeja sensu lato).

Localidad. Málaga. Carratraca. Sierra de Alcaparaín. Minas del Rosario. 30SUF3878. Orientación: SO. Inclinación: $40^{\circ}$. Área: 200 $\mathrm{m}^{2}$. Litología: hazburguita y dunita piroxénica. Altitud: $410 \mathrm{~m}$. Altura vegetación: $170 \mathrm{~cm}$. Cobertura vegetación: 70\%. Características de comunidad: Macrochloa tenacissima 4, Centaurea carratracensis (terr.) + , Teucrium reverchonii 1, Alyssum serpyllifolium malacitanum +, Scorzonera baetica 1. Características de unidades superiores: Convolvulus althaeoides 1, Dactylis glomerata hispanica +, Phlomis lychnitis +, Dipcadi serotinum + , Xiphion filifolium 1. Compañeras: Carex hallerana + , Cistus salvifolius + , Convolvulus siculus 1, Elaeoselinum asclepium millefolium +, Fumana thymifolia 2, Genista umbellata equisetiformis + , Lavandula stoechas +, Linum suffruticosum carratracense +, Reichardia picroides + , Rosmarinus officinalis 1, Sesamoides purpurascens 1, Ulex baeticus + , Urginea marítima 1 .

\section{Comunidad de Scorzonera baetica y Celtica gigantea [Tabla 7]}

Tabla 7

13. Comunidad de Scorzonera baetica y Celtica gigantea

(Stipion tenacissimae, Lygeo sparti-Stipetalia tenacissimae, Lygeo sparti-Stipetea tenacissimae)

\begin{tabular}{lcc}
\hline INVENTARIO No & 1 & 2 \\
Orientación & $\mathrm{NO}$ & $\mathrm{N}$ \\
Inclinación $\left(^{\circ}\right)$ & 50 & 20 \\
${\text { Área }\left(\mathrm{m}^{2}\right)}^{\text {Litología }}$ & 50 & 100 \\
Altitud (m) & $\mathrm{Per}$ & $\mathrm{Per}$ \\
Altura vegetación (cm.) & 380 & 600 \\
Cobertura vegetación (\%) & 175 & 180 \\
& 100 & 60 \\
Características de comunidad & & \\
Celtica gigantea & 5 & 4 \\
Alyssum serpyllifolium & & \\
$\quad$ malacitanum (terr.) & + & 1 \\
Centaurea carratracensis (terr.) & - & 1 \\
Scorzonera baetica & - & 1 \\
Teucrium reverchonii (terr.) & - & + \\
& & \\
Características de unidades superiores & \\
Dactylis glomerata hispanica & + & 2 \\
Arrhenatherum album & + & - \\
Macrochloa tenacissima & & 2 \\
Xiphion filifolium & - & + \\
&
\end{tabular}

\section{Compañeras}

Elaeoselinum asclepium millefolium

Otras compañeras. En 1: Adenocarpus telonensis + , Anthyllis vulneraria + , Crambe filiformis 1, Leontodon longirrostris 2. Ulex baeticus 1. En 2: Cistus albidus 2, Cistus monspeliensis 1, Juniperus oxycedrus 1, Lavandula stoechas 1, Linum suffruticosum 1, Melica minuta 1, Phlomis purpurea + , Pinus halepensis 1, Pulicaria odora + , Rosmarinus officinalis 2, Thymus mastichina + .

Localidades. 1. Málaga. Carratraca. Sierra de Alcaparaín. Los Jarales. 30SUF3877. 2. Málaga. Carratraca. Sierra de Alcaparaín. Entre Los Arenales y El Alcornocal. 30SUF 3678. Per: hazburguitas y dunitas piroxénicas. terr.: taxón territorial.

Vegetación graminoide de elevada talla (más de $150 \mathrm{~cm}$ ) caracterizada por Celtica gigantea que habita gleras semimóviles serpentínicas (hazburguitas y dunitas piroxénicas) de elevada pendiente en el piso termomediterráneo y en la que participan algunos serpentinófitos como Centaurea carratracensis y Teucrium reverchonii. Sobre cenotopos también constituidos por gleras semimóviles y muy 
Tabla 8

15. Lavandulo stoechadis-Genistetum equisetiformis Rivas Goday \& Rivas-Martínez 1969 ulicetosum baetici subass. nova

(Calicotomo-Cistion ladaniferi, Lavanduletalia stoechadis, Cisto-Lavanduletea)

\begin{tabular}{|c|c|c|c|c|}
\hline INVENTARIO N ${ }^{\circ}$ & 1 & 2 & 3 & 4 \\
\hline Orientación & $\mathrm{O}$ & $\mathrm{E}$ & $\mathrm{E}$ & $\mathrm{E}$ \\
\hline Inclinación $\left({ }^{\circ}\right)$ & 20 & 25 & 40 & 10 \\
\hline Área $\left(m^{2}\right)$ & 400 & 150 & 150 & 50 \\
\hline Litología & Gne & Mic & Gne & Gne \\
\hline Altitud (m) & 600 & 685 & 790 & 550 \\
\hline Altura vegetación (cm.) & 300 & 60 & 120 & 180 \\
\hline Cobertura vegetación (\%) & 90 & 60 & 100 & 80 \\
\hline \multicolumn{5}{|c|}{ Características y diferenciales de asociación } \\
\hline Lavandula stoechas & 2 & 1 & - & 1 \\
\hline Genista umbellata equisetiformis & 1 & + & + & 2 \\
\hline \multicolumn{5}{|l|}{ Diferencial de subasociación } \\
\hline Ulex baeticus & 2 & 2 & 2 & 1 \\
\hline \multicolumn{5}{|c|}{ Características de unidades superiores } \\
\hline Cistus ladanifer africanus & 4 & 1 & - & 4 \\
\hline Cistus monspeliensis & 2 & 3 & 4 & - \\
\hline \multicolumn{5}{|l|}{ Compañeras } \\
\hline Phlomis purpurea & 1 & 1 & - & + \\
\hline Brachypodium retusum & - & 1 & 1 & - \\
\hline Pinus halepensis & + & + & - & - \\
\hline Quercus suber & + & + & - & - \\
\hline Rosmarinus officinalis & 2 & - & 2 & - \\
\hline
\end{tabular}

Otras compañeras. En 1: Chamaerops humilis +, Juniperus phoenicea turbinata + . En 2: Adenocarpus telonensis 1, Andryala integrifolia + , Dorycnium pentaphyllum 1 , Dittrichia viscosa + , Thapsia villosa + , Tolpis barbata +, Urginea maritima +. En 3: Centaurium majus 1, Cistus albidus +, Dactylis glomerata +, Daphne gnidium + , Foeniculum vulgare + , Halimium atriplicifolium + , Helichrysum stoechas + , Juniperus oxycedrus + , Lonicera implexa + , Quercus coccifera + , Rubia peregrina + , Teucrium fruticans 1.

Localidades. Málaga: 1 y 2. Casarabonela. Sierra de Alcaparaín. El Alcornocal. 30SUF3677. 3. Carratraca. Sierra de Alcaparaín. Casa forestal abandonada. 30SUF3480. 4. Casarabonela. Sierra de Alcaparaín. El Alcornocal. 30SUF3776. Gne: gneises. Mic: micaesquistos.

inclinados, calizo-dolomíticos, han sido descritas comunidades de Celtica gigantea en las cercanas Sierra Blanquilla (sector Rondeño) y Sierra de Huma (sector Antequerano) (Pérez Latorre et al., 2012, 2014).
14. Galio viridiflori-Schoenetum nigricantis Rivas Goday \& Esteve 1972 subass. schoenetosum nigricantis

Juncales serpentinícolas, ligados a cursos de agua permanentes, de importancia por la 
escasez del cenotopo y por la presencia del serpentinófito preferente Galium viridiflorum, especie amenazada y protegida (Pérez Latorre et al., 2013b).

Localidad. Casarabonela. Sierra de Alcaparaín. Arroyo de Las Cuevas. 30SUF3777. Orientación: E. Inclinación: $80^{\circ}$. Área: $10 \mathrm{~m}^{2}$. Litología: hazburguitas y dunitas piroxénicas. Altitud: $500 \mathrm{~m}$. Altura vegetación: $50 \mathrm{~cm}$. Cobertura vegetación: 70\%. Características y diferenciales de asociación: Schoenus nigricans 3. Galium viridiflorum 2. Compañeras: Adiantum capillus-veneris + , Rubia agostinhoi 1, Trachelium caeruleum + .

\section{Lavandulo stoechadis-Genistetum} equisetiformis Rivas Goday \& Rivas-Martínez 1969 [Tabla 8] subass. genistetosum equisetiformis subass. thymetosum capitati Martínez

Parras, Peinado \& Alcaraz 1986

\section{subass. ulicetosum baetici nova}

Los bolinares de Lavandulo-Genistetum equisetiformis se extienden desde el Valle del Guadalhorce al menos hasta la Alpujarra granadina (Pérez Latorre et al., 1997). Su gran extensión favorece un alto número de subasociaciones, tanto de índole geográfico como ecológico. En la sierra la subass. thymetosum capitati se encuentra sobre calizas alabeadas en el piso termomediterráneo, en las laderas xéricas que miran al valle del Guadalhorce (sector Malacitano-Axarquiense), mientras que la subass. genistetosum equisetiformis ocupa el mismo territorio pero sobre sustratos pizarrosos y areniscosos (tesela 2). En el sector Rondeño, los materiales silíceos situados en el piso termomediterráneo de la cuenca del río Guadalhorce pueden presentar esta asociación, pero se sustituye Ulex parviflorus por el endemismo de la Serranía de Ronda y bioindicador Ulex baeticus, con gran frecuencia y cobertura. Esto nos lleva a proponer la subasociación ulicetosum baetici subass. nova para estos territorios rondeños, desde la Sierra objeto de estudio hasta la Sierra de las Nieves en la zona de Yunquera y Tolox. Constituyen etapa serial de los alcornocales de la comunidad de Quercus suber. También en el sector Rondeño pero en el piso mesomediterráneo continentalizado, los afloramientos silíceos presentan como matorral una comunidad de Cistus monspeliensis (Pérez Latorre et al., 2012).

\section{Comunidad de Ulex baeticus y Cistus} ladanifer subsp. africanus [Tabla 9]

Jarales serpentinícolas de litosuelos (hazburguitas y dunitas piroxénicas). Se trata de una comunidad presidida por Cistus ladanifer subsp. africanus de elevada talla (hasta 2 metros) y densidad, que se acompaña de Ulex baeticus y de Centaurea carratracensis como especie territorial del subsector Carratracense. La presencia del taxón basófilo Macrochloa tenacissima es síntoma de la neutralidad en el $\mathrm{pH}$ de los suelos serpentínicos, sobre todo en zonas poco lluviosas (Rivas Goday \& Esteve, 1972). Dado el pirofilismo de Cistus ladanifer (Medes et al., 2015), es posible que su presencia abundante tenga relación con antiguos incendios en la zona. Esta comunidad se encuentra restringida hasta el momento a las peridotitas de Alcaparaín, aunque existen también jarales de este tipo en el subsector Bermejense sub. Calicotomo villosae-Genistetum hirsutae halimietosum serpentinicolae Asensi y Díez (1988) 1991 (Sierra de las Nieves) (Cabezudo et al., 1998; Pérez Latorre et al., 1998) que hemos incluido en la tabla 9.

\section{Galio boissierani-Staehelinetum baeticae} Rivas Goday \& Rivas-Martínez 1969 nom. mut. propos.

subass. staehelinetosum baeticae var. con Genista umbellata

Matorral serpentinicola que se desarrolla en el afloramiento peridotítico (hazburguitas y dunitas piroxénicas) de Alcaparaín que es continuación de la Sierra de Aguas. La 
Tabla 9

16. Comunidad de Ulex baeticus y Cistus ladanifer subsp. africanus

(Calicotomo-Cistion ladaniferi, Lavanduletalia stoechadis, Cisto-Lavanduletea)

\begin{tabular}{|c|c|c|c|c|}
\hline INVENTARIO N ${ }^{\circ}$ & 1 & 2 & 3 & 4 \\
\hline Orientación & $\mathrm{S}$ & $\mathrm{E}$ & - & $\mathrm{S}$ \\
\hline Inclinación $\left({ }^{\circ}\right)$ & 20 & 20 & 0 & 60 \\
\hline Área $\left(m^{2}\right)$ & 100 & 100 & 200 & 100 \\
\hline Litología & Per & Per & Rou & Rou \\
\hline Altitud (m) & 600 & 500 & 780 & - \\
\hline Altura vegetación (cm.) & 150 & 200 & 150 & 100 \\
\hline Cobertura vegetación (\%) & 90 & 70 & 80 & 70 \\
\hline \multicolumn{5}{|l|}{ Características de comunidad } \\
\hline Cistus ladanifer africanus & 4 & 4 & - & - \\
\hline Cistus ladanifer s. l. & - & - & 2 & 3 \\
\hline Ulex baeticus & 3 & 1 & 3 & 1 \\
\hline Halimium atriplicifolium & - & - & + & + \\
\hline Centaurea carratracensis (terr.) & + & + & - & - \\
\hline Genista hirsuta lanuginosa & - & - & 2 & + \\
\hline Staehelina baetica & - & - & - & 1 \\
\hline Scorzonera baetica & - & 1 & - & - \\
\hline \multicolumn{5}{|c|}{ Características de unidades superiores } \\
\hline Cistus monspeliensis & 2 & + & 3 & 1 \\
\hline Lavandula stoechas & + & 1 & + & 1 \\
\hline Genista umbellata equisetiformis & - & + & - & - \\
\hline Cistus crispus & - & - & - & 1 \\
\hline Glandora prostrata lusitanica & - & - & - & 1 \\
\hline \multicolumn{5}{|l|}{ Compañeras } \\
\hline Juniperus oxycedrus & 1 & 3 & + & 1 \\
\hline Macrochloa tenacissima & 3 & + & 1 & 2 \\
\hline Phlomis purpurea & + & + & 1 & + \\
\hline Brachypodium retusum & - & - & 1 & 3 \\
\hline Chamaerops humilis & 1 & 1 & - & + \\
\hline Dactylis glomerata hispanica & - & 2 & + & - \\
\hline
\end{tabular}

Otras compañeras. En 1: Adenocarpus telonensis + , Pinus halepensis (ref.) + , Rosmarinus officinalis 2. En 2: Avenula gervaisii,+ Celtica gigantea + , Crepis bermejana,+ Fumana thymifolia,+ Linum suffruticosum 1. En 3: Elaeoselinum asclepium millefolium + , Iberis fontqueri,+ Omphalodes commutata + , Sanguisorba minor +. En 4: Daphne gnidium +, Klasea flavescens +, Quercus coccifera 2, Teucrium fruticans +. ref.: reforestado.

Localidades. 1. Málaga. Casarabonela. Sierra de Alcaparaín. El Alcornocal. 30SUF 3677. 2. Málaga. Casarabonela. Sierra de Alcaparaín. Alrededores del Ayo. de Las Cuevas. 30SUF3777. 3. Málaga. Tolox. P. N. Sierra de las Nieves. Sierra Parda. UTM: UF 3060. 4. Málaga. Istán. P. N. Sierra de las Nieves. Bohornoque, Loma de las Cabezuelas UTM: UF 2956. Per: hazburguitas y dunitas piroxénicas. Rou: rocas ultrabásicas. terr.: territorial. 
variante más xerófila de estos matorrales es la que ha sido inventariada en el territorio (var. con Genista umbellata). La fuerte antropización de este afloramiento, con actividades mineras, repoblaciones forestales (Pinus pinea) e incendios, ha dejado escasos cenotopos en un estado al menos seminatural donde este tipo de vegetación pueda desarrollarse, lo que se refleja en la escasez de serpentinófitos, comandados por Centaurea carratracensis, endemismo del subsector. Esto hace también que el matorral se acerque en composición al existente en otros afloramientos peridotíticos del valle del Guadalhorce como Sierra de Cártama (Hidalgo \& Pérez Latorre, 2013), pero en este caso identificados como LavanduloGenistetum equisetiformis en una variante con Avenula gervaisii.

Localidad. Málaga. Carratraca. Sierra de Alcaparaín. Cerro Minas. 30SUF3677. Orientación: E. Inclinación: $35^{\circ}$. Área: $300 \mathrm{~m}^{2}$. Litología: hazburguitas y dunitas piroxénicas. Altitud: $560 \mathrm{~m}$. Altura vegetación: $50 \mathrm{~cm}$. Cobertura vegetación: $60 \%$. Características y diferenciales de asociación: Centaurea carratracensis 1. Diferenciales de variante: Genista umbellata equisetiformis +, Thymelaea argentata + . Características de unidades superiores: Teucrium reverchonii + , Scorzonera baetica 1, Cistus ladanifer africanus 2, Lavandula stoechas + , Ulex baeticus 3, Cistus monspeliensis + , Linum suffruticosum carratracensis 1, Crepis bermejana +. Compañeras: Pinus pinea (ref.) 3, Macrochloa tenacissima 2, Rosmarinus officinalis 2, Avenula gervaisii 1, Carex halleriana 1, Celtica gigantea 1, Juniperus oxycedrus 1, Melica minuta 1, Phlomis purpurea 1, Adenocarpus telonensis +, Carlina hispanica + , Coronilla juncea + , Elaeoselinum asclepium millefolium. + , Fumana thymifolia + , Sanguisorba verrucosa + , Urginea maritima + , Xiphion filifolium + . ref: reforestado.
Tabla 10

18. Comunidad de Ulex baeticus y Halimium atriplicifolium sensu Pérez Latorre et al. (1998)

(Saturejo micranthae-Thymbrion capitati, Rosmarinetalia officinalis, Cisto-Micromerietea julianae)

\begin{tabular}{|c|c|}
\hline INVENTARIO N ${ }^{\circ}$ & 1 \\
\hline Orientación & $\mathrm{N}$ \\
\hline Inclinación $\left(^{\circ}\right)$ & 35 \\
\hline Área $\left(\mathrm{m}^{2}\right)$ & 250 \\
\hline Litología & Kak \\
\hline Altitud (m) & 650 \\
\hline Altura vegetación (cm.) & 150 \\
\hline Cobertura vegetación (\%) & 90 \\
\hline
\end{tabular}

Características de comunidad

$\begin{array}{lll}\text { Ulex baeticus } & 3 & 1\end{array}$

Halimium atriplicifolium $\quad$ - 3

Teucrium lusitanicum $\quad 1 \quad-$

Thymbra capitata - +

Características de unidades superiores

Cistus albidus

21

Ptilostemon hispanicus

Rosmarinus officinalis

$1 \quad 1$

$4 \quad 4$

Otras características

En 2: Convolvulus lanuginosus +, Anthyllis polycephala +, Asperula aristata +, Fumana ericifolia + .

\section{Compañeras}

Brachypodium retusum $\quad+\quad 1$

Bupleurum gibraltaricum $++\quad+$

Juniperus oxycedrus $\quad+\quad+$

Macrochloa tenacissima $\quad+\quad 2$

Melica minuta $\quad 1 \quad+$

Rhamnus lycioides oleoides $\quad+\quad+$

Otras compañeras. En 1: Andryala ragusina ramosissima 1, Bellis pappulosa 2, Clematis flammula +, Helichrysum stoechas 1, Leuzea conifera + , Phlomis purpurea + , Pinus halepensis 3, Quercus rotundifolia +, Rhamnus myrtifolia +, Ruta angustifolia 1, Thymus mastichina 1. En 2: Asparagus horridus + , Carex hallerana + , Linum suffruticosum +, Phlomis lychnitis +, Pistacia lentiscus + , Quercus coccifera + , Reseda barrelieri + , Stipa offneri + .

Localidades. 1. Málaga. Carratraca. Sierra de Alcaparaín. Los Arenales. 30SUF3678. 2. Málaga. Carratraca. Sierra de Alcaparaín. Cañada de la Búa. 30SUF3479. Kak: kakiritas. Dol: dolomías. 
Tabla 11

19. Lavandulo lanate-Ulicetum baetici Martínez Parras, Peinado y De la Cruz 1987 nom. inv. Asensi y Díez Garretas 1988

ulicetosum baetici, var. con Halimium atriplicifolium

erinaceetosum Martínez Parras, Peinado y De la Cruz 1987

\begin{tabular}{|c|c|c|c|c|c|c|c|c|c|c|c|c|}
\hline INVENTARIO $\mathrm{N}^{\mathrm{o}}$ & 1 & 2 & 3 & 4 & 5 & 6 & 7 & 8 & 9 & 10 & 11 & 12 \\
\hline Orientación & $\mathrm{O}$ & $\mathrm{O}$ & $\mathrm{N}$ & SO & $\mathrm{E}$ & $\mathrm{E}$ & $\mathrm{O}$ & - & $\mathrm{N}$ & SO & $\mathrm{O}$ & SE \\
\hline Inclinación $\left(^{\circ}\right)$ & 30 & 40 & 30 & 30 & 25 & 70 & 40 & - & 45 & 5 & 5 & 45 \\
\hline Área $\left(\mathrm{m}^{2}\right)$ & 200 & 50 & 100 & 100 & 100 & 100 & 100 & 200 & 150 & 250 & 200 & 75 \\
\hline Litología & Dol & Dol & Dol & Dol & Dol & Dol & Dol & Dol & Kak & Dol & Dol & Dol \\
\hline Altitud (m) & 850 & 700 & 900 & 900 & 750 & 750 & 1200 & 1100 & 680 & 1280 & 1140 & 10 \\
\hline Altura vegetación (cm) & 120 & 150 & 150 & 150 & 150 & 150 & 70 & 100 & 150 & 60 & 80 & 80 \\
\hline Cobertura vegetación (\%) & 70 & 70 & 100 & 100 & 100 & 100 & 40 & 100 & 100 & 60 & 80 & 80 \\
\hline
\end{tabular}

Características y diferenciales de asociación y subasociación

Ulex baeticus

Lavandula lanata

$\begin{array}{llllllllllll}2 & 3 & 3 & 1 & 2 & 4 & 3 & 3 & 3 & 3 & 2 & 2 \\ 2 & 2 & - & - & - & 1 & - & + & - & - & + & -\end{array}$

Diferencial de variante

Halimium atriplicifolium

$3-\quad-3-\quad-22$

Diferenciales y territorial de subasociación

Bupleurum spinosum

Phlomis crinita malacitana

Armeria grajoana (terr.)

Arenaria erinacea

\section{Características de unidades superiores}

Cistus albidus

Rosmarinus officinalis

Ptilostemon hispanicus

Thymus granatensis

Sideritis incana occidentalis

Helianthemun appeninum suffruticosum

Linum suffruticosum

Teucrium lusitanicum

Coris monspeliensis

Fumana thymifolia

Helianthemum cinereum rotundifolium

Jurinea pinnata

Salvia candelabrum

Thesium humifusum 
Otras características. En 1: Phlomis purpurea +, Klasea pinnatifida 1. En 8: Lithodora fruticosa 1. En 9: Paronychia sufruticosa 1. En 10: Arenaria armerina 1, Erysimum mediohispanicum rondae +, Guillonea scabra +. En 12: Galium baeticum +, Helianthemum syriacum +.

\section{Compañeras}

Macrochloa tenacissima

Pinus halepensis

Quercus rotundifolia

Brachypodium retusum

Rhamnus lycioides oleoides

Stipa offneri

Juniperus oxycedrus

Bupleurum gibraltaricum

Helichrysum stoechas

Quercus coccifera

Rhamnus myrtifolia

Thymus mastichina

Carex halleriana

Anthyllis polycephala

Celtica gigantea

Daphne gnidium

Helictotrichon filifolium arundanum

Koeleria crassipes filifolia

Melica minuta

Phlomis lychnitis

Thapsia villosa

$$
\begin{array}{llllllllllll}
3 & + & - & 2 & 2 & - & 2 & 3 & + & 2 & 2 & 2 \\
+ & - & - & + & + & + & - & 1 & 1 & - & - & + \\
+ & - & + & - & - & + & + & 3 & - & + & 1 & - \\
2 & 2 & 2 & - & - & 2 & - & 3 & 1 & - & - & - \\
+ & - & + & + & + & 1 & - & - & - & - & - & - \\
- & - & - & + & - & - & - & - & + & 1 & 1 & 1 \\
+ & - & 1 & + & - & 1 & - & 1 & - & - & - & - \\
- & - & - & - & 1 & - & - & - & 1 & + & - & - \\
+ & - & - & - & + & - & - & - & - & - & + & - \\
1 & - & - & 1 & - & - & - & + & - & - & - & - \\
+ & - & - & - & - & - & + & - & - & 1 & - & - \\
+ & - & - & - & - & + & - & - & - & - & + & - \\
- & - & - & - & - & - & - & - & 1 & - & 1 & 1 \\
- & - & - & - & 1 & - & - & - & - & - & + & - \\
+ & - & - & - & - & - & - & - & - & + & - & - \\
+ & - & - & - & - & + & - & - & - & - & - & - \\
- & - & - & - & - & - & 1 & - & - & 1 & - & - \\
- & - & - & - & - & - & - & - & + & + & - & - \\
- & - & + & - & - & - & - & - & - & + & - & - \\
+ & - & - & - & - & - & - & - & - & + & - & - \\
- & - & - & - & - & - & 2 & - & - & + & - & -
\end{array}
$$

Otras compañeras. En 1: Asparagus horridus + , Asphodelus ramosus 1, Biscutella laxa + , Chamaerops humilis + , Digitalis obscura laciniata + , Genista umbellata equisetifomis,+ Rhaponticum coniferum + , Smilax aspera +. En 2: Juniperus phoenicea 1, Ranunculus spicatus blepharicarpos. 1. En 3: Ruscus aculeatus + ${ }^{\prime}$. En 5: Centaurea aspera +. En 6: Pistacia terebinthus + , Rubia peregrina 1. En 8: Teucrium fruticans 1. En 9: Bellis pappulosa +. En 10: Dactylis glomerata hispanica +. En 11: Sedum sediforme +. En 12: Orobanche latisquama + .

Localidades. 1. Málaga. Casarabonela. Sierra de Alcaparaín. Vertiente este, "Los Reconcos". 30SUF3476. 2. Málaga. Casarabonela. Sierra de Alcaparaín. Ayo. De la Cueva. 30SUF3278. 3 y 4. Málaga. Carratraca. Sierra de Alcaparaín. Subida al cerro de la Canana. 30SUF 3479. 5. Málaga. Carratraca. Sierra de Alcaparaín. Desde Hoyapata al Grajo. 30SUF3578. 6. Málaga. Carratraca. Sierra de Alcaparaín. Barranco del Ayo. De los Pinos. 30SUF3578. 7. Málaga. Casarabonela. Sierra de Alcaparaín. Pico Valdivia (El Grajo). 30SUF3577. 8. Málaga. Carratraca. Sierra de Alcaparaín. Cabecera del Ayo. De los Pinos. 30SUF3477. 9. Málaga. Carratraca. Sierra de Alcaparaín. Hoya Pata. 30SUF3678. 10. Málaga. Casarabonela. Sierra de Alcaparaín. Pico Valdivia (El Grajo). 30SUF3577. 11. Málaga. Casarabonela. Sierra de Alcaparaín. Puerto de Alcaparaín. 30SUF3379. 12. Málaga. Carratraca. Sierra de Alcaparaín. Cañada de la Búa. 30SUF3479. Dol: dolomías. Kak: kakiritas. terr.: territorial. 
18. Comunidad de Ulex baeticus y Halimium atriplicifolium sensu Pérez Latorre et al. (1998) [Tabla 10]

Aulagar-romerales (matorrales) dolomitícolas termomediterráneos, dominados por nanofanerófitos y caméfitos fruticosos, caracterizados por Ulex baeticus y Halimium atriplicifolium, con especies termófilas como Thymus capitatus. En el sector Rondeño solo hay descrita una asociación de matorral dolomitícola para el piso basal: Ulici baeticiCistetum clusii Rivas Goday \& Rivas-Martínez 1969 corr. Díez-Garretas \& Asensi 1994. Sin embargo esta asociación es endémica del subsector Mijense (Sierras de Mijas, Monda y Blanca-Canucha), de donde fue descrita, ya que presenta especies propias como Teucrium chrysotrichum Lange o Genista haenseleri Boiss. (Nieto et al., 1987; Rivas Goday \& Rivas Martínez, 1968). En la base dolomítica termomediterránea de la Sierra de las Nieves y Sierra Prieta, franja de escaso desarrollo altitudinal, aparecen matorrales de este tipo, pero se han interpretado de distinto modo (Pérez Latorre et al., 1998, 2005, 2012). A la vista de los inventarios de estos dos macizos dolomíticos y los de Alcaparaín, creemos conveniente reunir todos estos matorrales en la comunidad de Ulex baeticus y Halimium atriplicifolium.

\section{Lavandulo lanate-Ulicetum baetici} Martínez Parras, Peinado y De la Cruz 1987 nom. inv. Asensi y Díez Garretas 1988 [Tabla 11]

subass. ulicetosum baetici

var. con Halimium atriplicifolium

subass. erinaceetosum anthyllidis Martínez

Parras, Peinado y De la Cruz 1987

Matorrales meso-supra/mediterráneos dolomitícolas, de areal rondeño, que en la sierra de Alcaparaín están muy extendidos y presentan abundancia de Macrochloa tenacissima debido al uso ganadero y del fuego. En las zonas donde los incendios son más recientes y recurrentes hemos localizado una variante con profusión de Halimium atriplicifolium. En las zonas de cumbre por encima de $1200 \mathrm{~m}$. las condiciones más duras (viento, litosuelos) hacen que se presente finícola la subasociación supramediterránea erinaceetosum anthyllidis, únicamente con presencia del piorno Bupleurum spinosum, pero enriquecida con el endemismo local Armeria grajoana.

\section{Galio baetici-Thymetum granatensis Mota}

y Valle 1992 [Tabla 12]

subass. thymetosum granatensis

var. con Stipa offneri

Tomillares hiperxerófilos dolomitícolas, meso-supramediterráneos que se desarrollan sobre litosuelos, comúnmente llamados blanquizares, sobre sustratos dolomíticos y marmóreo-kakiritizados de las teselas $4 \mathrm{y}$ 5. Están caracterizados por un rico cortejo florístico de dolomitófitos (Mota et al., 2008) camefíticos y hemicriptofíticos destacando Jurinea pinnata y Thymus granatensis. Esta asociación es frecuente y alcanza los límites inferiores del piso mesomediterráneo, con las altitudes más bajas detectadas hasta el momento comparando con los datos de Blanca et al., 2011 (Mota y Valle, 1992; Pérez Latorre et al., 1998, 2012) para algunas especies (Koeleria crassipes -a 670 m., 330 metros menos-, Hormatophylla longicaulis -a 670 m., 550 metros menos-), por lo que se enriquece en especies propias de blanquizares del piso termomediterráneo (Andryalo-Crambion filiformis). La asociación se encuentra como una variante local con Stipa offneri, especie localmente abundante y ausente de esta asociación en otros territorios estudiados del sector Rondeño (Pérez Latorre et al., 1998, 2012). Además, en esta variante de la Sierra de Alcaparaín se localiza el dolomitófito (Mota et al., 2008) recién descrito Armeria grajoana (Cabezudo et al., 2015), siempre en biotopos subrupestres en zonas de cumbres.

\section{Galio viridiflori-Salicetum pedicellatae}


Díez Garretas, Asensi \& Rivas Martínez 2011

Saucedas arbustivas, edafohigrófilas serpentinícolas, muy escasas en el territorio estudiado e inventariadas para el subsector Carratracense solo de la Sierra de la Robla (Pérez Latorre et al., 2013a) y el inventario que aportamos, empobrecido en especies debido al uso antrópico de los escasos cursos de agua permanente en la zona.

Localidad. Málaga. Casarabonela. Sierra de Alcaparaín. Ayo. de Las Cuevas. 30SUF3777. Orientación: E. Inclinación: $60^{\circ}$. Área: $50 \mathrm{~m}^{2}$. Litología: hazburguitas y dunitas piroxénicas Altitud: $500 \mathrm{~m}$. Altura vegetación: $400 \mathrm{~cm}$. Cobertura vegetación: 100\%. Característica de comunidad: Salix pedicellata 5. Compañeras: Rubus ulmifolius 4, Tamus communis 2, Rubia agostinhoi +, Rosa canina 1 .

\section{Comunidad de Quercus suber}

Alcornocales meso-termomediterráneos subhúmedos, silicícolas, que alcanzan el territorio de estudio en la unidad teselar silícea del SE de la Sierra (gneises). Se pueden considerar casi criptoclimácicos ya que la mayor parte de su zonopotencialidad está ocupada por vegetación serial (jarales y pastizales), cultivos leñosos (almendros) y herbáceos y forestaciones de Pinus halepensis. Presentan en el sotobosque algunas especies esciohumícolas (Origanetalia vulgaris Müller 1962) como Calamintha sylvatica y Campanula rapunculus, indicando cierta conservación del ambiente nemoral. Estos alcornocales ya fueron mencionados en el trabajo de Ceballos \& Vicioso (1933).

Localidad. Málaga. Casarabonela. Sierra de Alcaparaín. El Alcornocal. 30SUF3677. Orientación: NE. Inclinación: $45^{\circ}$. Área: 250 $\mathrm{m}^{2}$. Litología: Gneis. Altitud: $680 \mathrm{~m}$. Altura vegetación: $12 \mathrm{~m}$. Cobertura vegetación: $80 \%$. Características de comunidad: Quercus suber 4, Quercus faginea +, Calamintha sylvatica +, Campanula rapunculus + , Pulicaria odora + .
Características de unidades superiores: Pinus halepensis 1, Rubia peregrina 1, Juniperus oxycedrus + , Rubia agostinhoi + , Teucrium fruticans + . Compañeras: Adenocarpus telonensis + , Andryala integrifolia + , Briza maxima + , Cistus monspeliensis + , Cistus salvifolius 2, Cynosorus echinatus 1, Dactylis glomerata hispanica + , Helmintotheca echioides + , Holcus lanatus + , Lavandula stoechas + , Lonicera periclymenum hispanica +, Opopanax chironium 1, Phlomis purpurea 2, Piptatherum thomasii 1, Sanguisorba verrucosa + , Ulex baeticus 1 .

\section{Bupleuro gibraltarici-Pistacietum lentisci}

Martínez Parras, Peinado \& Alcaraz 1987

subass. viburnetosum tini Pérez Latorre \& Cabezudo 2004

Vegetación arbustiva termófila de gran porte (más de $3 \mathrm{~m}$.) que se desarrolla en cenotopos rocosos sobre dolomías y que puede presentar especies mesófilas como Phillyrea latifolia y Pistacia terebinthus, lo que le acerca a la subass. viburnetosum tini (Pérez Latorre et al., 2004). Inicialmente descritos para el sector Almijaro-Granatense (Martínez Parras et al., 1987; Pérez Latorre et al., 2004), se trata de la primera cita de esta asociación al menos en el sector Rondeño más oriental. Constituyen vegetación climácica permanente topogénica y la orla de las formaciones subrupícolas de encinas y madroños presentes en la Sierra.

Localidad. Málaga. Carratraca. Sierra de Alcaparaín. Hoya Pata. 30SUF3678. Orientación: E. Inclinación: $5^{\circ}$. Área: $100 \mathrm{~m}^{2}$. Litología: Dolomías. Altitud: $760 \mathrm{~m}$. Altura vegetación: $300 \mathrm{~cm}$. Cobertura vegetación: $100 \%$. Características y diferenciales de asociación: Bupleurum gibraltaricum 1, Pistacia lentiscus 4. Diferenciales de subasociación: Pistacia terebinthus 1, Phillyrea latifolia +. Características de unidades superiores: Lonicera implexa 2, Coronilla glauca 1, Phillyrea angustifolia 1, Ficus carica + , Rhamnus alaternus + , Juniperus oxycedrus + , 
Tabla 12

20. Galio baetici-Thymetum granatensis Mota y Valle 1992 thymetosum granatensis, var. con Stipa offneri

\begin{tabular}{lccccccc}
\hline & & & & & & & 7 \\
INVENTARIO N & & 2 & 3 & 4 & 5 & 6 & NE \\
Orientación & $\mathrm{E}$ & $\mathrm{E}$ & $\mathrm{N}$ & $\mathrm{N}$ & - & $\mathrm{E}$ & 50 \\
Inclinación $\left(^{\circ}\right)$ & - & - & 80 & 30 & - & 5 & 30 \\
Área $\left(\mathrm{m}^{2}\right)$ & 50 & 25 & 25 & 250 & 50 & 25 & 50 \\
Litología & $\mathrm{Kak}$ & $\mathrm{Kak}$ & $\mathrm{Kak}$ & $\mathrm{Kak}$ & $\mathrm{Kak}$ & $\mathrm{Kak}$ & $\mathrm{Kak}$ \\
Altitud (m) & 750 & 750 & 670 & 670 & 730 & 1130 & 1100 \\
Altura vegetación (cm.) & 20 & 30 & 20 & 50 & 25 & 25 & 30 \\
Cobertura vegetación $(\%)$ & 5 & 20 & 25 & 40 & 25 & 20 & 40
\end{tabular}

Características y diferenciales de asociación

Thymus granatensis

Jurinea pinnata

Asperula aristata scabra

Arenaria erinacea

Galium baeticum

Sideritis incana occidentalis

Variante local

Stipa offneri

Armeria grajoana

Características de unidades superiores

Helianthemun cinereum rotundifolium +

Paronychia suffruticosa hirsuta $\quad 1$

Helianthemum appeninum suffruticosum 1

Linum suffruticosum

Rosmarinus officinalis

Teucrium lusitanicum

Thesium humifusum

Anthyllis vulneraria

Cistus albidus

Erysimum medio-hispanicum rondae

Fumana ericifolia

Guillonea scabra

Otras características. En 1: Fumana laevipes +. En 2: Staehelina dubia 1. En 4: Ptilostemon hispanicus + , Scabiosa turolensis grosii + , Anthyllis polycephala + , Dianthus hispanicus + . En 5: Coris monspeliensis syrtica + .

Transgresivas de Andryalo-Crambion filiformis

Andryala ragusina ramosissima 
Echium albicans

Brassica repanda confusa

Reseda barrelieri

Linaria clementei

\section{Compañeras}

Helichrysum stoechas

Koeleria crassipes filifolia

Ulex baeticus

Arenaria armerina

Avenula gervaisii

Biscutella laxa

Carex halleriana

Centaurea aspera

$\begin{array}{lllllll}- & 1 & + & + & + & 1 & - \\ - & - & + & - & + & - & - \\ - & - & - & + & 2 & - & - \\ - & - & - & + & - & - & -\end{array}$

Otras compañeras. En 1: Paronychia capitata + . En 3: Silene mellifera + , Sanguisorba rupícola + , Micromeria graeca +, Iberis carnosa granatensis +. En 4: Melica minuta +, Aceras antropophorum +, Bupleurum gibraltaricum + , Leuzea conifera 1 , Ruta angustifolia + , Polygala rupestris + , Hormatophylla longicaulis +. En 5: Macrochloa tenacissima 1, Sedum sediforme 1, Sesamoides purpurascens + . En 6: Brachypodium retusum 1.

Localidades. 1 y 2. Málaga. Carratraca. Sierra de Alcaparaín. Subida al Pico Valdivia desde el Este. 30SUF3578. 3, 4 y 5. Málaga. Carratraca. Sierra de Alcaparaín. Hoya Pata. 30SUF3678. 6. Málaga. Casarabonela. Sierra de Alcaparaín. Carril del cerro del Gollino. 30SUF3477. 7. Málaga. Carratraca. Sierra de Alcaparaín. Collado cara norte del Grajo. 30SUF3577. Kak: kakiritas.

Daphne gnidium + , Smilax aspera + , Rhamnus lycioides oleoides + , Rubia peregrina + . Compañeras: Salvia candelabrum 1, Smyrnium olusatrum +, Tamus communis + , Euphorbia characias + .

\section{Comunidad de Quercus coccifera $\mathrm{BC}$}

Las formaciones arbustivas densas y de gran talla caracterizadas por Quercus coccifera del piso mesomediterráneo son muy pobres florísticamente en el territorio de estudio. No se pueden incluir en Crataego-Quercetum cocciferae Martínez Parras, Peinado \& Alcaraz 1985 por la falta del propio Crataegus monogyna y la inexistencia de los encinares de Paeonio-Quercetum rotundifoliae a los que suele acompañar de modo dinámico. Estos coscojares de Alcaparaín podrían incluirse en una facies muy empobrecida de los existentes en el subsector Mijense descritos como
Rhamno-Quercetum cocciferae Nieto, Pérez Sanz y cabezudo 1987 (Nieto et al., 1987) pero en Alcaparaín no se hallan Rhamnus velutinus ni Ephedra fragilis. Optamos por incluir este tipo de vegetación en una comunidad basal de Rhamno-Quercion cocciferae dominada por Q. coccifera.

Localidad. Málaga. Ardales. Sierra de Alcaparaín. Cerro del Gollino. 30SUF3480. Orientación: N. Inclinación: $10^{\circ}$. Área: 250 $\mathrm{m}^{2}$. Litología: brechas dolomíticas. Altitud: $800 \mathrm{~m}$. Altura vegetación: $200 \mathrm{~cm}$. Cobertura vegetación: $90 \%$. Características de comunidad y unidades superiores: Quercus coccifera 4, Juniperus oxycedrus 1, Quercus rotundifolia 1, Teucrium fruticans + , Pinus halepensis +. Compañeras: Brachypodium retusum 3, Cistus albidus 1, Macrochloa tenacissima +, Phlomis lychnitis + , Phlomis purpurea 1, Ulex baeticus 1 . 
Tabla 13

26. Pino halepensis-Juniperetum phoeniceae Pérez Latorre \& Cabezudo in Pérez Latorre, P. Navas, D. Navas, Y. Gil \& Cabezudo 1998

rhamnetosum myrtifoliae subass. nova

(Pino pinastri-Juniperion phoeniceae, Pistacio lentisci-Rhamnetalia alaterni, Quercetea ilicis)

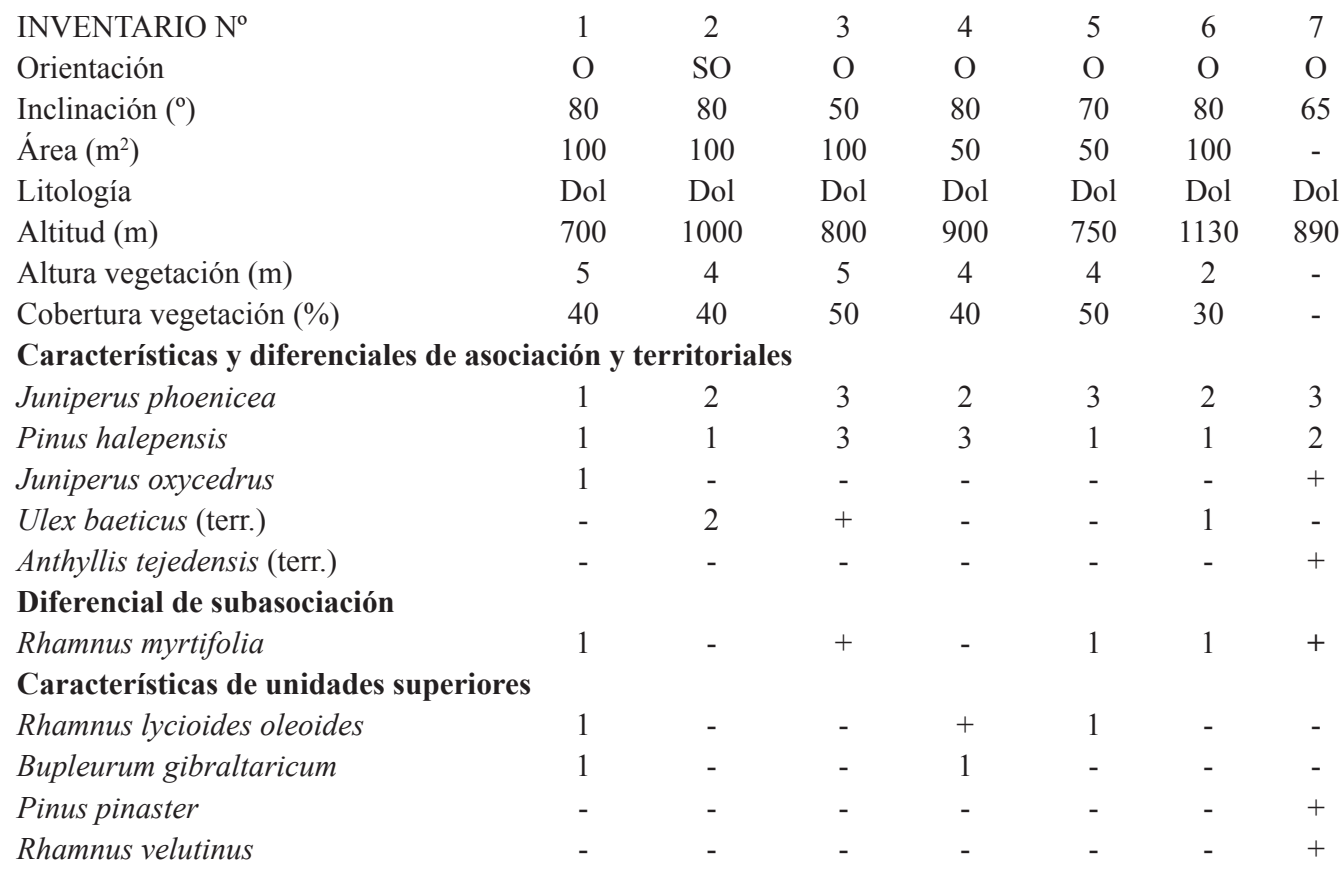

Otras características. En 3: Asparagus horridus +, Pistacia lentiscus + . En 5: Chamaerops humilis 3, Olea sylvestris 1. En 6: Quercus rotundifolia 1.

\section{Compañeras}

Macrochloa tenacissima

Rosmarinus officinalis

Cistus albidus

Lavandula lanata

Melica minuta

Stipa offneri

$\begin{array}{lllllll}- & 2 & 2 & + & 1 & + & - \\ + & 2 & 1 & + & - & - & 1 \\ - & 2 & 1 & - & - & 1 & + \\ + & + & - & - & - & - & - \\ 1 & - & + & - & - & - & - \\ - & - & 2 & - & 1 & - & -\end{array}$

Otras compañeras. En 1: Galium baeticum +, Ranunculus spicatus blepharicarpos 1, Sarcocapnos baetica + . En 6: Anthyllis polycephala + , Crambe filiformis + , Dianthus hispanicus,+ Echium albicans,+ Fumana ericifolia + , Helianthemun appeninum suffruticosum + , Ptilostemon hispanicus + , Sedum sediforme + . En 7: Aphyllantes monspeliensis +, Brachypodium boissieri 1, Cistus clusii 1, Cytisus fontanesii + , Ranunculus graminifolius + , Ulex parviflorus + .

Localidades. 1. Málaga. Casarabonela. Sierra de Alcaparaín. Cabecera Ayo. De la Cueva. 30SUF3278. 2. Málaga. Casarabonela. Sierra de Alcaparaín. Por encima de Cueva Bermeja. 30SUF3378. 3, 4 y 5. Málaga. Casarabonela. Sierra de Alcaparaín. Cueva Bermeja. 30SUF3377. 6. Málaga. Casarabonela. Sierra de Alcaparaín. Cerro de la Canana. 30SUF3378. 7. Granada. Jayena. Sierra de Almijara. Río Bacal. (tomado de Pérez Latorre et al., 2004: 128). Dol: dolomías. 
26. Pino halepensis-Juniperetum phoeniceae Pérez Latorre \& Cabezudo in Pérez Latorre, P. Navas, D. Navas, Y. Gil \& Cabezudo 1998

subass. rhamnetosum myrtifoliae nova [Tabla 13, holotypus hoc loco inv. $n^{\circ}$ 6]

Los pinares carrascos con sabinas negrales (Pino halepensis-Juniperetum phoeniceae) corresponden a vegetación gimnospérmica arbóreo-arbustiva, de baja cobertura, edafoxerófila y termófila, sobre suelos intrazonales en litosuelos y hábitats rocosos marmóreo-dolomíticos, de los sectores Rondeño y Almijaro-Granatense. Estos pinarsabinares fueron descritos de la cara sur de la Sierra de Tolox, básicamente en el piso termomediterráneo (Pérez Latorre et al., 1998) pero alcanzan el mesomediterráneo en la Sierra de Almijara (Pérez Latorre et al., 2004). En la Sierra de Alcaparaín los pinares-sabinares también alcanzan el piso mesomediterráneo inferior, lo que queda indicado por la presencia de Rhamnus myrtifolia y la inexistencia de Ceratonia siliqua en la subasociación rhamnetosum myrtifoliae subass. nova. Añadimos a la tabla 13 el inventario $\mathrm{n}^{\circ} 7$ localizado en Sierra de Almijara (sector Almijaro-Granatense) para completar el areal de la nueva subasociación.

27. Comunidad de Juniperus oxycedrus BC [Tabla 14]

Enebrales serpentinícolas (hazburguitas y dunitas piroxénicas) de elevada cobertura y con dominancia de Juniperus oxycedrus. A causa probablemente del fuego, podrían sustituir o derivar de los típicos coscojarespinares serpentinícolas climácicos y propios de los afloramientos ultramáficos suribéricos (Cabezudo et al., 1989) pero ausentes del territorio de estudio. Unas formaciones semejantes (agrupaciones o individuos de $J$. oxycedrus) fueron detectadas en las cercanas Sierra de la Robla (Pérez Latorre et al., 2013a) y en la base de Sierra Prieta (Pérez Latorre et
Tabla 14

27. Comunidad de Juniperus oxycedrus BC

(Pino pinastri-Juniperion phoeniceae, Pistacio lentisci-Rhamnetalia alaterni, Quercetea ilicis)

\begin{tabular}{lccc}
\hline INVENTARIO N & & 2 & 3 \\
Orientación & $\mathrm{NE}$ & $\mathrm{NE}$ & $\mathrm{N}$ \\
Inclinación $\left({ }^{\circ}\right)$ & 20 & 20 & 20 \\
Área $\left(\mathrm{m}^{2}\right)$ & 100 & 100 & 200 \\
Litología & Per & Per & Per \\
Altitud (m) & 550 & 500 & 600 \\
Altura vegetación $(\mathrm{cm})$ & 200 & 200 & 250 \\
Cobertura vegetación $(\%)$ & 80 & 90 & 100
\end{tabular}

Característica de comunidad y territoriales

$\begin{array}{llll}\text { Juniperus oxycedrus } & 4 & 5 & 4\end{array}$

Centaurea carratracensis

(terr.)

Crepis bermejana (terr.)

Características de unidades superiores

Daphne gnidium

Pulicaria odora

$+\quad+$

Otras características. En 1: Rhamnus alaternus + , Coronilla juncea + . En 2: Quercus coccifera + , Aristolochia baetica + . En 3: Olea europaea sylvestris,+ Rhamnus lycioides oleoides + , Pistacia terebinthus + , Rubia agostinhoi + .

\section{Compañeras}

Celtica gigantea

Cistus ladanifer africanus

Dactylis glomerata hispanica

Elaeoselinum asclepium millefolium

Pinus halepensis (ref.)

$\begin{array}{ccc}+ & 1 & 1 \\ + & 2 & 2 \\ 1 & 1 & + \\ + & 1 & + \\ 1 & 2 & - \\ 2 & 2 & -\end{array}$

Rosmarinus officinalis

Ulex baeticus

Brachypodium retusum

Melica minuta

Linum suffruticosum

carratracensis

Otras compañeras. En 3: Cistus salvifolius 1, Phlomis purpurea 1, Scorzonera baetica +, Cistus monspeliensis 1, Lavandula stoechas +, Campanula rapunculus + , Adenocarpus telonensis + , Anarrhinum bellidifolium + , Ficus carica + .

Localidades. 1 y 2. Málaga. Casarabonela. Sierra de Alcaparaín. El Alcornocal. 30SUF3776. 3. Málaga. Carratraca. Sierra de Alcaparaín. Entre El Alcornocal y Los Arenales. 30SUF3678. Per: hazburguitas y dunitas piroxénicas. terr.: territorial. ref.: reforestado. 
al., 2012) también sobre peridotitas.

\section{Rhamno myrtifoliae-Quercetum rotundifoliae ass. nova [Tabla 15, holotypus hoc loco inv. $\mathrm{n}^{\mathrm{o}} 3$ ] \\ subass. quercetosum rotundifoliae var. con Halimium halimifolium}

Nanobosques de Quercus rotundifolia, densos, de unos 2 a 3 metros de altura, muy pobres en su sotobosque y sin especies típicamente nemorales, entre ellas destaca la ausencia de especies del género Paeonia. Se desarrollan sobre suelos dolomíticos y brechoides-dolomíticos de muy escasa profundidad (litosoles y rendsinas) en el piso mesomediterráneo de la tesela dolomítica, en zonas de cumbre de la Sierra de Alcaparaín. Están caracterizados por un cortejo florístico con especies propias de la alianza edafoxerófila Pino pinastri-Juniperion phoeniceae (Pérez Latorre et al. 1998): Rhamnus myrtifolia, Ephedra fragilis, y más escasos, Juniperus phoenicea y Pinus halepensis. Consideramos a estos encinares como edafoxerófilos y alejados ecológica y florísticamente de los encinares del Paeonio coriaceae-Quercetum rotundifoliae Rivas-Martínez 1964 que biogeográficamente constituirían la zonopotencialidad de esta zona y en las Sierras Béticas en general (Martínez Parras et al., 1984). Estos encinares edafoxerófilos fueron inventariados por Pérez Sanz en similares condiciones ecológicas y biogeográficas en la cumbre dolomítica mesomediterránea de la Sierra de Mijas (subsector Mijense, sector Rondeño) como Smilaci-Quercetum rotundifoliae Barbéro, Quèzel \& Rivas Martínez 1981 (Pérez Sanz, 1986: 159, tabla 1) de cuyo trabajo hemos incluido los inventarios representativos del piso mesomediterráneo en la tabla 15 , entre los que se incluye la variante sobre arenales kakiríticos con Halimium halimifolium. Nieto et al. (1987) ya habían asignado como vegetación potencial al conjunto de la sierra de Mijas coscojares edafoxerófilos (Rhamno velutini-
Quercetum cocciferae Nieto Caldera, Pérez Sanz \& Cabezudo 1987) que podían incluir encinas. Consideramos que esta asociación nueva presenta areal rondeño, pero podría existir en otras zonas de la provincia Bética, por la existencia de cenotopos apropiados.

\section{Otras formaciones vegetales}

Laguna et al. (1884: 39) citan "una docena de pinsapos" en la zona alta de la Sierra, mezclados con Pinus pinaster. Ceballos y Vicioso (1933: 84, 146) citan que existieron formaciones de Pinus pinaster en la cumbre de Alcaparaín, además asociados a pies aislados de Abies pinsapo (sin duda los citados por Laguna et al. op. cit.), desaparecidos a causa de los incendios (en los años 20; Soto, 2006).

Con las informaciones de Laguna et al. (1884), Ceballos y Vicioso (1933) y Soto (2006) no se puede confirmar la existencia pretérita de pinsapares en la Sierra de Alcaparaín, tan solo de individuos aislados de Abies pinsapo que pudieron llegar hasta tiempos recientes (años 80; Soto, op . cit.). Por lo tanto, quedan fuera de la asignación de zonopotencialidad en la Sierra los pinsapares dolomitícolas correspondientes de Paeonio broteroi-Abietetum pinsaponis juniperetosum phoeniceae Pérez Latorre \& Cabezudo 1998 (Pérez Latorre et al., 1998), hecho acorde además con el bioclima poco apto (Pérez Latorre \& Cabezudo, 2012). Esto implica que las políticas de reintroducción de Abies pinsapo en la zona tendrían que ser muy puntuales (muy pocos individuos) y solo en las localidades exactas donde habitaban antes de su desaparición a causa de incendios (reintroducción). Lo mismo que para Abies pinsapo se puede afirmar para Pinus pinaster, que también fue muy escaso, estuvo muy localizado y ha desaparecido hoy día a causa de los incendios (Ceballos y Vicioso, 1933). Queda, por tanto, fuera de asignación de zonopotencialidad en la Sierra los pinar- 
Tabla 15

28. Rhamno myrtifoliae-Quercetum rotundifoliae ass. nova quercetosum rotundifoliae, var. con Halimium halimifolium

(Pino pinastri-Juniperion phoeniceae, Pistacio lentisci-Rhamnetalia alaterni, Quercetea ilicis)

\begin{tabular}{lccccccc}
\hline INVENTARIO N $^{\circ}$ & 1 & 2 & 3 & 4 & 5 & 6 & 7 \\
Orientación & $\mathrm{O}$ & $\mathrm{N}$ & - & - & $\mathrm{S}$ & - & $\mathrm{NW}$ \\
Inclinación $\left.^{\circ}{ }^{\circ}\right)$ & 30 & 10 & 5 & - & 5 & - & 10 \\
Área $\left(\mathrm{m}^{2}\right)$ & 100 & 400 & 400 & 100 & 50 & 200 & 200 \\
Litología & Dol & Bre & Bre & Dol & Dol & Dol & Dol \\
Altitud $(\mathrm{m})$ & 1000 & 800 & 1100 & 1150 & 1120 & 950 & 1100 \\
Altura vegetación (cm.) & 180 & 300 & 250 & 250 & - & - & - \\
Cobertura vegetación $(\%)$ & 90 & 90 & 100 & 100 & 100 & 100 & 100
\end{tabular}

\section{Características y diferenciales de asociación}

Quercus rotundifolia

Juniperus oxycedrus

Rhamnus myrtifolia

Ephedra fragilis

Juniperus phoenicea

Pinus halepensis

Diferencial de variante

Halimium halimifolium

Características de unidades superiores

Quercus coccifera

Rubia peregrina

Smilax aspera

Teucrium fruticans

Chamaerops humilis

Lonicera implexa

Phillyrea angustifolia

$\begin{array}{lllllll}3 & 4 & 5 & 5 & 5 & 4 & 4 \\ 1 & - & 1 & - & - & 1 & + \\ - & - & + & - & + & + & - \\ - & - & - & - & - & + & + \\ - & - & - & + & - & - & - \\ - & + & - & - & - & - & - \\ - & - & - & - & - & + & - \\ & & & & & & \\ - & 2 & 2 & - & - & + & + \\ - & 1 & - & 2 & + & - & + \\ - & - & - & - & 1 & 1 & + \\ - & 1 & - & - & - & + & + \\ - & - & - & - & - & + & + \\ - & - & - & - & + & + & - \\ - & - & - & - & - & + & +\end{array}$

Otras características. En 6: Daphne gnidium +, Pistacia lentiscus +, Ruscus aculeatus +.

Compañeras

Ulex baeticus

Cistus albidus

Macrochloa tenacissima

Phlomis lychnitis

Brachypodium retusum

Phlomis purpurea

Rosmarinus officinalis

Asphodelus ramosus distalis

Cistus clusii

Hedera helix

Lithodora fruticosa

$\begin{array}{lllllll}2 & 1 & 1 & 2 & - & + & 2 \\ + & 1 & 1 & - & - & + & + \\ 1 & + & - & - & - & + & + \\ + & + & 1 & - & - & - & + \\ - & 3 & 4 & 1 & - & - & - \\ - & + & 2 & - & - & + & - \\ 2 & - & - & - & - & 1 & 1 \\ + & - & - & + & - & - & - \\ - & - & - & - & - & + & 1 \\ - & - & - & - & 1 & - & + \\ 1 & - & 1 & - & - & - & \end{array}$

Otras compañeras. En 1: Ballota hirsuta,+ Lavandula lanata + . En 3: Phlomis crinita malacitana + . En 4: Guillonea scabra + , Sideritis incana occidentalis + , Thapsia villosa + . En 7: Cerastium boissieri + , Helianthemum croceum + , Klasea flavescens + , Teucrium lusitanicum + , Thymus mastichina + .

Localidades. Málaga: 1. Málaga. Casarabonela. Sierra de Alcaparaín. Entre Cueva Bermeja y Cerro de la Canana. 30SUF3378. 2. Málaga. Ardales. Sierra de Alcaparaín Cerro del Gollino. 30SUF3480. 3. Málaga. Casarabonela. Sierra de Alcaparaín. Subida al Pico Valdivia. 30SUF3477. 4. Málaga. Carratraca. Sierra de Alcaparaín. Puerto de Alcaparaín. 30SU3378. Invs. Tomados de Pérez Sanz (1986: 150, tabla 1, invs. 1, 2 y 3): 5. Málaga. Mijas. Sierra de Mijas. Cabezo de las Cruces. 6. Málaga. Mijas. Sierra de Mijas. Del Puerto de la Encina al Tajo del caballo. 7. Málaga. Pico de Mijas. Dol: dolomías. Bre: brechas dolomíticas. 
sabinares de Rhamno myrtifolae-Juniperetum phoeniceae Molero Mesa \& Pérez Raya 1987 con Pinus pinaster (Pérez Latorre et al., 1998).

La presencia de una pequeña población de Juniperus turbinata en la cara sudeste de la Sierra, no puede, con la información disponible hasta el momento, dar pie a reconocer la existencia de los sabinares relictos de Asparago horridi-Juniperetum turbinatae Díez Garretas, Asensi \& Martín Osorio 1996, pero sí a que su presencia sea debida a la influencia de uno de los paleobrazos de mar existentes en el Valle del río Guadalhorce en épocas miocénicas (Hidalgo et al., 2014).

En la zona nordeste de la Sierra, en biotopos especiales constituidos por estratos verticales dolomíticos, en el piso mesomediterráneo, se desarrolla una formación rupícola de encinas (Quercus rotundifolia) que se acompaña de arbustos como Arbutus unedo, Pistacia terebinthus y Bupleurum gibraltaricum. Esta vegetación podría estar relacionada con las manifestaciones de Bupleuro-Pistacietum lentisci viburnetosum tini detectadas también en cenotopos rupestres. Estos encinares subrupícolas con madroños también existen en otras sierras Béticas como en Cazorla, donde fueron incluidos en Paeonio-Quercetum rotundifoliae arbutetosum unedi Gómez Mercado y Valle 1990 (Gómez Mercado, 2011). En la cercana Sierra Prieta, se desarrollan también formaciones topogénicas de encinas (Quercus rotundifolia) y cornicabras (Pistacia terebinthus) arbustivos en grandes grietas (Pérez Latorre et al., 2012: 131).

En la base SW de la Sierra, en una zona abrupta con numerosos abrigos y grandes bloques de rocas, a veces tobáceas, y ligada a una vaguada, existe una pequeña formación de almeces (Celtis australis), que podrían estar relacionados con las agrupaciones de Celtis australis detectadas en el cercano travertino de Casarabonela (Pérez Latorre et al., 2012: 124), sujetas a mayor disponibilidad de agua freática.

\section{Series de vegetación}

En la mayor parte del territorio de estudio, la vegetación natural (excluidas reforestaciones con Pinus halepensis y/o P. pinea) corresponde a etapas seriales de matorral o a incipientes formaciones climácicas arbustivo-arbóreas, como en el caso de los encinares y pinares carrascos autóctonos. Los incendios recurrentes que ha sufrido la sierra y el pastoreo (Ceballos y Vicioso, 1933: 84), el uso minero en la tesela peridotítica y los cultivos en la tesela silícea, deben de ser la causa de la escasez de las formaciones climácicas boscosas. Ya Ceballos y Vicioso (1933) indican en su mapa forestal que la mayor parte de la sierra está ocupada por el matorral, como actualmente ocurre, aunque señalan buenas masas de pinar autóctono de $P$. halepensis en la ladera oeste (hoy en regeneración) y otra masa más pequeña en la ladera noroeste, y lo indican como climácico en la sierra de "Caparaín", con su matorral de sustitución (Ceballos y Vicioso, 1933: 83-84). También indican una pequeña masa de alcornocal (Quercus suber) en la zona sudeste que a día de hoy aún subsiste y que ha sido inventariada en este trabajo (comunidad de Quercus suber).

De este modo la vegetación arbóreoboscosa en el territorio estudiado se ha de considerar mayoritariamente criptoclimácica y quedando relegada a las zonas donde los incendios, cultivos y minería no han llegado, generalmente zonas rocosas, abruptas e inaccesibles.

La vegetación natural actual está influenciada por las reforestaciones, mayoritariamente con Pinus halepensis sobre calizas y dolomías (unidades 3 y 4), que ocupan grandes extensiones en la falda sur de la Sierra. Sobre peridotitas, los aterrazamientos presentan reforestaciones de Pinus pinea y $P$. pinaster, ésta última especie considerada climácica en la zona por Ceballos y Vicioso (1933). Tras 


\begin{tabular}{|c|c|c|c|}
\hline Litología & Termotipo & Ombrotipo & Zonopotencialidad \\
\hline \multicolumn{4}{|c|}{$\begin{array}{l}\text { Sector Rondeño, subsector Rondense (teselas } 2 \text {-parte-, 3, } 4 \text { y 5): núcleo de la Sierra, } \\
\text { El Grajo y EI Gollino. }\end{array}$} \\
\hline Calizas y dolomías & termomediterráneo & subhúmedo & $\begin{array}{l}\text { Encinares y pinares (Quercus } \\
\text { rotundifolia, Pinus halepensis) }\end{array}$ \\
\hline Dolomías, brechas & mesomediterráneo & subhúmedo & $\begin{array}{c}\text { Pinar-sabinar, encinar } \\
\text { (Pinus halepensis, Juniperus } \\
\text { phoenicea, Quercus } \\
\text { rotundifolia) }\end{array}$ \\
\hline Dolomías, brechas & $\begin{array}{l}\text { mesomediterráneo } \\
\text { superior }\end{array}$ & subhúmedo & $\begin{array}{l}\text { Matorral con piornos (Ulex } \\
\text { baeticus, Bupleurum spinosum) }\end{array}$ \\
\hline Kakiritas & $\begin{array}{l}\text { termomediterráneo y } \\
\text { mesomediterráneo }\end{array}$ & subhúmedo & $\begin{array}{l}\text { Pinar-sabinar (Pinus halepensis, } \\
\text { Juniperus phoenicea) }\end{array}$ \\
\hline $\begin{array}{l}\text { Gneises, micaesquistos, } \\
\text { filitas }\end{array}$ & $\begin{array}{l}\text { meso- } \\
\text { termomediterráneo }\end{array}$ & subhúmedo & Alcornocal (Quercus suber) \\
\hline \multicolumn{4}{|c|}{$\begin{array}{c}\text { Sector Malacitano-Axarquiense, subsector Malacitano, Distrito Pizarreño (tesela } 2 \text {-parte-): base } \\
\text { silícea de la Sierra }\end{array}$} \\
\hline $\begin{array}{l}\text { Pizarras, grauvacas, } \\
\text { calizas alabeadas }\end{array}$ & termomediterráneo & $\begin{array}{l}\text { seco- } \\
\text { subhúmedo }\end{array}$ & $\begin{array}{c}\text { Encinares con alcornoques } \\
\text { (Quercus rotundifolia, } Q \text {. suber) }\end{array}$ \\
\hline \multicolumn{4}{|c|}{ Sector Bermejense, Subsector Carratracense (tesela 1): Las Minas, afloramiento ultramáfico } \\
\hline $\begin{array}{l}\text { Hazburguitas, dunitas } \\
\text { piroxénicas }\end{array}$ & termomediterráneo & seco-subhúmedo & Enebrales (Juniperus oxycedrus) \\
\hline Id. en arroyos & termomediterráneo & seco-subhúmedo & Saucedas (Salix pedicellata) \\
\hline
\end{tabular}

Tabla 16. Formaciones climácicas boscosas, arbustivas y de matorral del territorio según la zonopotencialidad litológica y bioclimática en las tres unidades fitogeográficas. Forests and shrubland vegetation in the study area according to zono-potential lithology and bioclimatology in the phytogeographical units.

los incendios se observa regeneración de Pinus halepensis de modo natural en toda la Sierra.

Curiosamente, en el aspecto dinámico de la vegetación, Ceballos y Vicioso (1933) no hacen mención a los extensos bosquetes arbustivos de Quercus rotundifolia hoy día existentes en la planicie más elevada de la Sierra.

En la tabla 16 se hace un resumen de la zonopotencialidad vegetal de la Sierra de Alcaparaín.

\section{Series climatófilas}

Encinares

Los bosques termófilos de Quercus rotundifolia se consideran hoy día criptoclimácicos, pues tan solo es posible reconocer encinas adultas o en pequeños grupos. Sin embargo, en el piso mesomediterráneo, el encinar ocupa grandes extensiones, aunque en un estado arbustivo, con individuos multicaules, provenientes de la regeneración post-fuego mediante yemas subterráneas (Cabezudo et al., 1995).

\section{Smilaco mauritanicae-Querco} rotundifoliae $S$ [Tesela 2]

Serie tingitano-onubo-algarviense, bética y mauritánica, termomediterránea, seco-subhúmeda de la encina (Quercus rotundifolia). 
Esta serie indica en la zona de estudio al sector Malacitano-Axarquiense, distrito Pizarreño.

1a. faciación basófila seca-subhúmeda con encinas quercetoso rotundifoliae $s$

Tan solo es reconocible en la zonopotencialidad de estos encinares criptoclimácicos el bolinar-tomillar sobre calizas alabeadas de Lavandulo-Genistetum equisetiformis thymetosum capitati, sobre antiguos terrenos cultivados. En sus claros aparecen manifestaciones de pastizal anual de la comunidad de Biscutella baetica, pero ésta dominada por Trachynia dystachia.

2a. Faciación silicícola subhúmeda con alcornoques quercetoso suberis $s$

Los encinares con alcornoques también son criptoclimácicos en la zona de estudio, y su zonopotencialidad, sustratos silíceos térmicos, está ocupada por cultivos leñosos y reforestaciones o por el jaral de LavanduloGenistetum equisetiformis y en sus claros por un pastizal oligótrofo anual de la comunidad de Biscutella baetica.

\section{Alcornocales}

2. Criptoserie de Quercus suber [Tesela 2]

Esta serie indica en la zona de estudio al sector Rondeño, subsector Rondense.

Serie propuesta por Pérez Latorre et al., (2012: 124) para la contigua Sierra Blanquilla y al norte de la Sierra de las Nieves (Yunquera) en el piso mesomediterráneo y que alcanza en Alcaparaín el contacto con el piso termomediterráneo.

Los sustratos silíceos de la base de la Sierra de Alcaparaín han sido muy utilizados por el ser humano, de modo que solo se encuentran hoy día cultivos (almendral, olivar, cereal), algunas reforestaciones (Pinus halepensis) y formaciones de matorral con Quercus suber, $Q$. rotundifolia y $Q$. faginea dispersos, mientras que los alcornocales zonopotenciales son criptoclimácicos y relegados a zonas más inaccesibles. Estos alcornocales de la comunidad de Quercus suber presentan, al igual que en los otros territorios rondeños, un escobonal de la comunidad de Cytisus grandiflorus y Adenocarpus telonensis en zonas de taludes, y son sustituidos por jaguarzaljarales de Lavandulo-Genistetum equisetiformis ulicetosum baetici sobre suelos decapitados y en zonas incendiadas.

\section{Series edafoxerófilas}

Encinares

3. Rhamno myrtifoliae-Querco rotundifoliae $S$ [Tesela 5]

Serie rondeña, edafoxerófilo-dolomitícola, mesomediterránea, subhúmeda de la encina (Quercus rotundifolia).

Esta serie indica en la zona de estudio al sector Rondeño, subsector Rondense.

Serie edafoxerófila que se desarrolla sobre dolomías y brechas dolomíticas. Está constituida por encinares climácicos arbustivos de Rhamno myrtifoliae-Quercetum rotundifoliae, que a causa de los incendios, pueden ser sustituidos por coscojares de la comunidad de Quercus coccifera BC. La recurrencia del fuego y el pastoreo favorecen a su vez su sustitución por vegetación serial de matorral dolomitícola de Lavandulo lanatae-Ulicetum baetici, en cuyos claros puede desarrollarse el tomillar hiperxerófilo de Galio baetici-Thymetum granatensis, que se acompaña en acúmulos arenosos de la comunidad de Chaenorrhinum rubrifolium.

Pinar-sabinares

\section{Pino halepensis-Junipero phoeniceae} $\boldsymbol{S}$ [Teselas 3 y 4 ]

Serie rondeña y almijarense, dolomitícola, termo-mesomediterránea, subhúmeda-húmeda 
del pino carrasco y la sabina mora (Pinus halepensis y Juniperus phoenicea).

Esta serie indica en la zona de estudio al sector Rondeño, subsector Rondense.

4a. Faciación típica termomediterránea juniperetoso phoeniceae $s$

El dinamismo de esta serie es muy similar al que se da en la Sierra de Tolox, donde fue descrita, incluso en la vegetación exoserial. El pinar (Pino halepensis-Juniperetum phoeniceae) ocupa las teselas 3 y 4 calizodolomíticas, muy abruptas, de la vertiente este de la Sierra. Fundamentalmente debido a los incendios recurrentes (Ceballos y Vicioso, 1933; Soto, 2006) la formación que sustituye al pinar-sabinar es el matorral-aulagar dolomitícola de la comunidad de Ulex baeticus y Halimium atriplicifolium. En el afloramiento de kakiritas de la cara este, en los claros del aulagar, laderas arenosas y canteras abandonadas se ha instalado el pastizal perenne de Linario clementei-Andryaletum ramosissimae y en sus claros aparece el nanopastizal fugaz de Jasiono penicillatae-Linarietum saturejoides sobre litosuelos arenosos.

4b. Faciación mesomediterránea rhamnetoso myrtifoliae $s$

En el piso mesomediterráneo, existen pinares-sabinares de Pino halepensisJuniperetum phoeniceae rhamnetosum myrtifoliae en las zonas más abruptas de las laderas, faltando en muchos casos Juniperus phoenicea por su incapacidad de regeneración tras los incendios, dominando entonces Pinus halepensis y Juniperus oxycedrus. Esta asociación se encuentra en mosaico con matorrales de Lavandulo lanatae-Ulicetum baetici y, en las zonas de cumbre por encima de 1200 m., por su subasociación erinaceetosum anthyllidis, en zonas donde el pinar-sabinar ha desaparecido y donde posiblemente se hallaban los reductos de Pinus pinaster y Abies pinsapo citados con anterioridad.
Pinar-coscojares

\section{Querco cocciferae-Pineto pinastri $S$} [Tesela 1]

Serie bermejense, edafoxerófiloserpentinícola, termo-mesomediterránea, subhúmedo-húmeda de la coscoja y el pino negral (Quercus coccifera y Pinus pinaster).

Esta serie indica en la zona de estudio al sector Bermejense, subsector Carratracense.

En la actualidad constituye una criptoserie de pinar-coscojares criptoclimácicos, ya que el uso del territorio ha sido muy intenso, con minería, reforestaciones con Pinus spp. y otras gimnospermas arbóreas (Cupressus spp.) e incendios. La vegetación arbustiva es muy escasa y relegada a zonas abruptas, representada por enebrales de la comunidad de Juniperus oxycedrus BC. Bajo las reforestaciones con Pinus, en los litosuelos serpentínicos se desarrolla el jaguarzal de Galio-Staehelinetum baeticae, salvo en zonas recientemente incendiadas donde prevalece el jaral de la comunidad de Ulex baeticus y Cistus ladanifer subsp. africanus. En espolones rocosos muy xéricos y soleados, se pueden encontrar representaciones de espartal de la comunidad de Scorzonera baetica y Stipa tenacissima. En laderas con incipientes regoso les, es posible el desarrollo de pastizales xerófilos (yesquerales) de Cerastio gibraltarici-Brachypodietum retusi elaeoselinetosum millefolii.

\section{Series edafohidrófilas}

Saucedas

\footnotetext{
6. Galio viridiflori-Saliceto pedicellatae $\boldsymbol{S}$ [Tesela 1]

Serie edafohigrófila riparia rondeña, bermejense y almijaro-granatense, magnesícola, termo-mesomediterránea inferior del sauce pedicelado (Salix pedicellata).

Esta serie indica en la zona de estudio al
} 
sector Bermejense, subsector Carratracense.

Los escasos arroyos con agua permanente pueden mostrar tramos con saucedas arbustivas de Galio viridiflori-Salicetum pedicellatae, en muchos casos muy ricos en zarzales con Rubus ulmifolius, y que son sustituidos en zonas rocosas rezumantes por juncales de Galio viridiflori-Schoenetum nigricantis.

\section{Adelfares}

En algunos cauces estacionales de la sierra se pueden encontrar agrupaciones de Nerium oleander, poco desarrolladas en el aspecto fitocenológico. En cualquier caso pertenecerían a aspectos fragmentarios de la asociación de amplia disctribución Rubo ulmifolii-Nerietum oleandri O. Bolòs 1956.

\section{Complejos topogénicos de vegetación}

La vegetación rupícola y glerícola, junto con la de matorral, es la más desarrollada en la sierra, debido al fuerte uso antrópico secular, al ocupar los cenotopos incultivables e inaccesibles

IVa. Rupícolas arborescente-arbustivos

7. Vegetación con Quercus rotundifolia: Bupleuro-Pistacietum lentisci viburnetosum tini

Se trata de complejos de vegetación ligados a grandes roquedos y estratos verticales existentes en las gargantas situadas al este de la Sierra. Los encinares ocupan las grandes grietas en zonas de estratos verticales y los lentiscares de Bupleuro-Pistacietum lentisci viburnetosum tini los cenotopos de fondo de vaguada y base de los estratos.

IVb. Casmofíticos

8. Comunidad de Saxifraga globulifera

9. Sarcocapnetum baeticae var. con
Polygala webbiana: Rhamno-Saxifragetum granatensis var. con Hieracium baeticum: Chaenorrhino-Parietarietum judaicae.

Vegetación herbácea perenne, ligada a las pequeñas grietas en substrato calizodolomítico que se distribuye en función del piso bioclimático, apareciendo en el termomediterráneo la comunidad de Saxifraga globulifera. En el termotipo mesomediterráneo se desarrolla el Sarcocapnetum baeticae var. con Polygala webbiana, en rocas extraplomadas y abrigos, mientras que en grietas verticales se desarrolla el RhamnoSaxifragetum granatensis var. con Hieracium baeticum, sustituido esporádicamente en zonas nitrificadas por el herbazal ténero del Chaenorrhino-Parietarietum judaicae.

IVc. Glerícolas-dolomitícolas

10. Galio baetici-Thymetum granatensis: Linario clementei-Andryaletum ramosissimae: Jasiono-Linarietum saturejoides: Comunidad de Chaenorrhinum rubrifolium

Este tipo de vegetación se halla casi exclusivamente sobre sustrato dolomítico kakiritizado o en blanquizares con litosuelos dolomíticos. Sobre suelo arenoso kakirítico, en el límite entre los pisos termo y mesomediterráneo se desarrollan pastizales perennes de LinarioAndryaletum ramosissimae que llevan en sus claros pastizales anuales nanoterofiticos de Jasiono-Linarietum saturejoides, mientras que en el termotipo mesomediterráneo se han detectado nanopastizales de la comunidad de Chaenorrhinum rubrifolium. En los blanquizares y arenales-guijarrales mesomediterráneos domina el tomillar hiperxerófilo de Galio-Thymetum granatensis.

IVd. Glerícolas-serpentinícolas

11. Comunidad de Narduroides salzmanii y Arenaria retusa: Crambe-Centaureetum carratracensis: Comunidad de Scorzonera 


\section{baetica y Celtica gigantea}

Vegetación propia de laderas fuertemente inclinadas con peridotita (hazburguita y dunita piroxénica) disgregada con distintos tamaños y movilidad. En los taludes propios de carriles y aterrazamientos es frecuente el pastizal perenne de Crambe-Centaureetum carratracensis. En gleras estabilizadas en laderas de fuerte pendiente se localizan pastizales graminoides de gran talla de la comunidad de Scorzonera baetica y Celtica gigantea. Sobre litosuelos arenosos, aunque de grano grueso, también en cenotopos con pendiente acusada y umbríos se desarrolla el nanopastizal serpentinícola de la comunidad de Narduroides salzmanii y Arenaria retusa.

\section{ESQUEMA SINTAXONÓMICO Y ECOFISIONÓMICO}

Se presenta a continuación la clasificación fitosociológica de la vegetación del área de estudio, siguiendo básicamente el esquema propuesto por Rivas Martínez et al. (2002) a nivel de clases y grupos ecofisionómicos. Cada asociación, subasociación, comunidad (o comunidad basal, BC) y variante (todas resaltadas en negrita) se acompañan de una breve descripción con datos fisionómicos, fitoecológicos y/o corológicos para la zona de estudio. Entre paréntesis y en negrita aparece el código del Anexo I de la Directiva 92/43UE de "Hábitats".

\section{Vegetación casmofítica, glerícola y epifítica}

\section{IVa. Vegetación casmofítica}

ASPLENIETEA TRICHOMANIS (Br.-Bl. in Meier \& Br.-Bl. 1934) Oberdorfer 1977

+ Asplenietalia petrarchae (glandulosi) Br.-Bl. in Meier \& Br.-Bl. 1934

++ Tinguarrenalia siculae (Daumas, Quèzel \&
Santa 1952) Galán de Mera in Pérez Latorre, Galán de Mera, Deil \& Cabezudo 1996

* Campanulion velutinae Martínez Parras \& Peinado 1990

** Campanulenion velutinae

1. Comunidad de Saxifraga globulifera (8210)

+ Potentilletalia caulescentis Br.-Bl. in Br.-Bl. \& Jenny 1926

* Saxifragion camposii Cuatrecasas ex Quézel 1953

2. Rhamno pumilae-Saxifragetum granatensis Pérez Latorre \& Cabezudo in Pérez Latorre, P. Navas, D. Navas, Gil \& Cabezudo 1998 (8210) saxifragetosum granatensis

var. de Hieracium baeticum. [Vegetación rupícola basófila orófila, variante xeroheliófila].

PARIETARIETEA Rivas-Martínez in Rivas Goday 1964

+ Parietarietalia judaicae Rivas-Martínez in Rivas Goday 1964

* Parietario-Galion murale Rivas Martínez ex Rivas Goday 1964

3. Chaenorrhino granatensis-Parietarietum judaicae Gómez Mercado y F. Valle 1991 [Vegetación rupícola herbácea nitrófila y umbrófila]

PETROCOPTIDO-SARCOCAPNETEA ENNEAPHYLLAE Rivas-Martínez, Cantó \& Izco in Rivas-Martínez, Díaz, FernándezGonzález, Izco, Loidi, Lousã \& Penas 2002

+ Sarcocapnetalia enneaphyllae Fdez. Casas 1972 em. Deil \& Galán de Mera 1997

* Sarcocapnion crassifoliae Fdez. Casas 1972 em. Deil \& Galán de Mera 1997

4. Sarcocapnetum baeticae Pérez Latorre \& Cabezudo in Pérez Latorre, P. Navas, D. Navas, Gil \& Cabezudo 1998 [Vegetación bética de extraplomos] (8210)

sarcocapnetosum baeticae

var. con Polygala webbiana [Variante relictual] moehringietosum giennensis Fernández Casas 1972 corr. Mota, Gómez Mercado y F. Valle 
1991 comb. nova et stat. nov. [Subasociación subbética con Moehringia]

\section{PHAGNALO-RUMICETEA INDURATI} (Rivas Goday \& Esteve 1972) Rivas-Martínez, Izco \& Costa 1973

+ Phagnalo-Rumicetalia indurati Rivas Goday \& Esteve 1972

* Andryalo-Crambion filiformis (Rivas Goday \& esteve 1972) Rivas Martínez, Izco \& Costa 1973

** Andryalo-Crambeenion filiformis

5. Linario clementei-Andryaletum ramosissimae Rivas Martínez in Rivas Goday 1964 [Pastizal vivaz sobre kakiritas] (8210)

** Centaureenion lainzii-carratracensis suball. nova

6. Crambe filiformis-Centaureetum carratracensis stat. nov. et ass. nova (8210)

\section{Vegetación pratense y pascícola}

\section{VIIa. Pastizales terofíticos}

HELIANTHEMETEA GUTTATI (Br.-Bl. in Br.-B1., Roussine \& Nègre 1952) Rivas Goday \& Rivas-Martínez 1963 em. Rivas-Martínez 1978

+ Helianthemetalia guttati Br.-B1. in Br.-B1., Molinier \& Wagner 1940

* Helianthemion guttati Br.-Bl., in Br.-Bl., Molinier \& Wagner 1940

7. Com de Biscutella baetica [Pastizales anuales oligótrofos]

+ Trachynietalia distachyae Rivas-Martínez 1978

* Omphalodion commutatae Rivas Martínez, Izco \& Costa in Izco 1973 corr. Pérez Raya 1988

** Silenenion germanae Pérez Raya 1987 ex Nieto, Cabezudo \& Trigo 1989

8. Jasiono penicillatae-Linarietum saturejoides Rivas-Martínez, Izco \& Costa 1973

linarietosum saturejoides [Pastizales terofíticos fugaces sobre kakiritas] (6220)
9. Comunidad de Chaenorrhinum rubrifolium (6220)

** Arenario capillipedis-Iberidenion fontqueri suball. nova

10. Comunidad de Narduroides salzmanii y Arenaria retusa [Pastizales terofíticos fugaces sobre peridotitas] (6220)

VIIb. Pastizales y prados vivaces xerofíticos y mesofíticos

\section{LYGEO SPARTI-STIPETEATENACISSIMAE} Rivas-Martínez 1978

+ Lygeo sparti-Stipetalia tenacissimae Br-Bl. \& O. Bolós 1958 em. Rivas-Martínez 1978

* Thero-Brachypodion Br. - B1. 1925

11. Cerastio gibraltarici-Brachypodietum retusi Díez Garretas \& Asensi in Rivas Martínez \& al. 2011

elaeoselinetosum millefolii Pérez Latorre, Hidalgo, Casimiro-Soriguer y Cabezudo 2013 var. con Centaurea carratracensis [Yesqueral serpentinícola, variante carratracense] (6220)

* Stipion tenacissimae Rivas-Martínez 1978

12. Comunidad de Scorzonera baetica y Macrochloa tenacissima [Espartal serpentinícola, forma carratracense con Centaurea carratracensis]

13. Comunidad de Scorzonera baetica y Celtica gigantea [Espartal de talla elevada, serpentinícola, forma carratracense con Centaurea carratracensis]

VIIc. Vegetación de praderas antropizadas de siega y pastoreo

MOLINIO-ARRHENATHERETEA R. Tx. 1937

+ Holoschoenetalia Br.-B1. (1931) 1947

* Molinio-Holoschoenion Br.-Bl. (1931) 1947

** Ericenion terminali-erigenae Rivas Martínez, Salazar, A. García y F. Valle 2011

14. Galio viridiflori-Schoenetum nigricantis Rivas Goday \& Esteve 1972 (6420)

schoenetosum nigricantis [Juncal negro 
serpentinícola]

\section{Vegetación serial sufruticosa, fruticosa y arbustiva}

\section{VIIIa. Vegetación serial sufruticosa}

CISTO-LAVANDULETEA Br.-B1. in Br.-B1., Molinier \& Wagner 1940

+ Lavanduletalia stoechadis Br.-Bl. in Br.-Bl., Molinier \& Wagner 1940

* Calicotomo-Cistion ladaniferi Br. - Bl. (1931) 1940 em. Rivas Martínez 1979

** Genistenion umbellatae Peinado, Alcaraz \& Martínez Parras 1992

15. Lavandulo stoechadis-Genistetum equisetiformis Rivas Goday \& Rivas-Martínez 1969

genistetosum equisetiformis [Bolinares acidófilos]

thymetosum capitati Martínez Parras, Peinado \& Alcaraz 1986 [Bolinares xerófilos basófilos] ulicetosum baetici subass. nov. [Bolinares acidófilos rondeños]

16. Comunidad de Ulex baeticus y Cistus ladanifer subsp. africanus [Jaral serpentinícola, forma carratracense con Centaurea carratracensis]

* Staehelino baeticae-Ulicion baetici Rivas Goday \& Rivas Martínez 1968

17. Galio boissierani-Staehelinetum baeticae Rivas Goday \& Rivas-Martínez 1969 nom. mut. propos.

staehelinetosum baeticae

var. con Genista umbellata [Jaguarzal serpentinícola carratracense, variante xerófila] (5330)

CISTO-MICROMERIETEA JULIANAE Oberdorfer 1954

+ Rosmarinetalia officinalis Br.-Bl. ex Molinier 1934

* Saturejo micranthae-Thymbrion capitati Rivas-Goday \& Rivas-Martínez 1969

18. Comunidad de Ulex baeticus y Halimium atriplicifolium sensu Pérez Latorre et al. (1998) (5330) [Aulagares-romerales termomediterráneos dolomitícolas rondeños orientales]

* Lavandulo lanatae-Echinospartion (Genistion) boissieri Rivas Goday \& Rivas-Martínez 1969

19. Lavandulo lanate-Ulicetum baetici Martínez Parras, Peinado y De la Cruz 1987 nom. inv. Asensi y Díez Garretas 1988 (5330) ulicetosum baetici [Aulagares dolomitícolas] var. con Halimium atriplicifolium [Variante con jaguarzo blanco]

erinaceetosum Martínez Parras, Peinado y De la Cruz 1987 [Subasociación orófila con piornos]

+ Convolvuletalia boissieri Rivas-Martínez, Pérez Raya y Molero Mesa in Pérez Raya 1987

* Andryalion agardhii Rivas-Martínez ex Rivas Goday y Mayor 1966

20. Galio baetici-Thymetum granatensis Mota y Valle 1992 (5330)

thymetosum granatensis [Tomillar de dolomías]

var. con Stipa offneri [Variante local]

VIIIb. Vegetación serial arbustiva y de margen de bosque

CYTISETEA SCOPARIO-STRIATII Rivas Martínez 1974

+ Cytisetalia scopario-striatii Rivas Martínez 1974

21. Comunidad de Cytisus grandiflorus y Adenocarpus telonensis sensu Pérez Latorre et al. (2004) [Escobonales silicícolas]

IX. Vegetación potencial forestal (bosques), preforestal (arbustedas), semidesértica y desértica

IXa. Arbustedas y bosques palustres, quionófilos o colonizadores riparios

SALICI-POPULETEA (Rivas-Martínez 
\& Cantó ex Rivas-Martínez et al. 1991) Rivas-Martínez \& Cantó 2002

+ Salicetalia purpureae Moor 1958

* Salicion pedicellatae Galán de Mera, Pérez

Latorre \& Cabezudo in Pérez Latorre, Galán de Mera, P. Navas, D. Navas, Y. Gil \& Cabezudo 1999

22. Galio viridiflori-Salicetum pedicellatae Díez Garretas, Asensi \& Rivas Martínez 2011 [saucedos serpentinícolas] (3280)

IXb. Vegetación climatófila y edafófila potencial mediterránea y eurosiberiana

QUERCETEA ILICIS Br.-B1. ex A. \& O. Bolòs 1950

+ Quercetalia ilicis Br.-Bl. ex Molinier 1934 em. Rivas-Martínez 1975

* Quercion broteroi Br.-B1., P. Silva \& Rozeira 1956 corr. Ladero 1974 em. Rivas-Martínez 1975

23. Com. de Quercus suber [Alcornocales meso-termomediterráneos rondeños] (9330)

+ Pistacio lentisci-Rhamnetalia alaterni Rivas-Martínez 1975

* Asparago-Rhamnion oleoidis (Rivas Goday 1964) Rivas Martínez 1975

24. Bupleuro gibraltarici-Pistacietum lentisci Martínez Parras, Peinado \& Alcaraz 1987 viburnetosum tini Pérez Latorre \& Cabezudo 2004 [Arbustedas de gran talla subrupícolas basófilas]

* Rhamno lycioidis-Quercion cocciferae Rivas Goday ex Rivas Martínez 1975

25. Comunidad de Quercus coccifera BC [Coscojares mesomediterráneos basófilos]

* Pino pinastri-Juniperion phoeniceae Pérez Latorre \& Cabezudo in Pérez Latorre, P. Navas, D. Navas, Y. Gil \& Cabezudo 1998

26. Pino halepensis-Juniperetum phoeniceae Pérez Latorre \& Cabezudo in Pérez Latorre, P. Navas, D. Navas, Y. Gil \& Cabezudo 1998 [Sabinares con pinos carrascos, edafoxerófilos, termo y mesomediterráneos, rondeños y almijarenses] (9560) juniperetosum phoeniceae [Subasociación termomediterránea]

rhamnetosum myrtifoliae subass. nova [Subasociación mesomediterránea]

27. Comunidad de Juniperus oxycedrus BC [Enebrales serpentinícolas, forma carratracense con Centaurea carratracensis] (9560)

28. Rhamno myrtifoliae-Quercetum rotundifoliae ass. nova [Encinares edafoxerófilos dolomitícolas mesomediterráneos] (9240)

quercetosum rotundifoliae

var. de Halimium halimifolium [Variante de arenales kakiríticos]

AGRAdeCimientos. A los agentes de medio ambiente de la Junta de Andalucía que nos acompañaron en algunos trabajos de campo. Al Herbario de la Universidad de Málaga (MGC) y, en especial, a su conservador José García Sanchez, que nos facilitó los listados de especies incluidas en las bases de datos ANTHOS y GBIF. A Noelia Hidalgo Triana por la elaboración del mapa de situación y colaboración en recolecciones.

\section{ANEXO 1}

\section{PTERIDOFITOS}

ADIANTACEAE

Adiantum capillus-veneris rup.(higr.)/rr.

ASPLENIACEAE

Asplenium onopteris

Asplenium petrarchae

rup.;mat.sil./rr.

rup./oc.

Asplenium trichomanes quadrivalens rup./oc.

Ceterach officinarum

Pleurosorus hispanicus

SINOPTERIDACEAE

Cheilanthes acrostica

Cheilanthes guanchica

rup./oc.

rup./rr.

rup./oc. rup./rr.

\section{GIMNOSPERMAS}

\section{CUPRESSACEAE}

Juniperus oxycedrus

Juniperus phoenicea

Juniperus turbinata

EPHEDRACEAE

Ephedra fragilis

PINACEAE

Abies pinsapo arb.;mat.ind./fr. arb.;mat.ind./r. arb.,mat.sil./rr.

mat.basof.;rup./oc. arb.;mat.basof./rr. 
Pinus halepensis

Pinus pinea

\section{ANGIOSPERMAS}

AMARYLLIDACEAE

Lapiedra martinezii

Narcissus cantabricus

ANACARDIACEAE

Pistacia lentiscus

Pistacia terebinthus

ARACEAE

Arisarum simorrhinum

ARISTOLOCHIACEAE

Aristolochia baetica

BERBERIDACEAE

Berberis hispanica

BORAGINACEAE

Buglossoides arvensis

Cynoglossum cheirifolium

Cynoglossum creticum

Echium albicans

Lithodora fruticosa

Neatostema apulum

Nonea vesicaria

Omphalodes commutata

Omphalodes linifolia

CAMPANULACEAE

Campanula erinus

Campanula mollis

Campanula rapunculus

Jasione blepharodon

Trachelium caeruleum

CAPPARACEAE

Cleome violacea

CAPRIFOLIACEAE

Lonicera implexa

Lonicera periclymenum hispanica

CARYOPHYLLACEAE

Arenaria armerina

Arenaria arundana

Arenaria erinacea

Arenaria modesta

Arenaria retusa

Cerastium brachypetalum

Cerastium dichotomum

Cerastium gibraltaricum

lanuginosum

Cerastium glomeratum

Corrigiola telephiifolia

Dianthus anticarius

Dianthus hispanicus

Minuartia campestris

Minuartia hybrida

Minuartia mediterranea

Minuartia montana

Moehringia pentandra arb.;mat.ind./co. arb.;mat.serpt./oc.

$$
\begin{array}{r}
\text { rup./oc. } \\
\text { mat.basof.;rup./ra. } \\
\text { arb.;mat.ind./oc. } \\
\text { mat.basof./oc. } \\
\text { mat.ind./oc. }
\end{array}
$$

arb.;mat.basof./oc.

arb.;mat.basof./rr.

mat.basof;past./ra. mat.basof./oc. rud./oc.

mat.basof./oc.

mat.basof./oc. rud./oc. rud./oc.

past.basof./ra.

past.basof./ra.

past.; rud./oc. rup./oc.

mat.sil/ra.

past.basof./ra.

rup.;higr./ra.

past.serpt./ra.

arb.;mat.ind/oc. higr./rr.

mat.basof./oc. past.basof./ra. mat.basof./oc. past.basof./oc. past./ra. rud./oc. rud./oc.

mat.basof./oc. rud./oc.

mat.serpt./oc. mat.basof./oc. mat.basof./oc. past.basof./ra. rud./oc.

past.basof./ra. past.basof./ra. rup./ra.
Paronychia capitata

mat.basof./oc. Paronychia echinulata past.sil.;past.serpt./ra. Paronychia suffruticosa hirsuta mat.basof./oc. Petrorhagia nanteuilii Petrorhagia prolifera

Petrorhagia saxifraga

Silene andryalifolia

Silene colorata

Silene gallica

Silene germana

Silene inaperta

Silene mellifera

Silene secundiflora

Silene tridentata

Silene vulgaris

commutata

Velezia rigida

CISTACEAE

Cistus albidus

Cistus crispus

Cistus ladanifer africanus

Cistus laurifolius

Cistus monspeliensis

Cistus salviifolius

Fumana ericifolia

Fumana laevipes

Fumana thymifolia

Halimium atriplicifolium

Helianthemum apenninum

suffruticosum

Helianthemum cinereum rotundifolium

Helianthemum ledifolium

Helianthemum salicifolium

Helianthemum syriacum

\section{COMPOSITAE}

Aetheorhiza bulbosa

Andryala integrifolia

Andryala ragusina ramosissima

Anthemis pedunculata

Atractylis cancellata

Bellis pappulosa

Bombycilaena discolor

Calendula suffruticosa

Carlina hispanica

Carlina racemosa

Carthamus creticus

Centaurea aspera

Centaurea carratracensis

Centaurea ornata

Chiliadenus glutinosus

Conyza canadensis

Crepis albida

Crepis bermejana

Crepis taraxacifolia

Crupina crupinastrum

Crupina vulgaris rud./oc.

rud./oc.

rup./ra.

rup./oc..

past.;rud./fr. rud./oc.

past.basof./oc.

past.: rud./oc.

mat.basof./oc. rud./fr.

past.basof./oc.

past.basof./oc. past.basof./fr.

mat.ind./co.

mat.sil;mat.serpt./oc. mat.serpt./fr. mat.basof./rr. mat.ind./co.

mat.sil;mat.serpt./fr. mat.basof./oc. mat.basof./oc. mat.ind./fr. mat.basof./co.

mat.basof./oc.

mat.basof./oc. past.basof./oc. past.basof./oc. mat.basof./oc.

past.ind./oc. rud./fr.

mat.basof./oc. mat.basof./oc. past.ind./fr. past.ind./oc. past.ind./oc. rup./ra. rud./fr. rud./fr. rud./fr. rud./fr.

mat.serpt./fr. rud./ra. rup./ra. rud./oc. rup./fr.

mat.serpt./ra. mat.basof; rud./fr. mat.basof;rud./fr. mat.basof; rud/oc. 
Cynara humilis

Dittrichia viscosa

Filago pyramidata

Helichrysum stoechas

Helminthotheca comosa

Helminthotheca echioides

Hyoseris radiata

Hypochaeris achyrophorus

Hypochaeris radicata

Jurinea pinnata

Klasea pinnatifida

Lactuca tenerrima

Leontodon longirostris

Logfia gallica

Pallenis spinosa

Phagnalon rupestre

Phagnalon saxatile

Phagnalon sordidum

Ptilostemon hispanicus

Pulicaria odora

Reichardia intermedia

Reichardia picroides

Rhaponticum coniferum

Scorzonera angustifolia

Scorzonera baetica

Scorzonera hispanica crispatula

Senecio minutus

Staehelina dubia

Taraxacum obovatum

Tolpis barbata

Tolpis umbellata

Tyrimnus leucographus

Xeranthemum inapertum

CONVOLVULACEAE

Convolvulus althaeoides

Convolvulus lanuginosus

Convolvulus siculus

CRASSULACEAE

Sedum acre

Sedum album

Sedum amplexicaule

Sedum dasyphyllum

Sedum mucizonia

Sedum sediforme

CRUCIFERAE

Alyssum serpyllifolium

malacitanum

Alyssum simplex

Alyssum strigosum

Arabidopsis thaliana

Arabis auriculata

Arabis verna

Biscutella baetica

Biscutella laxa

Brassica repanda confusa

Capsella bursa-pastoris

Crambe filiformis rud./oc.

rud./fr.

past.ind./fr.

mat.ind./oc.

mat.serpt./oc.

rud./oc.

rup;mat.basof./fr.

past.ind./oc.

past.ind./fr.

mat.basof./oc.

mat.basof./oc. rup./oc.

past.ind./co.

past.ind./fr.

rud./fr.

rup./oc.

rup./oc.

rup./ra.

mat.basof./oc.

mat.sil;mat.serpt./oc. rud./oc.

mat.serpt./fr.

mat.basof./oc. rud./oc.

mat.serpt./fr. rud./oc.

past.basof./fr.

mat.basof./oc. rud./oc.

past.sil;past.serpt./oc.

past.sil.; past.serpt./oc.

rud./oc.

past.basof./fr.

rud./fr.

mat.basof./fr.

rud;rup./oc.

rup./oc.

rup./fr.

rup./oc.

rup./fr.

rup./fr.

rup./fr.

mat.serpt./fr. rud./oc.

past.basof./oc.

past.sil./oc.

past.basof./oc.

past.basof./oc.

past.sil; past.serpt./oc. mat.basof./fr. mat.basof./fr. rud./oc. rup./fr
Erophila verna

Erucastrum virgatum baeticum

Erysimum medio-hispanicum rondae

Hormathophylla longicaulis

Hornungia petraea

Iberis carnosa granatensis

Iberis ciliata contracta

Iberis nazarita

Lobularia maritima

Sisymbrium crassifolium

CYPERACEAE

Carex distachya

Carex halleriana

Eleocharis uniglumis

Schoenus nigricans

Scirpoides holoschoenus

DIOSCOREACEAE

Tamus communis

DIPSACACEAE

Cephalaria leucantha

Scabiosa galianoi

Scabiosa turolensis grosii

EUPHORBIACEAE

Euphorbia characias

Euphorbia exigua

Euphorbia segetalis

Mercurialis tomentosa

FAGACEAE

Quercus coccifera

Quercus faginea faginea

Quercus rotundifolia

Quercus suber

GENTIANACEAE

Blackstonia perfoliata serotina

Centaurium majus

Centaurium maritimum

mat.basof:mat serpt./oc.

GERANIACEAE

Erodium cheilanthifolium rup./oc.

Erodium cicutarium

Erodium malacoides

Geranium lucidum

Geranium purpureum

GRAMINEAE

Aegilops geniculata

Aegilops triuncialis

Andropogon distachyos

Arrhenatherum album

Arrhenatherum elatius baeticum

Avenula gervaisii arundana

Avenula gervaisii

Brachypodium retusum

Brachypodium sylvaticum

Briza maxima

Bromus hordeaceus

Bromus matritensis

Catapodium rigidum past.basof./fr.

mat.basof./oc.

mat.basof./oc.

mat.basof./ra.

past.basof./oc.

mat.basof./fr.

mat.basof./oc.

mat.ind./oc.

mat.ind./fr.

rup./ra.

mat.ind/oc.

mat.basof./fr.

higrf./rr.

higrf./rr.

higrf./oc.

arb.; mat.basof./oc.

mat.ind/oc. rud./oc.

rup;mat.basof./oc.

mat.basof./ra.

past.ind./fr.

mat.basof./oc.

mat.ind;rud./oc.

arb.;mat.ind./fr.

arb.;mat.sil/ra.

arb.;mat.basof./co.

arb.;mat.sil/co.

past.ind./oc. past.sil.;past.serpt/ra.

rud./fr.

rud./fr.

rup;rud/oc.

past.ind./oc.

past.ind./co.

past.ind./co.

mat.serpt./rr.

mat.ind./fr.

mat.basof./fr.

mat.basof./fr.

mat.basof;mat.serpt./fr.

mat.ind./co.

mat.sil/ra.

past.sil;past.serpt./oc.

rud./fr.

rud./fr.

past.ind./fr. 
Celtica gigantea gigantea

Cynosurus echinatus

Dactylis glomerata hispanica

Festuca arundinacea

Festuca patula

Gastridium phleoides

Helictotrichon filifolium arundanum mat.basof./fr.

Holcus lanatus

Hyparrhenia sinaica

Koeleria crassipes filifolia

Koeleria vallesiana

Lagurus ovatus

Lamarckia aurea

Macrochloa tenacissima

Melica minuta

Piptatherum coerulescens

Piptatherum miliaceum

Piptatherum paradoxum

Piptatherum thomasii

Poa bulbosa

Poa ligulata

Stipa offneri

Trachynia distachya

Vulpia membranacea

Vulpia muralis

\section{GUTTIFERAE}

Hypericum perfoliatum

Hypericum perforatum

Hypericum pubescens

\section{IRIDACEAE}

Gladiolus communis

Xiphion filifolium

\section{LABIATAE}

Acinos rotundifolius

Ballota hirsuta

Calamintha sylvatica

Lamium amplexicaule

Lavandula lanata

Lavandula stoechas

Micromeria graeca

Phlomis composita

Phlomis crinita

malacitana

Phlomis lychnitis

Phlomis purpurea

Rosmarinus officinalis

Salvia candelabrum

Sideritis arborescens

Sideritis incana occidentalis

Stachys circinata

Teucrium capitatum

Teucrium fruticans

Teucrium haenseleri

Teucrium lusitanicum

Teucrium reverchonii

Teucrium similatum mat.serpt./fr.

past.ind./oc.

mat.ind./fr.

higrf./ra.

mat.basof/ra.

past.basof./oc. past.basof.;rud./oc.

mat.ind./oc.

mat.basof./fr.

mat.basof./oc.

rud./fr.

rud./fr.

mat.basof;mat.serpt./fr.

mat.basof./fr.

mat.basof./oc. rud./fr.

mat.basof./oc.

mat.sil./rr.

past.basof/co.

past.basof./rr. mat.basof./co. past.ind./co.

past.basof./oc. past.ind./oc.

rud./oc. rud./oc.

higrf./rr.

past.ind./ra.

mat.basof./rr. rud./fr.

mat.ind./oc. rud./fr.

mat.basof./oc.

mat.sil;mat.serpt./fr. mat.ind./fr. mat.basof./ra.

mat.basof./oc. mat.ind./fr. mat.ind./co. mat.ind./co. mat.basof./oc. mat.basof./oc. mat.basof./fr. rup./oc. mat.ind./oc.

arb.;mat.ind./oc. mat.ind./oc. mat.ind./fr. mat.serpt./oc. mat.basof./fr. mat.serpt./oc.
Thymbra capitata

Thymus baeticus

Thymus granatensis

Thymus mastichina

\section{LEGUMINOSAE}

Adenocarpus telonensis

Anagyris foetida

Anthyllis cytisoides

Anthyllis polycephala

Anthyllis vulneraria arundana

Anthyllis vulneraria reuteri

Argyrolobium zanonii

Calicotome villosa

Coronilla glauca

Coronilla juncea

Cytisus arboreus baeticus

Cytisus grandiflorus

Dorycnium pentaphyllum

Genista cinerea

Genista umbellata equisetiformis

Hippocrepis bourgaei

Hippocrepis ciliata

Hippocrepis rupestris

Lathyrus angulatus

Lotus longisiliquosus

Medicago littoralis

Medicago polymorpha

Ononis laxiflora

Ononis pusilla calycina

Ononis reclinata mollis

Ononis speciosa

Ononis spinosa

Retama sphaerocarpa

Spartium junceum

Trifolium arvense

Trifolium cherleri

Ulex baeticus

Ulex parviflorus

LILIACEAE

Allium roseum

Allium sphaerocephalon

Asparagus acutifolius

Asparagus horridus

Asphodelus cerasiferus

Asphodelus ramosus distalis

Dipcadi serotinum

Gagea polymorpha

Hyacinthoides hispanica

Muscari atlanticum

Muscari comosum

Ornithogalum algeriense baeticum

Ruscus aculeatus

Tulipa sylvestris australis

Urginea maritima

LINACEAE

Linum narbonense mat.basof./fr. mat.basof./fr. mat.basof./fr. mat.ind./oc.

mat.sil;mat.serpt./oc. mat.basof; rud./ra. mat.ind./fr.

mat.basof;rup./oc. mat.basof./oc. mat.basof./oc. mat.basof./oc. mat.serpt./fr. mat.basof./ra. mat.ind/oc. mat.ind./ra. mat.sil./ra. mat.ind./ra. mat.basof./ra. mat.ind/oc. mat.basof./oc. past.basof/fr. mat.basof.loc. rud./oc. mat.basof./fr. past.ind./oc. past.ind./fr. past.basof./oc. mat.basof./oc. past.ind./oc. mat.sil/ra. rud./oc. mat.ind./oc. higrf./ra. past.ind./oc. past.sil;past.serpt./fr. mat.ind./oc. mat.sil/ra.

past.ind./oc. rud./oc. mat.sil/ra. mat.basof;mat.serpt./oc. rud./fr. rud./fr. past.ind./fr. mat.basof./ra. mat.basof./oc. mat.basof./oc. rud./oc.

mat.basof./oc. mat.basof./ra. mat.basof./oc. mat.ind/oc.

mat.basof./oc. 
Linum strictum

Linum suffruticosum carratracensis

Linum suffruticosum

Linum tenue

MALVACEAE

Althaea hirsuta

Lavatera maritima

Malva sylvestris

MORACEAE

Ficus carica

OLEACEAE

Olea europaea

sylvestris

Phillyrea angustifolia

Phillyrea latifolia

ORCHIDACEAE

Aceras anthropophorum

Barlia robertiana

Neotinea maculata

Ophrys apifera

Ophrys atlantica

Ophrys bombyliflora

Ophrys fusca

Ophrys lutea

Ophrys scolopax

Ophrys speculum

Orchis langei

Orchis mascula

Orchis papilionacea

OROBANCHACEAE

Orobanche artemisiae campestris

Orobanche gracilis

Orobanche latisquama

PALMAE

Chamaerops humilis

PAPAVERACEAE

Fumaria macrosepala

Fumaria petteri calcarata

Papaver pinnatifidum

Platycapnos tenuiloba parallela

Sarcocapnos baetica

PLANTAGINACEAE

Plantago albicans

Plantago bellardii

Plantago lagopus

\section{PLUMBAGINACEAE}

Armeria grajoana

POLYGALACEAE

Polygala monspeliaca

Polygala rupestris

Polygala webbiana

POLYGONACEAE

Rumex bucephalophorus gallicus

Rumex induratus

PRIMULACEAE

Anagallis arvensis past.ind./oc. Asterolinon linum-stellatum

Coris monspeliensis syrtica

mat.serpt./fr. RAFFLESIACEAE

mat.basof./fr.

past.ind./oc.

rud./fr.

mat.basof.;rup./oc. rud./fr.

rup./oc.

arb.;mat.ind./fr. arb.;mat.ind/oc. arb.;mat.ind/oc.

mat.basof./ra. mat.basof./ra. mat.basof./ra. mat.ind/oc. mat.ind./ra. mat.ind./ra. mat.ind./ra. mat.ind./oc. mat.ind./oc. mat.ind./oc. mat.ind./oc. mat.ind./ra. mat.sil./ra.

mat.basof./ra. mat.basof./ra. mat.ind./oc.

arb.;mat.ind/oc.

mat.basof;rup./oc. rup./ra. rud

past.basof./rr. rup./fr

past.ind./fr. past.ind./oc. rud./oc.

mat.basof.;rup./ra.

past.basof./oc. rup./fr. rup./rr.

past.basof./fr. mat.serpt./oc.

rud./co.
Cytinus ruber

RANUNCULACEAE

Anemone palmata

Clematis flammula

Delphinium pentagynum

Ranunculus bulbosus

Ranunculus gramineus

Ranunculus paludosus

Ranunculus spicatus blepharicarpos

\section{RESEDACEAE}

Reseda barrelieri sessiliflora

Reseda gayana

Reseda lutea

Reseda media

Reseda phyteuma

Sesamoides purpurascens

\section{RHAMNACEAE}

Rhamnus alaternus

Rhamnus lycioides oleoides

Rhamnus myrtifolia

ROSACEAE

Potentilla caulescens

Rosa canina

Rosa pouzinii

Rubus ulmifolius

Sanguisorba hybrida

Sanguisorba minor

Sanguisorba rupicola

Sanguisorba verrucosa

RUBIACEAE

Asperula aristata scabra

Asperula hirsuta

Crucianella angustifolia

Galium baeticum

Galium boissierianum

Galium minutulum

Galium verticillatum

Galium viridiflorum

Putoria calabrica

Rubia agostinhoi

Rubia peregrina

Sherardia arvensis

Valantia hispida

Valantia muralis

RUTACEAE

Ruta angustifolia

SALICACEAE

Salix pedicellata

SANTALACEAE

Thesium humifusum

SAXIFRAGACEAE

Saxifraga globulifera

Saxifraga granulata past.ind./fr.

mat.basof./oc.

mat.basof./ra.

past.ind./oc.

mat.ind./oc.

past.basof./ra. higrf./ra.

mat.basof./oc.

past.basof./oc.

past.basof.;rup./oc.

mat.basof./oc. mat.basof./oc. rud./oc. rud./ra. rud./oc.

mat.serpt./oc.

arb.;mat.ind./fr. arb.;mat.basof./fr. arb.;mat.basof;rup./oc.

rup./rr. arb., mat.ind./oc. arb.;mat.ind./ra. higrf./oc. mat.sil./rr. past.ind./ra. rup./ra.

mat.ind;rud./oc.

mat.basof./oc. mat.ind./fr. past.ind./oc. mat.basof.;rup./fr. mat.serpt./oc. past.basof./oc. past.basof./ra. higr.(rup.)/rr. rup./fr. mat.serpt./oc. mat.ind/oc. past.ind./fr. past.ind./fr. past.ind./fr.

mat.ind./oc.

higrf./ra.

mat.basof./oc.

rup./oc. past.basof./oc 
Saxifraga tridactylites

SCROPHULARIACEAE

Anarrhinum bellidifolium

Antirrhinum controversum

Antirrhinum litigiosum

Bartsia trixago

Chaenorhinum rubrifolium

Chaenorhinum villosum granatense

Chaenorhinum villosum

Digitalis obscura laciniata

Linaria aeruginea

Linaria clementei

Linaria oblongifolia haenseleri

Linaria saturejoides

Linaria tristis

Linaria viscosa

Misopates orontium

Parentucellia latifolia

Scrophularia canina

Scrophularia crithmifolia

Scrophularia scorodonia

Veronica praecox

Veronica triloba

SMILACACEAE

Smilax aspera

SOLANACEAE

Atropa baetica

Hyoscyamus albus

TAMARICACEAE

Tamarix gallica

THYMELAEACEAE

Daphne gnidium

Thymelaea argentata

ULMACEAE

Celtis australis

UMBELLIFERAE

Anthriscus caucalis

Bunium macuca

Bupleurum gibraltaricum

Bupleurum lancifolium

Bupleurum spinosum

Conopodium marianum

Conopodium thalictrifolium

Distichoselinum tenuifolium

Elaeoselinum asclepium millefolium

Eryngium campestre

Foeniculum vulgare

Guillonea scabra canescens

Magydaris panacifolia

Oenanthe globulosa

Opopanax chironium

Scandix australis microcarpa

Scandix pecten-veneris

Smyrnium olusatrum past.basof./oc. Thapsia villosa

Torilis arvensis neglecta

mat.serpt./rr. Torilis japonica

rup.;rud./oc.

rup;rud/oc. rud./oc.

past.basof./oc. rup./fr rup./fr.

mat.basof;mat.serpt./oc. mat.basof./ra. mat.basof./oc. past.basof./oc. past.basof./oc. mat.serpt./oc. mat.sil./ra. rud.;past.basof./fr. rud.;past.basof./fr. rud./oc. mat.basof./oc. mat.basof./oc.

Torilis webbii

URTICACEAE

Parietaria judaica

VALERIANACEAE

Centranthus calcitrapae

Centranthus macrosiphon

Valerianella coronata

Valerianella discoidea

Valerianella eriocarpa

VIOLACEAE

Viola demetria

Viola kitaibeliana

VITACEAE

Vitis sylvestris mat.ind/oc. rud./oc. rud./oc. rud./oc.

rup./fr.

past.ind./oc. past.ind./oc. rud./oc. rud./oc. rud./oc.

past.basof./oc. past.basof./ra.

higrf./ra.

\section{BIBLIOGRAFÍA}

ASENSI A. \& B. DÍEZ -1977- Nota fitosociológica. Centaurea lainzii Fdez. Casas en la Sierra Bermeja de Estepona (Málaga). Anal. Inst. Bot. Cavanilles 34 (1): 183-188.

BALSERA MEDINA, J. -1989- Mapa de suelos de Andalucía. CSIC-IARA. Madrid.

BAÑARES, Á., G. BLANCA, J. GÜEMES, J.C. MORENO \& S. ORTIZ (Eds.) -2004- Atlas y Libro Rojo de la Flora Vascular Amenazada de España. Dirección General de Conservación de la Naturaleza. Madrid.

BAÑARES, Á., G. BLANCA, J. GÜEMES, J.C. MORENO \& S. ORTIZ (Eds.) -2010-. Atlas y Libro Rojo de la Flora Vascular Amenazada de España (Adenda 2010). Dirección General de Medio Natural y Política Forestal (Ministerio de Medio Ambiente, y Medio Rural y Marino)-Sociedad Española de Biología de la Conservación de Plantas. Madrid.

BLANCA, G., B. CABEZUDO, J.E. HERNÁNDEZBERMEJO, C.M. HERRERA, J. MOLERO MESA, J. MUÑOZ \& B. VALDÉS -1999/ 2000-Libro rojo de la flora silvestre amenazada de Andalucía. (2 vols.) Consejería de Medio Ambiente, Junta de Andalucía, Sevilla.

mat.basof./oc. mat.basof./oc. higr./rr.

mat.basof./oc. rud./oc. rud./oc. rud./oc.

BLANCA, G., B. CABEZUDO, M. CUETO, C. MORALES TORRES \& C. SALAZAR (eds.) -2011- Flora Vascular de Andalucía Oriental ( $2^{a}$ edición corregida y aumentada). Consejería de Medio Ambiente. Junta de Andalucía. Sevilla. 
BRAUN-BLANQUET, J. -1979- Fitosociología. Ed. Blume. Madrid.

CABEZUDO, B., J. M. NIETO \& A. V. PÉREZ LATORRE -1989- Contribución al conocimiento de la vegetación edafófila serpentinicola del sector Rondeño (Málaga). Acta Bot. Malacitana 14: 291-293.

CABEZUDO, B., A. V. PÉREZ LATORRE \& J. M. NIETO -1995- Regeneración de un alcornocal incendiado en el sur de España (Istan, Málaga). Acta Bot. Malacitana 20: 143-151.

CABEZUDO, B., A. V. PÉREZ LATORRE, P. NAVAS FERNÁNDEZ, Y. GIL JIMÉNEZ \& D. NAVAS FERNÁNDEZ -1998-Parque Natural de Sierra de las Nieves. Cartografía y evaluación de la flora y vegetación. Memoria de investigación. Departamento de Biología Vegetal. Universidad de Málaga. 367 pp.

CABEZUDO, B., P. NAVAS, A. V. PÉREZ LATORRE, Y. GIL, D. NAVAS \& T. NAVARRO -2000- Platycapnos tenuilobus subsp. paralellus in Blanca et al. Libro Rojo de la Flora Silvestre Amenazada de Andalucía: 272-273.

CABEZUDO, B., O. GAVIRA \& A.V. PÉREZ LATORRE -2005- Datos sobre la flora y vegetación de Sierra Prieta (Serranía de Ronda, Málaga, España). Acta Bot. Malacitana. 30: 209-215

CABEZUDO, B., F. CASIMIRO-SORIGUER SOLANAS \& A.V. PÉREZ LATORRE -2015Sobre el género Armeria en la provincia de Málaga (España). Acta Bot. Malacitana 40: 57-70.

CASTROVIEJO, S. et al. (coord.) -1986-2014Flora iberica. Real Jardín Botánico. CSIC. Madrid.

CEBALLOS Y FERNÁNDEZ DE CÓRDOBA, L. \& C. VICIOSO -1932- Notas sobre Flora malagueña. Boletín de la Real Sociedad Española de Historia Natural: 379-391.

CEBALLOS, L. \& C. VICIOSO -1933-Estudio sobre la vegetación y flora forestal de la provincia de Málaga. Inst. Forestal de Invest. y Exp. Madrid.

DE LEÓN LLAMAZARES, A. -1989Caracterización agroclimática de la provincia de Málaga. M. A. P. A.

DIERSCHKE, H. -1993- Grundlagen und Methoden der Planzensoziologie. Ulmer. Stuttgart.

FOCAULT, B. -1981-Réflexions su l'apprauvrissement des syntaxons aux limites chorologiques des unités phytosociologiques supérieurs et quelques unes de leurs consequences. Lazaroa 3: 75-100.

GALÁN DE MERA, A., A. V. PÉREZ LATORRE \& J.A. VICENTE ORELLANA -2003- Relaciones fitogeográficas entre el suroccidente de la Península Ibérica y el noroeste de África. Una propuesta de sectorización. Lagascalia 23: 27-52.

GEHÙ, J. M. \& S. RIVAS-MARTÍNEZ -1981Notions fondamentales de phytosociologie. In H. Dierschke (ed.). Syntaxonomie, Ber. Int. Symp. Int. Vereinigung Vegetationsk. pp. 5-33. J. Cramer, Vaduz.

GÓMEZ-MERCADO, F. -2011- Vegetación y flora de Sierra de Cazorla. Guineana 17: 1-481.

HIDALGO TRIANA, N. \& A. V. PÉREZ LATORRE -2013-Vegetación y flora de la Sierra de Cártama (Valle del Guadalhorce, Málaga, España). Acta Bot. Malacitana 38: 119-149.

HIDALGO TRIANA N., A. V. PÉREZ LATORRE, \& B. CABEZUDO -2014- Las poblaciones de Juniperus turbinata en el valle del río Guadalhorce (Málaga, España) como indicadoras de territorios relictos paleobiogeográficos. In: Cámara, R., B. Rodríguez \& J. L. Muriel (eds.). Biogeografia de Sistemas Litorales. Dinámica y Conservación. pp. 377-380. Sevilla.

IGME -1978- Mapa Geológico de Ardales a escala 1:50.0000. Hoja 1052. Segunda serie, Primera edición. Madrid

LAGUNA, M., P. DE ÁVILA \& J. DE SALINAS -1884- Flora Forestal Española. Ministerio de Fomento. Madrid.

LÓPEZ, G. -1975- Contribución al estudio florístico y fitosociológico de Sierra de Aguas. Acta Bot. Malacitana 1: 81-205

MARTÍNEZ-PARRAS, J.M., M. PEINADO \& F. ALCARAZ -1984- Estudio de la serie mesomediterránea basífila de la encina (PaeonioQuerceto rotundifoliae S). Lazaroa 5: 119-129.

MARTÍNEZ-PARRAS, J.M., M. PEINADO \& F. ALCARAZ -1987- Comunidades vegetales de Sierra Nevada (España). Serv. Publ. Univ. Alcalá de Henares. 74 pp. Alcalá de Henares.

MENDES, P., C. MEIRELES, C. VILA-VIÇOSA, C. MUSARELLA \& C. PINTO-GOMES -2015- Best management practices to face degraded territories occupied by Cistus ladanifer 
shrublands. Portugal case study. Plant Biosyst. 149(3): 494-502.

MERINO LÓPEZ, D. -1984- Flora y vegetación de Sierra Blanca (Marbella-Ojén) (Ensayo de sectorialización). Memoria de Licenciatura. Universidad de Málaga.

MOTA, J. F. \& F. VALLE -1992- Notas fitosociológicas sobre los blanquizares béticos. In: J. (Art. ) Conesa \& J. Recasens (ed.). Act. Simp. Intern. Bot. P. Font Quer (Lleida, 1988), vol. II Fanerogámia: 283-290. 496 pp. Lérida.

MOTA, J.F., J.M. MEDINA-CAZORLA, F.B NAVARRO, F.J. PÉREZ-GARCÍA, A.V., PÉREZ-LATORRE, P. SÁNCHEZ-GÓMEZ, J.A. TORRES, A. BENAVENTE, G. BLANCA, C. GIL, J. LORITE \& M.E. MERLO -2008Dolomite flora of the Baetic Ranges glades (South Spain). Flora 203(5): 359-375.

NIETO CALDERA, J.M., S. PEREZ SANZ \& B. CABEZUDO -1987- Datos sobre la vegetación dolomitícola del Sector Rondeño. Lazaroa 10: 35-46.

NIETO, J. M., \& B. CABEZUDO -1988- Datos sobre algunas comunidades glerícolas en los sectores Rondeño y Malacitano-Almijarense. Homenaje a Pedro Monserrat: 669-675. Jaca y Huesca.

NIETO CALDERA, J. M., A. V. PÉREZ LATORRE \& B. CABEZUDO -1991-. Biogeografía y series de vegetación de la provincia de Málaga (España). Acta Bot. Malacitana 16(2): 417-436.

PÉREZ LATORRE, A. V. -1989- Contribución al estudio fitocenológico y del estado de conservación de los bosques silicícolas y serpentinicolas de la vertiente mediterránea andaluza. Tesis de Licenciatura. Universidad de Málaga.

PÉREZ LATORRE, A.V., P. NAVAS, J. M. NIETO \& B. CABEZUDO -1997- Los jarales de la Clase Cisto-Lavanduletea en el Sur de la Península Ibérica (Andalucía, España). Acta Bot. Malacitana 22: 171-185

PÉREZ LATORRE A. V., P. NAVAS, D. NAVAS, Y. GIL \& B. CABEZUDO -1998-. Datos sobre la Flora y Vegetación de la Serranía de Ronda (Málaga, España). Acta Bot. Malacitana 23:149-191.

PÉREZ LATORRE A. V. \& B. CABEZUDO -2002La flora y el paisaje vegetal de la provincia de Málaga: importancia y conservación. Jábega 90: 25-39.
PÉREZ LATORRE A. V., D. NAVAS FERNÁNDEZ, O. GAVIRA, G. CABALLERO \& B. CABEZUDO -2004- Vegetación del P. N. de las Sierras Tejeda, Almijara y Alhama. Acta Bot. Malacitana 29: 117-190.

PÉREZ LATORRE A. V., G. CABALLERO, F. CASIMIRO-SORIGUER SOLANAS, O. GAVIRA \& B. CABEZUDO -2008- Vegetación del sector Malacitano-Axarquiense (comarca de la Axarquía, Montes de Málaga). Acta Bot. Malacitana 33: 215- 270.

PÉREZ LATORRE A. \& B. CABEZUDO -2012Phenomorphology and ecomorphological traits in Abies pinsapo. A comparison to other Mediterranean species. Phytocoenologia 42: 16-27

PÉREZ LATORRE A. V., F. CASIMIROSORIGUER SOLANAS, O.GAVIRA \& B. CABEZUDO -2012- Vegetación de la Reserva de la Biosfera Sierra de las Nieves: Río Grande y Sierras Prieta y Blanquilla (Málaga, España). Acta Bot. Malacitana 37: 103 -140.

PÉREZ LATORRE A., N. HIDALGO TRIANA, F. CASIMIRO SORIGUER SOLANA \& B. CABEZUDO -2013a- Flora y vegetación serpentinícola ibérica: Sierras de La Alpujata y de La Robla (Málaga, España). Lagascalia 33: 43-74

PÉREZ-LATORRE, A. V., N. HIDALGO \& B. CABEZUDO. 2013b-Composition, ecology and conservation of sout-Iberian serpentine flora in the context of the Mediterranean basin. Anales del Jard. Bot. Madrid 70:62-71.

PÉREZ LATORRE, A.V., F. CASIMIROSORIGUER SOLANAS, J. GARCÍA SÁNCHEZ \& B. CABEZUDO -2014- Flora y vegetación del Paraje Natural Desfiladero de los Gaitanes y su entorno (Málaga, España). Acta Bot. Malacitana 39: 129

PÉREZ SANZ S. -1983- Flora y Vegetación de la Sierra de Mijas (Málaga). Tesina de Licenciatura. Málaga.

RIVAS GODAY, S. \& S. RIVAS MARTÍNEZ -1968- Matorrales y tomillares de la Península Ibérica comprendidos en la clase OnonidoRosmarinetea. Anales Inst. Bot. Cavanilles 25: 5-197.

RIVAS GODAY, S. \& F. ESTEVE CHUECA -1972Flora serpentinicola española. Nota segunda. Nuevos edafismos endémicos y sus respectivas 
asociaciones del Reino de Granada. Anales Real Academia de Farmacia 38 (3): 409-462.

RIVAS MARTINEZ, S. -1987- Memoria y mapa de las series de vegetación de España (1: 400.000). ICONA. Madrid.

RIVAS MARTÍNEZ, S. -2007- Mapa de series, geoseries y geopermaseries de vegetación de España. Memoria del Mapa de Vegetación Potencial de España. Parte I. Itinera Geobot. 17: 1-436.

RIVAS MARTÍNEZ, S. -2011- Mapa de series, geoseries y geopermaseries de vegetación de España. Memoria del Mapa de Vegetación Potencial de España. Parte II. Itinera Geobot. 18(1): 5-424.

RIVAS MARTÍNEZ, S. J. IZCO \& M. COSTA -1973-Asplenium cuneifolium Viv. (A. serpentini Tausch) en Sierra Bermeja (Málaga). Trab. Dep.
Botánica y F. Veg. 6: 23-30.

RIVAS MARTÍNEZ, S., T. E. DÍAZ, F. FERNÁNDEZ GONZÁLEZ, J. IZCO, J. LOIDI \& A. PENAS -2002-Vascular plant communities of Spain and Portugal. Itinera Geobot. 15(1, 2): 5-432.

SCHUHWERK, F. -1990- Relikte und Endemiten in Pflanzengesellschaften Bayerns- eine vorlaufige Ubersicht. Ber. Bayer. Bot. Ges. 61: 303-323.

SOTO GARCÍA, D. -2006- Núcleos residuales de pinsapo perdidos en el siglo XX. Investigaciones Agrarias: Sistemas y Recursos Forestales (fuera de serie): 79-86.

VIGO, J. -1998- Some reflections on geobotany and vegetation mapping. Acta Bot. Barc. 45: 535-566.

WEBER, H. E., J. MORAVEC \& J. P. THEURILLAT -2000- International Code of Phytosociological Nomenclature. J. Veg. Sci. 11: 739-768. 